\title{
Zur Lokalizationsfrage der Zentren für die Epinephrinsekretion.
}

\author{
Von \\ Wataru Takahashi. \\ (高橋 潾) \\ (Aus dem Physiologischen Institut von Prof. I. Sataké, \\ Tohoku Reichsuniversität, Sendai.)
}

So ungeheuer die Literatur angewachsen ist, die sich mit dem Studium der Epinephrinsekretion aus der Nebenniere befasst, so gering sind jedoch die Untersuchungen welche sich mit der Frage der Lokalization der Zentren für die Sekretion beschäftigen.

Elliot $t^{12}$ und andere ${ }^{23366)}$ halten das verlängerten Mark für den Sitz des zentralen Mechanismus der Epinephrinsekretion, während von S tew art und $\mathrm{R}$ og of $\mathrm{f}^{4}$ Beobachtungen angeführt wurden, die darauf hinweisen, dass die Epinephrinsekretion nach der Durchschneidung des Rückenmarkes im Halsmark wie sonst vor sich gehen kann. Elliott bestimmte den Epinephringehalt der Nebenniere mittelst des Blutdruckverfahrens, ${ }^{1)}$ Cannon und Rapport ${ }^{2}$ die Epinephrinabgabe mittelst des denervierten Herzens, und Tournade und seine Mitarbeiter durch Versuche, in denen ein Hund fortwährend sein Nebennierenblut in den Blutkreislauf eines andern Hundes ergoss und der Blutdruck und das Milzvolum im zweiten Hunde registriert wurden. Elliott, sowie Cannon und Rapport gaben nach Untersuchungen an Katzen an, dass eine Entfernung der vor den Corpora quadrigemina gelegenen Gehirnteilen die epinephrinaustreibende Wirkung der sensorischen Reizung in keiner Weise störend beeinflusste, während eine sensorische Reizung nach der Durchschneidung des Rückenmarkes im zweiten Halsmark (Elliott) oder des verlängerten Markes $2 \mathrm{~mm}$ hinter den Corpora quadrigemina posterior keine Epinephrinsekretion mehr bewirkte (Cannon und Rapport). Nach der Kokainsierung des Rautengrubenbodens des ersten Hundes vermissten Tour-

1) Elli ott, J. of Physiol, 1912, 44, 406-407.

2) Cannon und Rapport, Am. J. of Physiol., 1921, 58, 338.

3) Tournade, Chabrol und Wagner, C. R. Soc. Biol., 1925, 93, 160.

4) Stewart und Rog off, J. of Exp. Med., 1917, 26, 613; Am. J. of Physiol., 1920, 51,484 . 
nade und Mitarbeiter eine Epinephrinabgabe aus der Nebenniere des zweiten Hundes, dem das Nebennierenblut des ersten infundiert wurde, $\mathrm{zu}$ beweisen.

Stewart und Rogoff bedienten sich der Cava-Taschenmethode zur Gewinnung des Nebennierenblutes, und der Kaninchendarmstückmethode und anderer zur Abschätzug der Epinephrinkonzentration. Thre spontane (entsprechend unserem: "sogenannte spontane") Abgabe des Epinephrins, d. h. eine spontane Abgabe beim narkotisierten und mit der Cava-Tasche versehenen Tiere (Katze, Hund und Affe) erfuhr meist keine Verminderung bei einer Durchschneidung des Rückenmarkes auf dem Niveau des letzten Halswirbels. Ferner um dabei das Intaktbleiben der Funktion des zentralen Mechanismus der Epinephrinsekretion zu prüfen benützten sie Strychnin, und zwar mit durchaus positiven Erfolg. Schliesslich nahmen sie die Rückenmarkdurchschneidung zuerst vor, und erst 1-13 Tage darauf wurden die Epinephrinsekretionsexperimente ohne und mit der Strychnindarreichung. angestellt, um damit die Shockwirkung auszuschalten. Der Ausfall der neuen Experimente bei überlebenden Tieren stand mit ihren früheren im Einklang.

Die Epinephrinabgabe in einem normalen Zustand der Ruhe ${ }^{5)}$ des Versuchstieres ist sehr viel kleiner als die spontane Sekretion nach Stewart und Rogoff; die von ihnen erzielte abnorm hohe Sekretion beruht auf einem Komplex von abnormalen Faktoren in ihren experimentellen Bedingungen, wie sensoriche Reizung und desgleichen mehr.

Zieht man diese Versuchsergebnisse von Stewart und Rogoff in Betracht, so würde es naheliegen anzunehmen, dass der zentrales Mechanismus der Epinephrinsekretion im Brustmark liegt, und, sei es ein führender, sei es ein untergeordneter, durch die abnormen Versuchsumstände in Tätigkeit gesetzt wird, was eine Hypersekretion des Epinephrins auslöst, und dass ferner Strychnin auf die Erregbarkeit des in Rede stehenden Mechanismus irgendwo im Reflexbogen steigernd einwirkt. Wie oben erwähnt wurde, erfuhren diese Beobachtungen offenbar bisher keine Bestätigung.

Auf Grund des Befundes, dass eine Reizung des Brustmarks selbst sowie dessen rorderen Wurzeln eine Epinephrinabgabe hervorrufen kann, ${ }^{6}$ ) scheint es uns gerechtfertigt zu dem Schluss zu kommen, dass die nervösen Bahnen des epinephrinaustreibenden Impulses darin verborgen sind, so bringen sie uns aber keinen Aufschluss über das Vorhandensein des Zentralmechanismus, sei es ein prodominierender, oder ein untergeordnetes, welcher in direkter oder reflektorischer Weise in Erregung gesetzt wird.

Zum Schluss der Literaturbesprechung wollen wir nicht verfehlen hier eine

5) Sataké, Sugaw ar a und W a ta n abé, Tohoku J. of Exp. Med., 1927, 8, 509 ff.

6) Tournade, Chabrol und Wagner, C. R. Soc. Biol., 1925, 93, 933. 
wichtige Anschaung von $\mathrm{H}$ ous say und Molinelliz) zu zitieren, nach welcher der Zentralmechanismus der Epiniephrinsekretion im infundibularen Teile des $Z$ wischenhirns zu suchen sei, trotzdem wir in den vorliegenden Versuchen keine Gelegenheit fanden dazu Stellung zu nelmen. Es sei noch bemerkt, dass der Reizversuch, wie die Piqûre von Cl. Bernard, für sich allein keinerlei Anhaltpunkt für Feststellung der Lokalization des Zentralmechanismus der Epinephrinsekretion liefern kann.

In Anbetracht der Widersprüche zwischen den oben genannten Autoren hat es urs nun sehr wünschenswert geschienen, in Erfahrung zu bringen, ob das Brustmark nach der Durchtrennung des Halsmarkes noch eine Epinephrinabsonderung herbeizuführen imstande ist, und eventuell in welchem Umfang wenn irgendein epinephrinaustreibendes Mittel zur Anwendung gebracht wird. Da eine Mehrsekretion des Epinephrins durch Aderlass und Pepton sich regelmässig und mühelos erzielen lässt, scheinen sie uns als Mittel geeignet. Eine Nachprüfung der früheren Angaben durch Anwendung sensorischer Reizung konnte ebenfalls von der Interesse sein.

Methodik: Grosse und kräftige Hunde allein wurden verwendet. Die Aufnahme des Nebennierenblutes erfolgte mit Hilfe der Lumbalroutemethode, und die Bestimmung des Epinephrins mittels des Kaninchendarmstück-Verfahrens. Über die Einzelheiten der Verfahren verweise ich auf die früheren Publikationen aus unseren Institute. ${ }^{8)}$ Die Ausführung der Lumbalroutemethode wurde durch gütiges Mitwirken von Herrn Dr. H. Sato, Assistent-Professor des Institutes, ermöglicht.

Die Blosslegung der untersten Halsmarke wurde unter Narkose vorgenommen, und zwar durch Entfernung des Processus spinosus und Arcus vertebrae der sechsten und siebenten Wirbel. Das Mark wurde dann ebenfalls unter Narkose durchschnitten, zuerst wurde das Ligamentum flavum mit einer Scheere in der Längsrichtung gespalten, das Fettgewebe im Cavum epidurale entfernt, und die Dura mater samt der Arachnoidea quer durchschnitten; die Zerebrospinalflüssigkeit fliesst dabei aus, die Schnittöffnung wurde dann mit einem Spatel erweitert, und dann das Mark samt der Pia mater mittels eines Spatels mit einem Griffe durchschnitten. Die beiden Markenden wurden mittels des Spatels voneinander entfernt; bei drei Hunden, Nr. 1,2 u, 3, wurde dies nicht getan, des wegen wurde der Operationserfolg durch Obduktion kontrolliert. Der mittlere Blutdruck wurde aus der A. femoralis der rechten Seite mittels eines Quecksilbermanometers registriert.

\section{I. Über den Einfluss der Durchtrennung des Rückenmarkes im untersten Halsmark auf die Epinephrinsekretion.}

Bei fünf Hunden wurde das Nebennierenblut vor sowie nach der Halsmarkdurchtrennung aufgenommen; eigentlich wurden die Ex-

7) Houssay und Molinelli, C. R. Soc. Biol., 1925, 93, 1454; Molinelli, La secrecion de adrenalina, Buenos Aires 1926, $122 \mathrm{ff}$.

8) Sataké, Suga wara und Watanabé, Tohoku J. of Exp. Med., 1927, 8, 503509 ; Sugawara, Watanabé und Saito, Ebenda, 1926, 7, 3-16. 
perimente vorgenommen nicht in der Hoffnung um irgendeinen Einfluss der Durchtrennung auf die Epinephrinabgabe aufzufinden, sondern eher um mich in der Ausführung der Operation auzubilden. Die

Beispiel 1.

9. III. 1928. Hund 2. to $22,3 \mathrm{~kg}$.

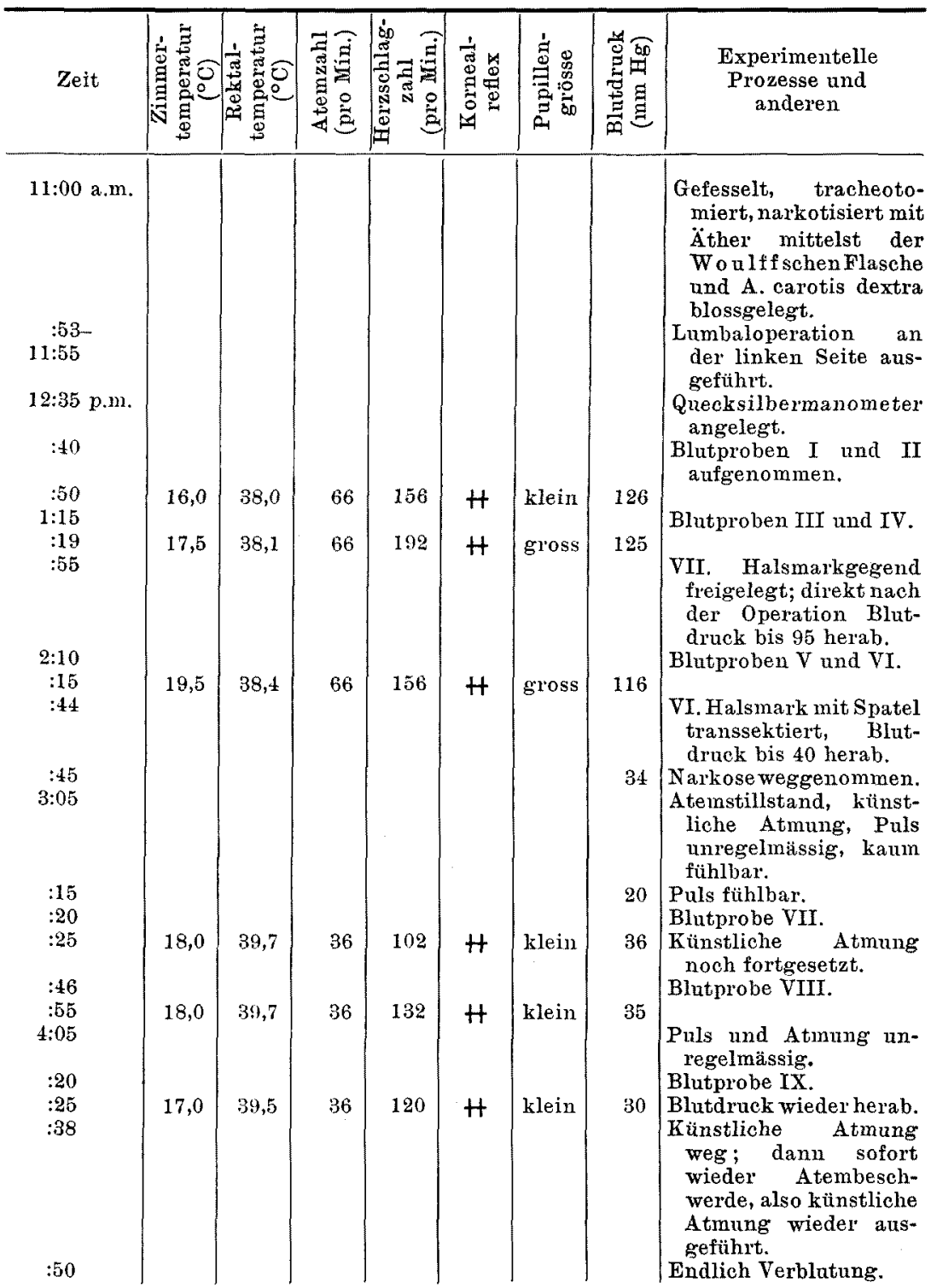




\section{Tabelle I.}

Einfluss der Transsektion des unteren Halsmarks auf die Epinephrinabgabe bei Hunden, deren Nebennierenvenenblut mittels der Lumbalroutemethode unter Äthernarkose aufgenommen wurde.

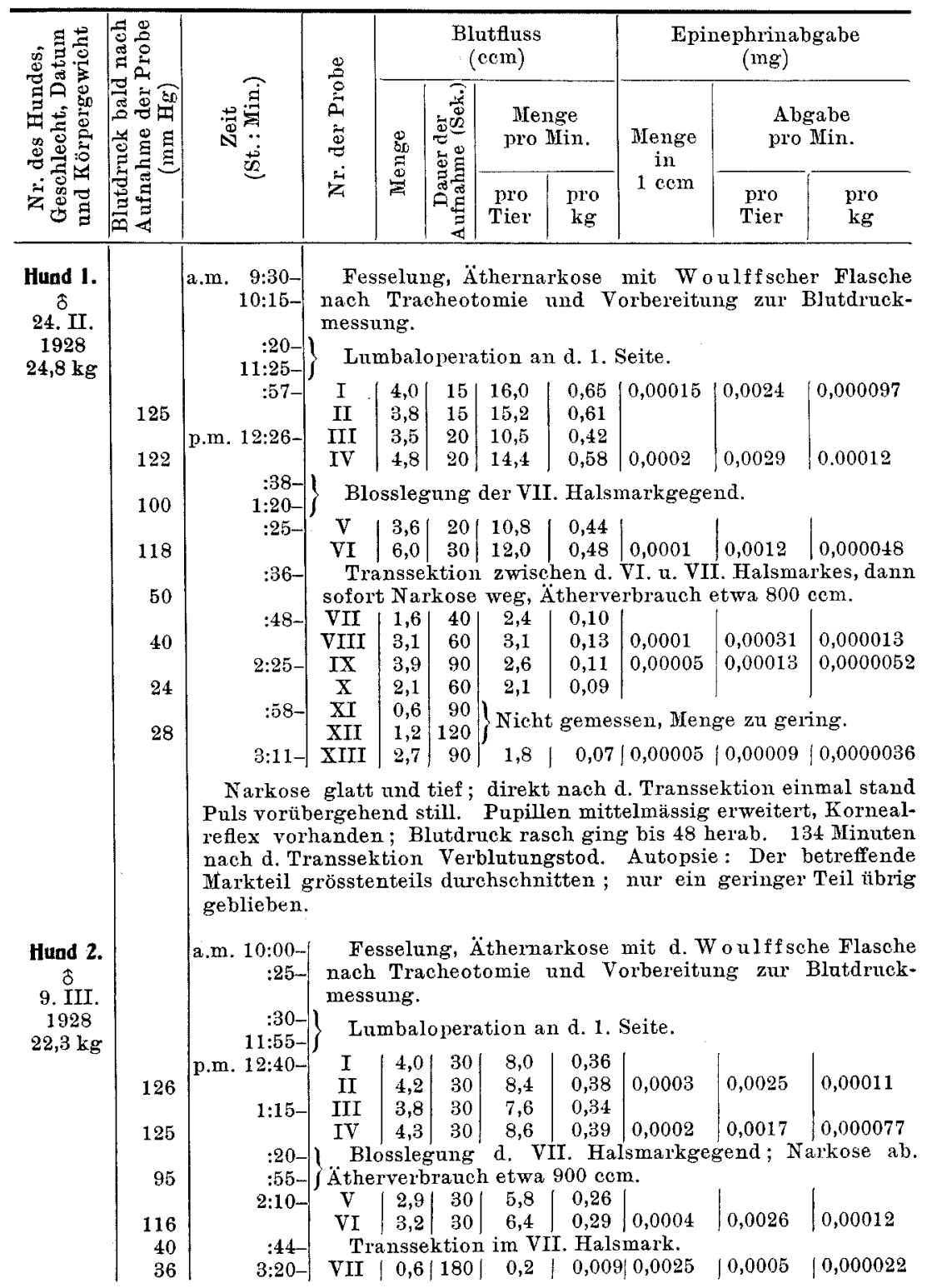




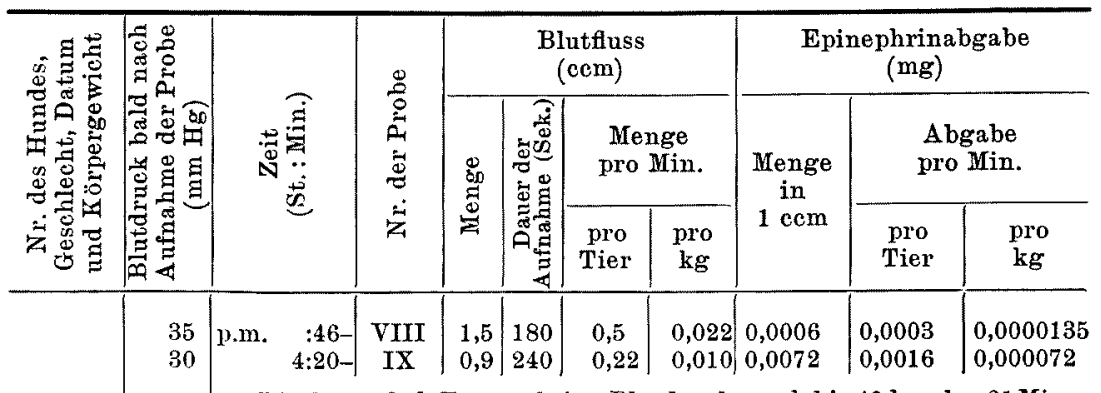

Direkt nach d. Transsektion Blntdruck rasch bis 40 herab. 21 Minuten nach der Transsektion vorübergehender Atemstillstand, Puls arhythmisch und sehwach. 81 Minnten nach d. Transsektion Atmung und Herzaktion unregelmässig. 114 Minuten nach der Transsektion wieder Atemnot; künstliche Atmung; endlich Verblutungstod. Autopsie : Schnitt zwischen d. VII. u. VIII. Halsmak.

Hund 3. $\hat{0}$

16. III.

$23,2 \mathrm{~kg}$
Hund 4 .

27. IV. 1928 $25.1 \mathrm{~kg}$

a.m. 9:30- Fesselung, Äthernarkose mit d. W oulff schen Flasche :50- nach Tracheotomie und Vorbereitung für Blutdruckmessung.

:54- Lumbaloperation an d. 1. Seite.

122 \begin{tabular}{r|r|r|r|r|r|r|r|r}
$12: 13-$ & I & 3,0 & 20 & 9,0 & 0,39 & 0,0002 & 0,0018 & 0,000076 \\
II & 5,2 & 30 & 10,4 & 0,45 & & & \\
III & 5,2 & 30 & 10,4 & 0,45 & & & \\
IV & 5,7 & 30 & 11,4 & 0,49 & 0,0003 & 0,0034 & 0,00015
\end{tabular}

$: 25-$ $: 50-$ Blosslegung d. VII. Halsmarkgegend.

\begin{tabular}{c|c|c|c|c|c|c|c|c} 
V & 3,3 & 40 & 4,9 & 0,21 & 0,00025 & 0,0012 & 0,000053 \\
VI & 2,7 & 40 & 4,1 & 0,18 & & & \\
VII & 2,7 & 40 & 4,1 & 0,18 & & &
\end{tabular}

70 p.m. 1:33- Transsektion im. VII. Halsmarks; kurz davor Narkose weg.

\begin{tabular}{|c|c|c|c|c|c|c|c|c|}
\hline \multirow{2}{*}{$: 40$} & VIII & 2,0 & 60 & 2,0 & 0,086 & & & \\
\hline & IX & 2,5 & 60 & 2,5 & 0,108 & 0,00005 & 0,000125 & 0,0000054 \\
\hline \multirow[t]{2}{*}{$2: 33$} & $\mathrm{X}$ & 2,0 & 90 & 1,3 & 0,056 & 0,0001 & 0,00013 & 0,0000056 \\
\hline & $\mathrm{XI}$ & 1,6 & 60 & 1,6 & 0,069 & & & \\
\hline \multirow[t]{2}{*}{$3: 15$} & XII & 2,2 & 90 & 1,5 & 0,065 & 0,00005 & 0,000075 & 0,0000032 \\
\hline & XIII & 1,5 & 60 & 1,5 & 0,065 & & & \\
\hline \multirow[t]{2}{*}{;33- } & XIV & 3,0 & 90 & 2,0 & 0,086 & 0,00005 & 0,00010 & 0,0000043 \\
\hline & $\mathbf{X V}$ & 2,3 & 60 & 2,3 & 0,099 & & & \\
\hline
\end{tabular}

43 Minuten vor d. Transsektion Zittern am ganzen Körper. $13 \mathrm{Minu-}$ ten vor d. Transsektion Erwachung von d. Narkose. Direkt nach d. Transsektion stieg Blutdruck auf (bis 150), dann rasch ab. Probeblut nach $d$. Transsektion ganz dunkel; endlich Verblutungstod. Ätherverbranch etwa $800 \mathrm{ccm}$.

a.m. 9:25- Fesselung, Äthernarkose mit d. W o u lff schen Flasche :40- nach Tracheotomie und Vorbereitung für Blutảruckmessung.

10:00- Lumbaloperation an d. 1. Seite. \begin{tabular}{l|l|l|l|l|l|l|l|l}
$11: 20-$ & \multicolumn{1}{c}{ p.m. 12:05- } \\
II & 5,5 & 30 & 11,0 & 0,44 & 0,0001 & 0,0011 & 0,000044 \\
II & 4,2 & 20 & 12,6 & 0,5 & & &
\end{tabular} :12- Blosslegung und Transsektion d. VII. Halsmarks, kurz :40- Javor Narkose weg. Ätherverbrauch etwa $750 \mathrm{ccm}$. :43- $\operatorname{III} \mid$\begin{tabular}{l|l|l|l|l|l|l|l|} 
& 1,7 & 90 & 1,1 & 0,044 & 0,0003 & 0,00033 & 0,000013
\end{tabular} \begin{tabular}{l|l|l|l|l|} 
IV & 2,0 & 90 & 1,3 & 0,052
\end{tabular} 


\begin{tabular}{|c|c|c|c|c|c|c|c|c|c|c|}
\hline \multirow{3}{*}{ 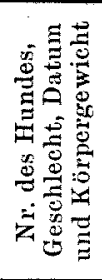 } & \multirow{3}{*}{ 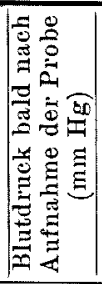 } & \multirow{3}{*}{ 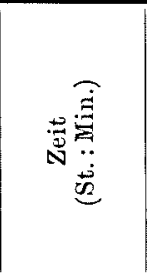 } & \multirow{3}{*}{ 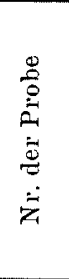 } & \multicolumn{4}{|c|}{$\begin{array}{l}\text { Blutfluss } \\
(\mathrm{ccm})\end{array}$} & \multicolumn{3}{|c|}{$\begin{array}{l}\text { Epinephrinabgabe } \\
\text { (mg) }\end{array}$} \\
\hline & & & & \multirow{2}{*}{$\stackrel{9}{\stackrel{9}{0}}$} & \multirow{2}{*}{ 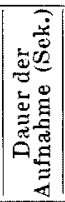 } & \multicolumn{2}{|c|}{$\begin{array}{c}\text { Menge } \\
\text { pro Min. }\end{array}$} & \multirow{2}{*}{$\begin{array}{l}\text { Menge } \\
\text { in } \\
1 \mathrm{ccm}\end{array}$} & \multicolumn{2}{|c|}{$\begin{array}{l}\text { Abgabe } \\
\text { pro Min. }\end{array}$} \\
\hline & & & & & & $\begin{array}{l}\text { pro } \\
\text { Tier }\end{array}$ & $\begin{array}{l}\text { pro } \\
\mathrm{kg}\end{array}$ & & $\begin{array}{l}\text { pro } \\
\text { Tier }\end{array}$ & $\begin{array}{l}\text { pro } \\
\mathrm{kg}\end{array}$ \\
\hline & & p.m. 1:10- & $\mathrm{V}$ & 1,8 & 90 & 1,2 & 0,048 & 0,00025 & 0,0003 & 0,000012 \\
\hline & 26 & & VI & 1,9 & 90 & 1,3 & 0,052 & & & \\
\hline & & $: 44$ & VII & 2,8 & 90 & 1,9 & 0,076 & 0,0001 & 0,00019 & 0,0000076 \\
\hline & 34 & & VIII & 2,8 & 90 & 1,9 & 0,076 & & & \\
\hline & & $2: 30$ & $\mathrm{IX}$ & 2,0 & 60 & 2,0 & 0,080 & 0,0001 & 0,0002 & 0,000008 \\
\hline & 40 & & $\mathrm{X}$ & 2,0 & 60 & 2,0 & 0,080 & & & \\
\hline & & $: 46-$ & $\mathrm{XI}$ & 1,6 & 60 & 1,6 & 0,064 & 0,0002 & 0,00082 & 0,000013 \\
\hline & 45 & & $\mathrm{XII}$ & 1,0 & 90 & 0,7 & 0,028 & & & \\
\hline & & $3: 35-$ & XIII & 2,1 & 60 & 2,1 & 0,084 & 0,0002 & 0,00042 & 0,000017 \\
\hline & 48 & & $\mathrm{XIV}$ & 1,8 & 60 & 1,8 & 0,072 & & & \\
\hline
\end{tabular}

50 Minuten vor d. Transsektion wurden etwa $40 \mathrm{ccm}$ Blut fehlerweise verloren. Direkt nach der Transsektion stieg Blutdruck rasch ab (bis $55 \mathrm{~mm} \mathrm{Hg}$ ) ; beim Durchschneiden der noch unverscht gebliebenen Dura weiter ab (etwa bis $28 \mathrm{~mm} \mathrm{Hg}$ ). Puls verkleinert, der allgemeine Zustand verschlimmert, aber wieder allmählich gebessert. Krampf trat am Halsmuskel auf, aber nur auf kurze Zeit. 133 Minuten nach d. Transsektion Aufregung. 180 Minuten nach d. Transsektion Tod durch Verblutung.

Hund 5. o 18. V. 1928 $16,4 \mathrm{~kg}$

a.m. 8:50- Fesselung nach Tracheotomie Äthelnarkose mit d. 9:05- Woulffschen Flasche und Vorbereitung zur Blutdruckmessung.

$\left.\begin{array}{r}: 20- \\ 1: 00-\end{array}\right\}$ Lumbaloperation an d. 1. Seite.

\begin{tabular}{cc|c|c|c|c|c|c|c}
$: 45-$ & I & 3,1 & 60 & 3,1 & 0,19 & 0,0005 & 0,00155 & 0,000094 \\
II & 3,2 & 60 & 3,2 & 0,195 & & &
\end{tabular}

98

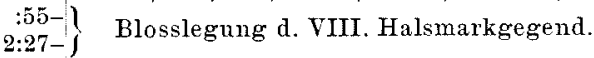

76 p.m. 12:27-

\begin{tabular}{l|l|l|l|l|l|l|l|l}
$: 32-$ & III & 2,9 & 60 & 2,9 & 0,177 & 0,0001 & 0,00029 & 0,000018
\end{tabular}

81 \begin{tabular}{l|l|l|r|r|} 
IV & 2,8 & 60 & 2,8 & 0,17
\end{tabular}

40- Narkose weg, Transsektion im VII. Halsmarke.

\begin{tabular}{ll|l|l|l|l|l|l|l|l}
62 & $1: 03-$ & V & 2,0 & 90 & 1,33 & 0,081 & & \\
& & VI & 1,9 & 90 & 1,27 & 0,077 & 0,00005 & 0,000063 & 0,0000038 \\
& $: 37-$ & VII & 2,1 & 90 & 1,4 & 0,085 & 0,00005 & 0,00007 & 0,0000043
\end{tabular}

77

75

86

\begin{tabular}{l|c|c|c|l|l|} 
& VIII & 1,5 & 90 & 1,0 & 0,061 \\
\hline $2: 08$ & IX & 1,4 & 90 & 0,93 & 0,057
\end{tabular}

\begin{tabular}{l|l|l|l|l|l|l|l|l}
$\mathrm{X}$ & 2,2 & 90 & 1,47 & 0,09 & 0,00005 & 0,000073 & 0,0000045
\end{tabular}

\begin{tabular}{|l|l|l|l|l|l|l|l|l|l|}
$50-$ & $\mathrm{XI}$ & 1,5 & 120 & 0,75 & 0,046 & 0,00005 & 0,000038 & 0,0000023
\end{tabular}

\begin{tabular}{l|l|l|l|l|l|l|l|l|l}
$3: 35-$ & XII & 1,6 & 60 & 1,6 & 0,098 & 0,00005 & 0,00008 & 0,0000049
\end{tabular}

12 Minuten nach d. Transsektion heftige Zittern am ganzen Körper. Pupillen mittelmässig erweitert. 67 Minuten nach der Transsektion rief Schneiden d. zuräckgebliebenen Dura keine Druckveränderung hervor. Endlich 195 Minuten nach der Transsektion Verblutungstod. Ätherverbrauch etwa $700 \mathrm{ccm}$.

Versuchsbedingungen waren vor und nach der Durchtrennung nicht dieselben, da die Narkose nach erfolgter Blosslegung nicht mehr verabreicht wurde. Diese Ungleichheit der Bedingungen lässt eine Differenz in der Sekretionsgeschwindigkeit, die für die Zeit vor und 
nach der Durchtrennung bemerkt war, gewissermassen an Bedeutung verlieren; jedoch scheinen die Resultate mit Heranziehung der Ergebnisse von früheren Beobachtern einige Anhaltspunkte für das Verständnis der Rolle des höheren Zentralnervensystems in der Epinephrinabgabe zu liefern.

Der Hund wurde auf dem Tische in der Bauchlage gefesselt, die Trachea blosslegt und eine Glaskanüle darin eingeführt, und dadurch dem Tier Äther aus einer Woulff'schen Flasche gegeben. Nach elfolgter Lumbalrouteoperation wurde das Nebennierenblut einige Male aufgenommen, dann das Rückenmark im untersten Halsmark durchgetrennt und das Nebennierenblut während etwa vier Stunden wiederholt aufgenommen. Kurz vor oder nach der Durchtrennung wurde $\ddot{A}$ ther nicht mehr gegeben.

Bei einigen Hunden wurde versucht, die betreffenden Marksäule mit einem Seidenfaden zu umschlingen und dieselbe unter leichter Hebung des Fadens mit einer Scheere durchzutrennen; die Prozedur erwies sich jedoch als wenig brauchbar, da sie einen relativ schnellen Tod des Tieres bewirkte.

Das Rückenmark wurde meistens im VW. Halsmark durchgetrennt, beim Hunde Nr. 1 jedoch im zwischen VI. und VII. Halsmark. Direkt nach der Durchtrennung sank der Blutdruck in erheblichem Masse, und die Ausströmungsgeschwindigkeit des Nebennierenblutes nahm dementsprechend ab. Die Hälfte bis zu einem Drittel des vorherigen Druckes war nach der Transsektion als der niedrigste Wert gefunden worden. Öfters stieg der Blutdruck wieder allmählich bis zum Tod des Tieres, aber bei den andern Fällen ging er noch weiter ganz langsam herunter. Beim Hunde Nr. 3 trat eine Blutdruckerhöhurg geringen Grades unmittelbar nach der Durchtrennung auf, die dann einer ausgiebigen Senkung Platz machte. Geschwächte Herzaktion, Atembeschwerden, Krämpfe am Halse, Zittern, Pupillenerweiterung, und Fehlen der Kornealreflexe traten in vereinzelten Fällen auf. Die Atemzahl nahm meistens ein wenig ab, die Pulszahl nahm jedesmal ab, die Körpertemperatur blieb fast unverändert, oder stieg oder sank ein wenig. Das aus der Nebenniere ausgeflossene Blut war nach der Durchtrennung in der Regel dunkelrot.

Die Ausströmungssgeschwindigkeit, die Epinephrinkonzentration und folglich die Geschwindigkeit der Epinephrinsekretion, welche vor der Durchtrennung bestimmt wurden, zeigen keine nennenswerte Abweichung gegenüber den Resultaten anderer Beobachter unter mit den vorliegenden beinahe identischen Versuchsbedingungen.. ${ }^{97}$ Die einfache Blosslegung des Halsmarks bewirkte bisweilen eine Verminderung der Ausströmung'sgeschwindigkeit des Nebennierenblutes, aber

9) Stewart und Rogoff, Am. J. of Physiol, 1921, 56, 211; Sataké, Sugawara und Watan abé, Tohoku J. of Exp. Med., 1927, 8, $525 \mathrm{ff}$. 
in andern Fällen wiederum nicht. Die Sekretionsgeschwindigkeit erlitt dabei auch eine Verringerung; ihr Grad war jedoch garnicht vergleichbar mit dem Unterschied zur Zeit vor und nach der Durchtrennung.

Die Sekretionsgeschwindigkeit des Epinephrins pro kg Körpergewicht pro Minute vor der Blosslegung des Halsmarks, nach derselben und nach erfolgter Durchtrenuung des Halsmarkes betrug 0,000097-0,00012 mg, bzw. 0,000048 mg, bzw. 0,000013 mg 13 Minuten, 0,000005 mg 50 Minutes u. $0,000004 \mathrm{mg}$ etwa 1,5 Stunde nach der Durchtrennung beim Hunde 1, 0,00011-0,000077 $\mathrm{mg}$, bzw. 0,00012 mg, bzw. 0,000022 $\mathrm{mg}$ etwa 40 Minuten, 0,0000135 mg eine Stunde, u. 0,000072 anderthalbe Stunden nach erfolgter Durchtrennung beim Hunde 2, 0,000076-0,00015 mg, bzw. 0,000053 mg, bzw. 0,000005 $4 \mathrm{mg} 7$ Minuten, 0,000056 $\mathrm{mg}$ eine Stunde, $0,0000032 \mathrm{mg}$ ca. 1,5 Stunden u. $0,0000043 \mathrm{mg} 2$ Stunden nach erfolgter Transsektion beim Hunde $3,0,000044 \mathrm{mg}$ vor der Blosslegung, und $0,000013 \mathrm{mg} 3$ Minuten, 0,000012 mg 20 Minuten, 0,0000076 mg 1 Stunde, $0,000008 \mathrm{mg}$ etwa 2 Stunden, u. $0,000017 \mathrm{mg} 3$ Stunden nach der Transsektion beim Hunde 4 , und endlich $0,00009+\mathrm{mg}$, bzw. $0,000018 \mathrm{mg}$, bzw. $0,0000038 \mathrm{mg}$ etwa 20 Minuten, $0,0000043 \mathrm{mg}$ eine Stunde, $0,0000045 \mathrm{mg}$ anderthalbe Stunden, $0,0000023 \mathrm{mg}$ zwei Stunden, u. $0,0000049 \mathrm{mg}$ drei Stunden nach der Durchtrennung beim Hunde 5 . Es sei noch bemerkt dass die letzte Probe beim Hunde 2, welche auf eine als die vorhergehende deutlich höhere Epinephrinsekretion hinwies, im asphyktischen Zustande des Tieres aufgenommen wurde.

Im grossen und ganzen wurde die Sekretionsgeschwindigkeit des Epimephrins durch die Durchschneidung des untersten Halsmarkes auf etwa ein Fünftel bis ein Vierzigstel des ursprünglichen Wertes beim Intaktbleiben des Rückenmarks verkleinert. Der niedrigste Wert $(0,000004 \mathrm{mg}$ pro kg Körpergewicht pro Minute beim Hunde 1, 0,000 $003 \mathrm{mg}$ beim Hunde 3, 0,000008 $\mathrm{mg}$ beim Hunde 4, 0,000002 $\mathrm{mg}$ beim Hunde 5) war bedeutend niedriger als der beim nicht narkotisierten, gefesselten und laparotomierten Hunde, der durchschnittlich 0,00003$0,00004 \mathrm{mg}$ pro $\mathrm{kg}$ und pro Minute beträgt. ${ }^{10}$ Beim Hund 2 war er nicht so klein, nämlich wurde $0,0000135 \mathrm{mg}$ pro $\mathrm{kg}$ und pro Minute nach der Durchtrennung gefunden.

Vergleicht man die Unterschiede der Sekretionsgeschwindigkeit vor und nach der Durchtrennung sowohl wie die zwischen der Epinephrinabgabe in der Ruhe beim normalen Hunde und derselben nach der Durchschneidung des Halsmarkes, so ist man wohl berechtigt die Beteiligung des höheren Zentralnervensystems auf die Epinephrinsekretion beim narkotisierten, gefesselten Hunde wie beim nicht-narkotisierten, nicht gefesselten Hunde zu bejagen. Wenngleich es nicht nahe zu liegen scheint diese Verminderung der Sekretionsgeschwindigkeit auf die Shockwirkung allein zurückzuführen, muss man zunächst davon absehen, aus den oben angegebenen Differenzen sofort auf den Umfang der die Epinephrinabgabe beeinflussenden Rolle des höhereren Zentralnervensystems in allgemeinen zu schliessen.

10) Satake, Sug a wara und Wat a nabé, Tohoku J. of Exp. Med., 1923, 13, 513. 
Aus den durch die Anwendung der Cava-Taschenmethode gewonnenen, zahlreichen Resultaten glauben die Cleveland-Physiologen eine gesetzmässige Beziehung ableiten zu können zwischen der Epinephrinkonzentration und der Ausströmungsgeschwindigkeit des Nebennierenblutes, sodass damit der Epinephrinabgabe eine konstante Geschwindigkeit zuzuschreiben ist. Wir selbst haben uns von der Richtigkeit ihrer Angabe überzengt, aber nur unter speziellen Umständen, sodass wir es bei den vorliegenden Fällen nicht für angebracht halten vorauszusetzen, dass die starke Verminderung der Ausströmungsgeschwindigkeit durch Vergrösserung der Epinephrinkonzentration im Sinne von Stew a r t und Rog off zu ersetzen ist. Anderes gesagt, es scheint uns auf Grund vorliegender Versuche gerechtfertigt auf die Möglichkeit hinzuweisen, dass eine ausgiebige Blutdrucksenkung und Veränderung des allgemeinen Zustandes des Tieres nach der Durchtrennung an der starken Verminderung dex Epinephrinabgabe zum Teil oder in etwas bedeutendem Masse schuld ist.

Bei allen vier Hunden von S te wart und Rog of $\mathrm{f}^{11}$ ) (Nr. 327, 352, $380 \mathrm{u}$. 351 ) bewirkte die Durchtrennung des untersten Halsmarkes eine deutliche Verminderung der Epinephrinabgabe, etwa wie in den vorliegenden Experimenten, und die Geschwindigkeit der Abgabe war nach der Durchtrennung ungefähr dieselbe gleichgiltig ob die Operation ummittelbar oder 2-13 Tage (Nr. 330, 345, 347 u. 395) vor der Aufnahme des Nebennierenblntes ausgeführt wurde. Die von ihmen nach der Durchtrennung angegeben Zahlen sind im allgemeinen etwas grösser als unsere, doch waren die Zahlen von unserem Hunde 2 mit denen ihrer Hunde häufig identisch, und die ihrer Hunde 351, 327, 330 und 395 häufig mit denen unserer Hunde.

Bei der Katze war es ihnen möglich gewesen die Wirkungslosigkeit der Durchtrennung des Halsmarkes auf die Epinephrinausscheidung wiederholt ${ }^{5 / 11}$ ) zu beobachten, was gewichtig in ihre Wagschale bei der Lösung der Frage fiel. Es sei jedoch bemerkt, dass der Ausfall ihrer Experimente an der Katze eher unregelmässig zu nennen ist.

\section{Einfluss der intravenösen Injektion von Pepton, der sensiblen Reizung und des Aderlasses auf die Epinephrinabgabe beim Hunde, dessen unterstes Halsmark vorher durchgetrennt war.}

Nach der Durchtrennung des Ruickenmarkes im untersten Halsmarke versuchten wir einige Mittel welche für ihr epinephrinaustreibendes Vermögen in hinreichender Weise bekannt sind, wie Peptonvergiftung und Aderlass, fermer die sensible Reizung, welche eine Hypersekretion des Epinephrins bis auf die zwei bis funf fache der normalen zur Folge hat, solange das Tier nicht nur nicht unter dem Einfluss der: Narkose steht, sondern auch sich sogut wie vollständig im normal physiologischen Zustand befindet. ${ }^{12)}$ Die sensible Reizung. kam von frühern Beobachtern bei den Studien über die hier behandelte Frage zur Anwendung. Da die Hypersekretion des Epinephrins

11) Stewart und Rogoff, Am. J. of Physiol, 1920, 51, 484.

12) Sataké, Watanabé und Sugawara, Tohoku J. of Exp. Med., 1927, 9, 1. 
durch Peptonvergiftung, Aderlass und auch sogar durch sensible Reizung sich nachweisen liess, scheint es uns nicht unbedingt erforderlich, die Untersuchung noch auf die Strychninvergiftung auszudehnen unter Berücksichtigung der Lokalization des Angriffspunktes des Giftes, um so mehr, als die Strychninexperimente von Stewart und Rog off durchwegs positiv ausfielen. ${ }^{11}$

Es darf hier nicht unterlassen werden den von den Herren H. Sato, S. $\mathrm{Kanow}$ oka und F. Ohmi in diesem Institute anschliessend an die vorliegende Arbeit vorgenommenen Experimente eine Erwähnung zu tun. Während Pepton und Aderlass, welche hier Anwendung gefunden haben, eine Hypersekretion des Epinephrins im Anschluss an die Blutdrucksenkung bewirken, sehen wir in dem Insulin eine Substanz welche im Anschluss an die Blutzuckerverminderung die Epinephrinabgabe vermehrt. Sie haben Insulin angewendet und gefunden, dass es sich in Betreff der vorliegenden Frage wesentlich anders als die den Blutdruck erniedrigenden Mittel verhält. Wir beschränken uns hier jedoch auf diese Angabe, und behalten uns vor, bei späterer Gelegenheit im Zusammenhang mit einer ausführlichen Darstellung der Insulinexperimente auf die Lokalisationsfrage des Zentralmechanismus für die Epinephrinabgabe noch einmal zurückzukommen.

\section{(A) Peptonvergiftung.}

Während das Pepton beim narkotisierten Hunde keine Vermehrung der Epinephrinabgabe hervorruft, stellt es beim nicht-narkotisierten ein hoch wirksames epinephrinaustreibendes Mittel dar. Eine fünf- bis dreissigfache Vergrösserung der normalen Abgabe des Epinephrins lässt sich durch intravenöse Darreichung von 0,1 bis $0,3 \mathrm{~g}$ Pepton pro $\mathrm{kg}$ Körpergewicht erzielen. ${ }^{13)}$

Peptonlösung wurde 13 Hunden denen das Halsmark durchtrennt. worden war intravenös infundiert; und zwar bei 4 Hunden 14-15 Stunden nach der Durchtrennung, und bei den übrigen etwa 3-6 Stunden darnach. In den letzteren Fällen wurde die betreffende Markgegend 1-8 Tage vorher unter der Äthernarkose blossgelegt, und am Tage der Aufnahme des Nebennierenblutes wieder unter Äther, diesmal aber mit dem Verbrauch einer möglichst kleinen Menge des Narkotikums, das Mark durchgetrennt, worauf die Lumbalrouteoperation erfolgte. In der Regel wurden dann zwei Stunden zwischen der Lumbalrouteoperation und der ersten Aufnahme des Nebennierenblutes gewartet. Unter Berücksichtigung des allgemeinen Zustandes des Tieres nach der Halsmarktranssektion, wurde zuerst eine sicher wirksame aber möglichst kleine Menge, $0,1 \mathrm{~g}$ Pepton pro kg, verabreicht, meistens mit dem sofortigen tödlichen Ausgang (Hunde Nr. 6, 8, 9 und 18). Es wurde dann eine noch kleinere Dose, 0,05 g pro kg, ge-

13) Wat a n a bé, Tohoku J. of Exp. Med., 1927, 9, 412. 
geben, welche sich nach Watanabe beim normalen Hunde in Hinsicht auf die Epinephrinsekretion noch wirksam erwies. Diese Dosis hatte den gewünschten Erfolg, d. h. die Tiere vertrugen dieselbe gut und eine Hypersekretion des Epinephrins war jedesmal nachweisbar.

Unmittelbar nach oder sogar während der intravenösen Infusion der Peptonlösung trat eine rasche Blutdrucksenkung in Erscheinung, welche öfters ein erhebliches Mass, eventuell sogar den Nullpunkt erreichte. Sie klang dann ab, um sich einige oder mehrere Minuten darnach dem ursprünglichen Wert wieder zu nähern, falls das Tier nicht unter sofortiger Entwicklung von Paralyse erlag. Das Herz schlug meistens schwächer, die Atmung war ebenfalls angestrengt, und bisweilen wurde künstliche Atmung eine Zeitlang ausgeführt, um das Tier aus dem Atemstillstand zu retten. Aufregung, Unruhe, Schreien, Erweiterung der Pupillen, Erlöschen des Kornealreflexes wurden auch öfters beobachtet; diese Erscheinungen blieben nach mehreren Minuten aus. Zittern, Muskelkrämpfe, Streckung der vorderen Beine, und Speichel- und Tränenausfluss traten mitunter zufällig auf. Die Körpertemperatur blieb meistens unverändert, stieg aber bisweilen ein wenig.

Wir waren bei diesen Versuchen imstande den Befund von Watanabe, dass die Veränderungen in der Geschwindigkeit der Epinephrinabgabe im grossen und ganzen mit den Vergiftungssymptomen einhergehen, voll zu bestätigen.

Bei 3 Hunden (Nr. 11, 12 u. 13) wurde die sensorische Reizung vor der Peptoninjektion ausprobiert, und bei 4 Hunden (Nr. 13, 14, 15 u. 16) Aderlass nach dem Abklingen der Peptonvergiftung. Die betreffenden Daten sind in den folgenden Abschnitten angeführt.

Die Epinephrinabgabe nach der Durchtrennung im untersten Halsmarke und direkt vor der Peptondarreichung betrug $0,000008 \mathrm{mg}$ pro kg Körpergewicht pro Minute (Hund Nr. 7), 0,00001 mg (Nr. 10), $0,000007 \mathrm{mg}$ (Nr. 11), 0,000009 mg (Nr. 12), 0,000004 mg (Nr. 13), $0,000003 \mathrm{mg}$ (Nr. 14), 0,000006 mg (Nr. 15), 0,000003 mg (Nr. 16) und $0,000004 \mathrm{mg}$ (Nr. 17). Die bei den anderen 4 Hunden (Nr. 6, 8, 9, u. 18), welche unmittelbar nach der Infusion des Peptons starben, zeigte sich auch dieselbe Geschwindigkeit $(0,000006 \mathrm{mg}$ pro $\mathrm{kg}$ pro Minute, $0,000002 \mathrm{mg}, 0,00004 \mathrm{mg}$ bzw. 0,00003 mg). Diese Werte und die oben bereits gegebenen, nach der Halsmarkdurchtrennung gewonnenen Zahlen, liegen also dicht beieinander.

Hund $\mathrm{Nr}$. 12 war der einzige der eine grössere Dose, $0,1 \mathrm{~g}$ pro $\mathrm{kg}$ und gut vertragen konnte. Im Anschluss an die Infusion nahm die Ausströmungsgeschwindigkeit des Nebennierenblutes wie üblich mässig ab, aber gleichzeitig vermehrte sich die Epinephrinkonzentration im Blut erheblich, und als Folge wurde die Sekretionsgeschwindigkeit des Epinephrins entscheidend vergrössert errechnet. Diese betrug $0,000009 \mathrm{mg}$ pro kg Körpergewicht pro Minute vor der Peptondarreichung und 0,0001 mg 5-11 Minuten sowie 23-31 Minuten nachher. Also eine etwa zehnfache Erhöhung der Geschwindigkeit der Epinephrinsekretion wurde durch $0,1 \mathrm{~g}$ Pepton pro $\mathrm{kg}$ erzielt. 
Hund 15. \&.

\section{Beispiel 2.}

27. IX. 1928. Nachmittags unter Äthernarkose (mit geringem Chloroformzusatz; $110 \mathrm{ccm}$ ) Blosslegung d. VII. Halsmarkgegend n. einfache Hautuähte.

28. IX. $21,8 \mathrm{~kg}$.

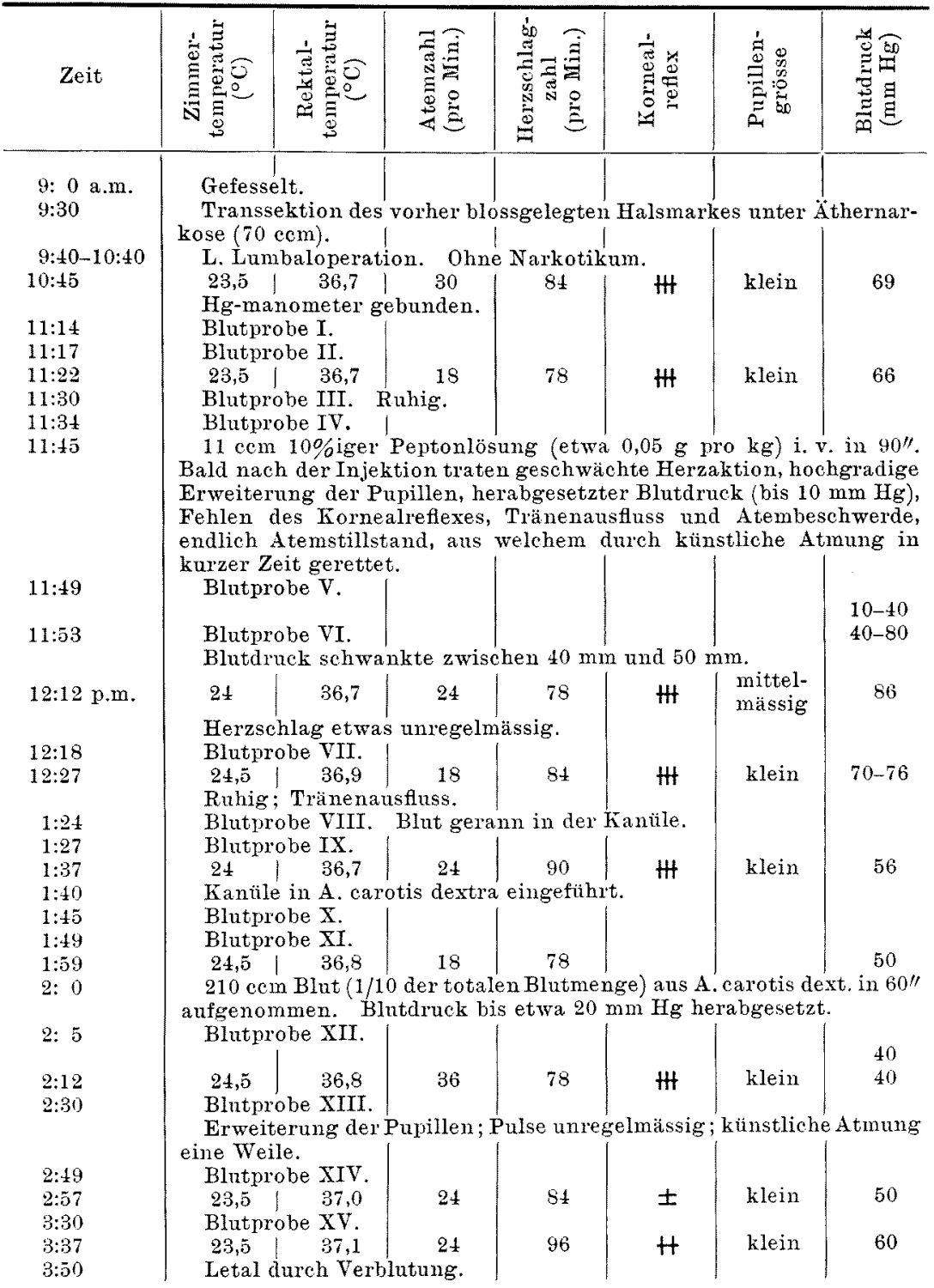




\section{Darmkurve (auf $\frac{1}{2}$ verkleinert).*}

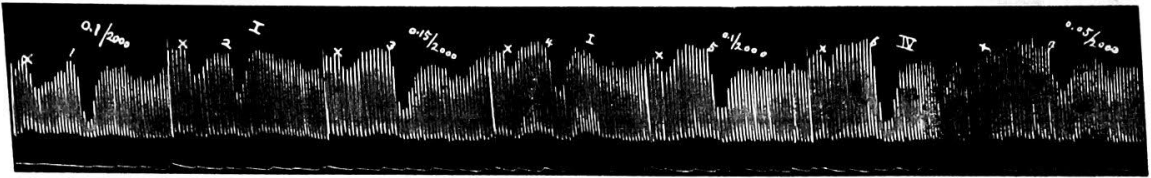

Fig. a. I: Ein wenig schwächer als $0,00005 \mathrm{mg}$, schwächer als $0,000075 \mathrm{mg}$. Fast gleich mit $0,000025 \mathrm{mg}$.

IV: Fast gleich mit $0,00005 \mathrm{mg}$ und ein wenig stärker als $0,000025 \mathrm{mg}$.

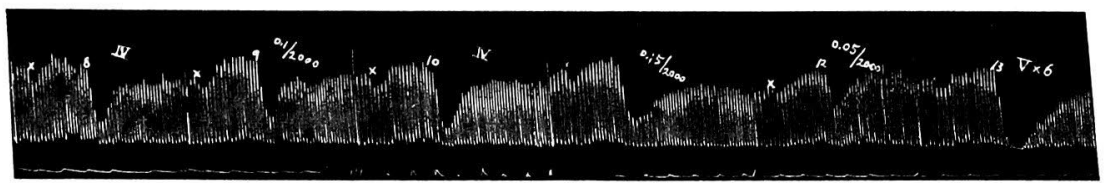

Fig. b. IV: Stärker als $0,000025 \mathrm{mg}$ ( 7 u. 8), fast gleich mit $0,00005 \mathrm{mg}$ und schwächer als $0,000075 \mathrm{mg}$.

$\mathrm{V} \times 6$ : Stärker als $0,000025 \mathrm{mg}$.

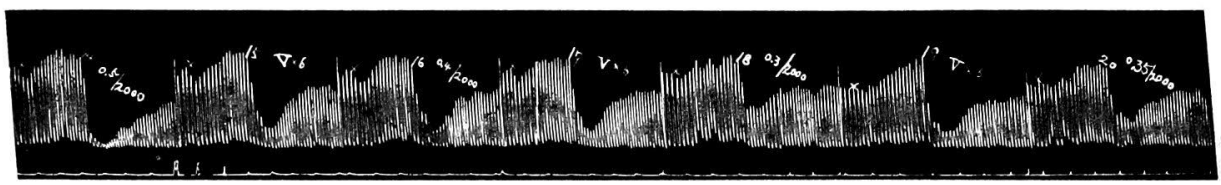

Fig. c. $V \times 6$ : Schwächer als $0,00025 \mathrm{mg}(13,14$, u. 15), fast gleich mit $0,0002 \mathrm{mg}$ und stärker als $0,00015 \mathrm{mg}$ und $0,000175 \mathrm{mg}$.

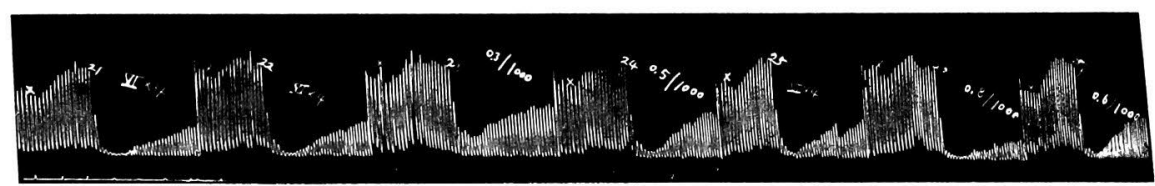

Fig. d. VI $\times 4$ : Stärker als $0,000175 \mathrm{mg}$ und $0,0003 \mathrm{mg}$, ein wenig stärker als 0,0005 $\mathrm{mg}$ und schwächer als $0,0008 \mathrm{mg}$.

* Darmkurve: Bei Zeichen „×“ Atropin-Ty rode'sche Lösung, in der Kaninchendünndarmstück rhythmisch schwingt, ist durch Indifferente-Blut-Lösung ersetzt. Bei dem Zahlzeichen ist die Indifferente-Blut-Lösung durch Adrenalin-Blut- oder Nebennierenblut-Lösung ersetzt. Alle Blutproben werden mit 4 facher Tyrode'scher Lösung verdünnt und für die einzelne Prüfung $0,5 \mathrm{ccm}$ Blut benutzt. Die Adrenalin-BlutLösung ist durch Mischung von $0,5 \mathrm{ccm}$ Indifferentblut mit einer bestimmten Menge der Adrenalinhydrochloridlösung von Sankyo Co. und Tyrode'scher Lösung hergestellt.

Nummer der Nebennierenvenenblutprobe, und Konzentration und Menge (ccm) der Adrenalinhydrochloridlösung sind bei jeder Darmkurve angegeben. Zum Beispiel bedeuted ,0,1/2000“ 0,1 ccm der Lösung von 1/2000 mg Adrenalinhydrochlorid (S a n k y o Co.) in $1 \mathrm{ccm}$, d. h. 0,00005 mg Adrenalinhydrochlorid.

Zeitsignal markierte jede 30 Sekunden. 


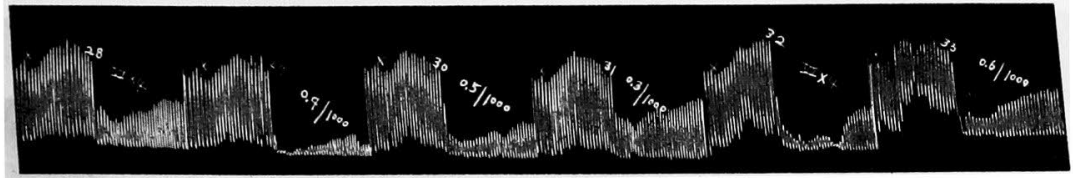

Fig. e. VI $\times 4$ : Ein wenig schwächer als $0,0006 \mathrm{mg}$ und schwächer als $0,0007 \mathrm{mg}$.

VII $\times 4$ : Stärker als $0,0003 \mathrm{mg}$ und $0,0006 \mathrm{mg}$.

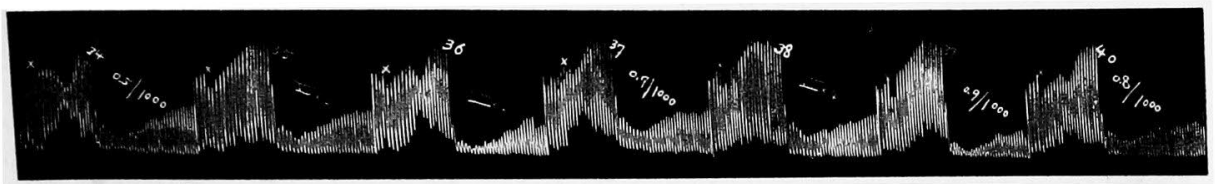

Fig. f. VII $\times 4$ : Stärker als $0,0005 \mathrm{mg}$ und $0,0007 \mathrm{mg}$, schwächer als $0,0009 \mathrm{mg}$ und ein wenig schwächer als $0,0008 \mathrm{mg}$.

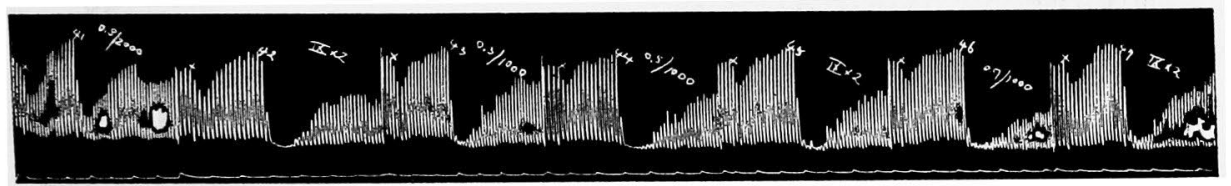

Fig. g. IX $\times 2$ : Stärker als $0,00015 \mathrm{mg}$ und $0,0003 \mathrm{mg}$. Fast gleich mit $0,0005 \mathrm{mg}$. Schwächer als $0,0007 \mathrm{mg}$.

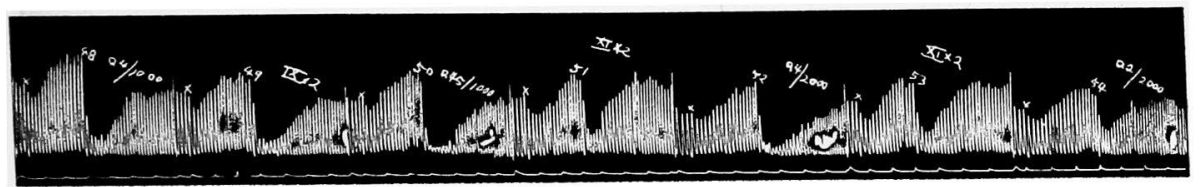

Fig. h. IX $\times 2$ : Stärker als $0,0004 \mathrm{mg}$ und sehr wenig stärker als $0,00045 \mathrm{mg}$.

$\mathrm{XI} \times 2$ : Schwächer als $0,00045 \mathrm{mg}, 0,0002 \mathrm{mg}$ und $0,0001 \mathrm{mg}$.

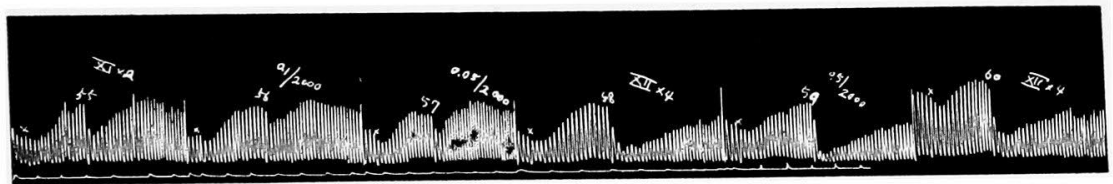

Fig. i. $\mathrm{XI} \times 2$ : Fast gleich mit $0,00005 \mathrm{mg}$.

XII $\times 4$ : Stärker als $0,000025 \mathrm{mg}$ und schwächer als $0,00025 \mathrm{mg}$.

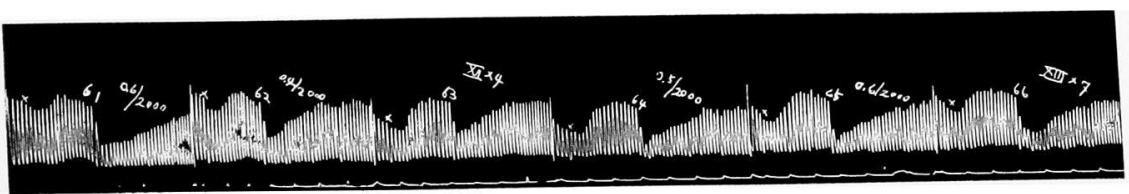

Fig. j. XII $\times 4$ : Schwächer als $0,0003 \mathrm{mg}$, stärker als $0,0002 \mathrm{mg}$ und schwächer als $0,00025 \mathrm{mg}$.

XIII $\times 7$ : Ein wenig stärker als $0,0003 \mathrm{mg}$. 


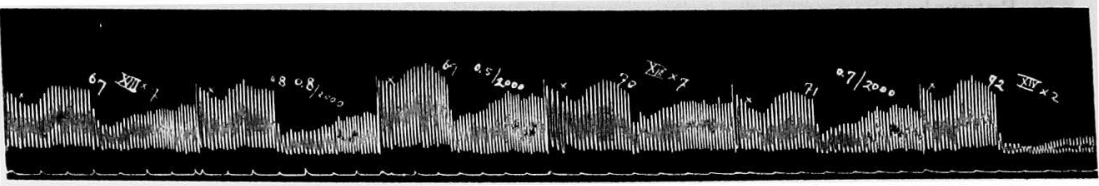

Fig. k. XIII $\times 7:$ Schwächer als $0,0004 \mathrm{mg}$, stärker als $0,00025 \mathrm{mg}$ und schwächer als $0,00035 \mathrm{mg}$.

$\mathrm{XIV} \times 2$ : Stärker als $0,00035 \mathrm{mg}$.

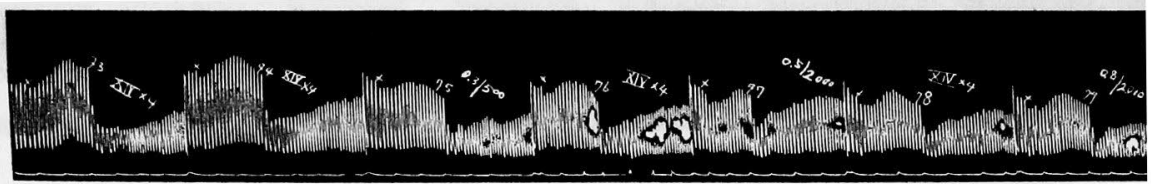

Fig. 1. XIV $\times 4$ : Schwächer als $0,0006 \mathrm{mg}$, stärker als $0,00025 \mathrm{mg}$ und schwächer als $0,0004 \mathrm{mg}$.

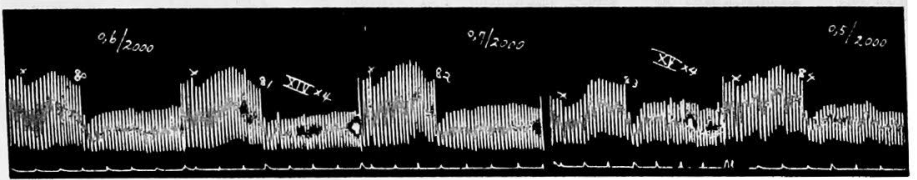

Fig. $\mathrm{m}$. XIV $\times 4$ : Stärker als $0,0003 \mathrm{mg}$ und $0,00035 \mathrm{mg}$.

$\mathrm{XV} \times 4$ : Schwächer als $0,00025 \mathrm{mg}$.

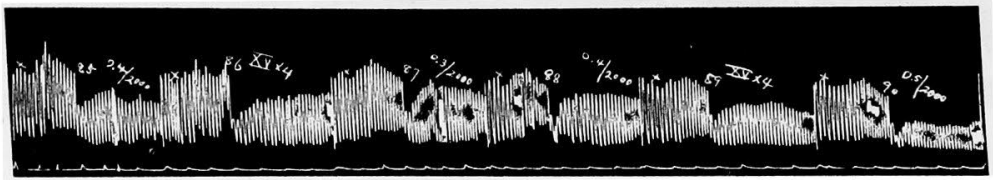

Fig. n. XV $\times 4$ : Sehr wenig stärker als oder fast gleich mit $0,0002 \mathrm{mg}$, stärker als $0,00015 \mathrm{mg}$, sehr wenig stärker als $0,0002 \mathrm{mg}$ und schwächer als $0,00025 \mathrm{mg}$.

Zusammenfassung der Bestimmungen.

Blutprobe I: Ein wenig schwächer als $0,00005 \mathrm{mg}$, schwächer als $0,000075 \mathrm{mg}$. Fast gleich mit $0,000025 \mathrm{mg}$. Diese Blutprobe ist als $0,00005 \mathrm{mg}$ pro $1 \mathrm{ccm}$ bestimmt worden.

Blutprobe IV: Fast gleich mit $0,00005 \mathrm{mg}$, und ein wenig stärker als $0,000025 \mathrm{mg}$. Stïrker als $0,000025 \mathrm{mg}$, fast gleich mit $0,00005 \mathrm{mg}$ und schwächer als $0,000075 \mathrm{mg}$. Sie ist also von uns als $0,0001 \mathrm{mg}$ pro $1 \mathrm{ccm}$ bestimmt worden.

Blutprobe V: Sie wurde vor der Bestimmung mit der 5 facher Menge des indifferenten Blutes verdünnt. $V \times 6$ : Stärker als $0,000025 \mathrm{mg}$. Schwächer als $0,00025 \mathrm{mg}$, fast gleich mit $0,0002 \mathrm{mg}$ und stärker als $0,00015 \mathrm{mg}$ und $0,000175 \mathrm{mg}$. Diese Blutprobe ist als $0,0024 \mathrm{mg}$ pro $1 \mathrm{ccm}$ bestimmt worden.

Blutprobe VI: Diese Blutprobe wurde vor der Bestimmung mit der 3 fachen Menge des indifferenten Blutes verdünnt. VI $\times 4$ : Stärker als $0,000175 \mathrm{mg}$ und $0,0003 \mathrm{mg}$, ein wenig stärker als $0,0005 \mathrm{mg}$ und schwächer als $0,0008 \mathrm{mg}$. Ein wenig schwächer als $0,0006 \mathrm{mg}$ und schwächer als $0,0007 \mathrm{mg}$. Sie ist von uns als $0,0044 \mathrm{mg}$ in $1 \mathrm{ccm}$ abgeschätzt worden. 
Butprobe VII: Sie wurde vor der Bestimmung mit der 3 fachen Menge des indifferenten Blutes verdünnt. VII $\times 4$ : Stärker als $0,0003 \mathrm{mg}$ und $0,0006 \mathrm{mg}$. Stärker als $0,0005 \mathrm{mg}$ und $0,0007 \mathrm{mg}$, schwächer als $0,0009 \mathrm{mg}$ und ein wenig schwächer als 0,0008 mg. Die Probe VII ist als $0,006 \mathrm{mg}$ in $1 \mathrm{ccm}$ bestimmt worden.

Blutprobe IX: Diese Probe wurde vor der Bestimmung mit der gleichen Menge des indifferenten Blutes verdünnt. IX $\times 2:$ Stärker als $0,00015 \mathrm{mg}$ und $0,0002 \mathrm{mg}$. Fast gleich mit $0,0005 \mathrm{mg}$. Schwächer als $0,0007 \mathrm{mg}$. Stärker als $0,0004 \mathrm{mg}$ und sehr wenig stärker als $0,00045 \mathrm{mg}$. Sie ist von uns als $0,002 \mathrm{mg}$ pro $1 \mathrm{cem}$ bestimmt worden.

Blutprobe XI: Sie wurde vor der Bestimmung mit der gleichen Menge des indifferenten Blutes verdünnt. $\mathrm{XI} \times 2$ : Schwächer als $0,00045 \mathrm{mg}$ und $0,0001 \mathrm{mg}$. Fast gleich mit $0,00005 \mathrm{mg}$. Die Probe XI ist von uns als $0,0002 \mathrm{mg}$ in $1 \mathrm{ccm}$ abgesehätzt worden.

Blutprobe XII: Diese Probe wurde vor der Bestimmung mit 3 fachen Menge des indifferenten Blutes verdünnt. XII $\times 4$ : Stärker als $0,000025 \mathrm{mg}$ und schwächer als $0,00025 \mathrm{mg}$. Schwächer als $0,0003 \mathrm{mg}$, stärker als $0,0002 \mathrm{mg}$ und schwächer als 0,00025 mg. Sie ist von uns als $0,0018 \mathrm{mg}$ in $1 \mathrm{ccm}$ bestimmt worden.

Blutprobe XIII: Sie wurde vor der Bestimmung mit der 6 fachen Menge des indifferenten Blutes verdünnt. XIII $\times 7$ : Ein wenig stärker als $0,0003 \mathrm{mg}$. Schwächer als $0,0004 \mathrm{mg}$, stärker als $0,00025 \mathrm{mg}$ und schwächer als $0,00035 \mathrm{mg}$. Diese Probe ist von uns als $0,00455 \mathrm{mg}$ pro $1 \mathrm{ccm}$ bestimmt worden.

Blutprobe XIV: Sie wurde vor Bestimmung mit der 3 fachen Menge des indifferenten Blutes verdünnt. $X I V \times 4$ : Schwächer als $0,0006 \mathrm{mg}$, stärker als $0,00025 \mathrm{mg}$ und schwächer als $0,0004 \mathrm{mg}$. Stärker als $0,0003 \mathrm{mg}$ und $0,00035 \mathrm{mg}$. Die Probe XIV ist von uns als $0,003 \mathrm{mg}$ pro $1 \mathrm{ccm}$ abgeschätzt worden.

Blutprobe XV: Sie wurde vor der Bestimmung mit der 3 fachen Menge des indifferenten Blutes verdünnt. $\mathrm{XV} \times 4:$ Schwächer als $0,00025 \mathrm{mg}$. Sehr wenig stärker als oder fast gleich mit $0,0002 \mathrm{mg}$, sehr wenig stärker als $0,0002 \mathrm{mg}$ und schwächer als $0,00025 \mathrm{mg}$. Die Probe XV ist von uns als $0,0016^{+} \mathrm{mg}$ in $1 \mathrm{ccm}$ abgeschätzt worden.

Nach dem Erlöschen der Vergiftungssymptome infolge der Injektion von $0,05 \mathrm{~g}$ pro kg Peptonlösung wurde einigen Hunden (Nr. 7, 10 u. 11) nochmals $0,1 \mathrm{~g}$ Pepton injiziert. Die Tiere konnten diese Dose gut überstehen, die Vergiftungssymptome waren aber viel geringer als vorher und nur in einem Falle (Hund Nr. 7) liess sich eine geringfügige Vermehrung des Epinephrins nachweisen.

$0,05 \mathrm{~g}$ Pepton pro $\mathrm{kg}$ Körpergewicht bewirkte in den meisten Fällen mehr oder weniger deutliche klinische Symptome sowie Vermehrung der Epinephrinsekretion, während dieselbe Dose bei anderen Tieren (Nr. 7 u. 16) fast keine klinischen Symptome und kaum eine vermehrte Epinephrinabgabe hervorrief. Beim Hunde Nr. 10 vermehrte sich die Sekretion von $0,00001 \mathrm{mg}$ pro $\mathrm{kg}$ pro Minute auf $0,00003 \mathrm{mg} 8$ Minuten nach der Infusion, was mindestens über eine halbe Stunde anhielt; beim Hund Nr. 11 von $0,000007 \mathrm{mg}$ auf 0,00006 mg 4-7 Minuten nach der Giftdarreichung; beim Hunde Nr. 14 von $0,00003 \mathrm{mg}$ auf $0,000013 \mathrm{mg} 5$ Minuten nach der Infusion, und beim Hunde Nr. 15 von $0,000006 \mathrm{mg}$ auf $0,00002 \mathrm{mg} 4$ Winuten nach der Injektion, und betrug $0,00005 \mathrm{mg}$ nach 7 Minuten, 0,0001 $\mathrm{mg}$ nach 33 Minuten und $0,00003 \mathrm{mg}$ nach etwa Hundert Minuten. In jedem Falle lag die vermehrte Konzentration des Epinephrins im Blute der Verg'rösserung der Sekretionsgeschwindigkeit zu Grunde, während die 


\section{Tabelle II.}

Einfluss der intravenösen Injektion des Peptons auf die Epinephrinabgabe bei den Hunden, deren Halsmark vorher unter Äthernarkose durch Transsektion durehgetrennt war.

\begin{tabular}{|c|c|c|c|c|c|c|c|c|c|c|c|}
\hline \multirow{3}{*}{ 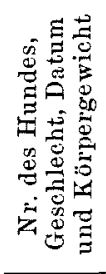 } & \multirow{3}{*}{ 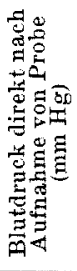 } & \multirow{3}{*}{\multicolumn{2}{|c|}{ 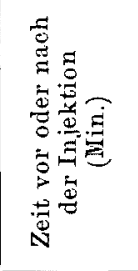 }} & \multirow{3}{*}{ 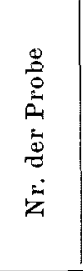 } & \multicolumn{4}{|c|}{$\begin{array}{l}\text { Blutfluss } \\
\text { (ccm) }\end{array}$} & \multicolumn{3}{|c|}{$\begin{array}{l}\text { Epinephrinabgabe } \\
\text { (mg) }\end{array}$} \\
\hline & & & & & \multirow{2}{*}{$\stackrel{0}{\underset{3}{0}}$} & \multirow{2}{*}{ 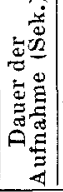 } & \multicolumn{2}{|c|}{$\begin{array}{c}\text { Menge } \\
\text { pro Min. }\end{array}$} & \multirow{2}{*}{$\begin{array}{l}\text { Menge } \\
\text { in } \\
1 \mathrm{ccm}\end{array}$} & \multicolumn{2}{|c|}{$\begin{array}{l}\text { Abgabe } \\
\text { pro Min. }\end{array}$} \\
\hline & & & & & & & $\begin{array}{l}\text { pro } \\
\text { Tier }\end{array}$ & $\begin{array}{l}\text { pro } \\
\text { kg }\end{array}$ & & $\begin{array}{l}\text { pro } \\
\text { Tier }\end{array}$ & $\begin{array}{r}\text { pro } \\
\mathrm{kg}\end{array}$ \\
\hline \multirow{23}{*}{$\begin{array}{c}\text { Hund } 7 . \\
\text { o } \\
8 . \text { VI. } \\
1928 \\
23,1 \mathrm{~kg}\end{array}$} & \multirow{4}{*}{63} & \multirow{2}{*}{\multicolumn{2}{|c|}{ 7. VI. }} & \multicolumn{8}{|c|}{$\begin{array}{l}\text { Nachmittags unter Morphin- u. Athernarkose Transsektion } \\
\text { d. VI. Halsmarkes, mit mässiger Blutung. Ätherverbrauch } \\
\text { etwa } 70 \mathrm{ccm} \text {. }\end{array}$} \\
\hline & & & & Lin & ke L & umba & loper & ion, D & auer 55 & Minuten. & \\
\hline & & & $49-$ & II & 3,0 & $\begin{array}{l}60 \\
60\end{array}$ & 3,0 & 0,13 & 0,00005 & 0,00015 & 0,0000065 \\
\hline & & & $20-$ & III & 3,2 & 60 & 3,2 & 0,139 & & & \\
\hline & \multirow[t]{2}{*}{64} & & $19-$ & IV & 3,8 & $60 \mid$ & 3,8 & 0,165 & 0,00005 & 0,00019 & 0,0000082 \\
\hline & & & & \multicolumn{8}{|c|}{$\begin{array}{l}23 \mathrm{ccm} 5 \% \text { iger Peptonlösung }(=0,05 \mathrm{~g} \text { pro } \mathrm{kg}) \text { i.v. in- } \\
\text { jiziert. Dauer } 90 / .\end{array}$} \\
\hline & \multirow{3}{*}{69} & $\mathrm{Nach}$ & $3-$ & $\mathrm{V}$ & 3,8 & 90 & 2,53 & 0,11 & 10,00005 & {$[0,000126$} & {$[0,0000055$} \\
\hline & & & & VI & 2,8 & 60 & 2,8 & 0,122 & & & \\
\hline & & & $11-$ & VII & 4,2 & 60 & 4,2 & 0,182 & 0,00005 & 0,00021 & 0,0000091 \\
\hline & \multirow[t]{2}{*}{62} & & 12 & VIII & 2,9 & 60 & 2,9 & 0,125 & & & \\
\hline & & & 44 & IX & 4,0 & 60 & 4.0 & 0,173 & & & \\
\hline & \multirow[t]{2}{*}{64} & & $45-$ & $\mathrm{X}$ & 3,5 & 60 & 3,5 & 0,152 & 0,00005 & 0,000175 & 0,0000076 \\
\hline & & Nach & $109-$ & XI & 2,9 & 60 & 2,9 & 0,126 & 0,00005 & 0,000145 & 0,0000063 \\
\hline & \multirow[t]{3}{*}{64} & & $10-$ & XII & 2,6 & 60 & 2,6 & 0,113 & & & \\
\hline & & & & \multicolumn{8}{|c|}{$\begin{array}{l}23 \text { cem } 10 \% \text { iger Peptonlösung }(=0,1 \mathrm{~g} \text { pro } \mathrm{kg}) \text { i.v. in- } \\
\text { iiziert. Dauer } 150 \% \text {. }\end{array}$} \\
\hline & & Nach & & XIII & 2,0 & $60 \mid$ & 2,0 & 0,087 & & & \\
\hline & \multirow[t]{2}{*}{68} & & $3-$ & $\mathrm{XIV}$ & 2,6 & 60 & 2,6 & 0,113 & 0,0001 & 0,00026 & 0,0000113 \\
\hline & & & $15-$ & $\mathrm{XV}$ & 2,6 & 60 & 2,6 & 0,113 & & & \\
\hline & \multirow[t]{2}{*}{57} & & $16-$ & XVI & 2,9 & 60 & 2,9 & 0,126 & 0,00005 & 0,000145 & 0,0000063 \\
\hline & & & $45-$ & XVII & 1,9 & 60 & 1,9 & 0,082 & & & \\
\hline & \multirow[t]{2}{*}{48} & & $46-$ & XVIII & 2,6 & 60 & 2,6 & 0,113 & 0,0001 & 0,00026 & 0,0000113 \\
\hline & & & $89-$ & $\mathrm{XIX}$ & 3,0 & 90 & 2,0 & 0,087 & 0,0001 & 0,0002 & 0,0000087 \\
\hline & 50 & & $91-$ & $\mathrm{XX}$ & 2,6 & 60 & 2,6 & 0,113 & & & \\
\hline
\end{tabular}

Gleich nach d. ersten Injektion traten Vergiftungssymptome ganz voriibergehend und spurweise auf. 109 Minuten nach der ersten Injektion Aufregung. Gleich nach d. Reinjektion kamen Erregung, Streckung der Vorderbeine, Salivation und Muskelkrämpfe in Erscheinung; Blutdruck bis $25-30$ herab, aber sofort sich wiederherstellt. 45 Minuten nach der Reinjektion Salivation nicht mehr bemerkt. 103 Minuten nach d. Reinjektion Wunde geschlossen. Etwa $250 \mathrm{ccm}$ indifferentes Blut aus A. lumbodorsalis sin. entnommen.

Hund 10. 今 $\mathrm{VI}$ 1928 $16,1 \mathrm{~kg}$
28. VI. ' Nachmittags unter Äthernarkose Blosslegung d. VII. Halsmarkes und einfache Hautnähte. Ätherverbrauch etwa 40 ecm mit geringem Zusatz von Chloroform.

30. VI.

Vor 285- Unter Äthernarkose Transsektion des schon blossgelegten Halsmarkes. Menge von $\ddot{A}$ ther etwa $20 \mathrm{ccm}$.

Linke Lumbaloperation, Dauer 69 Minuten. 


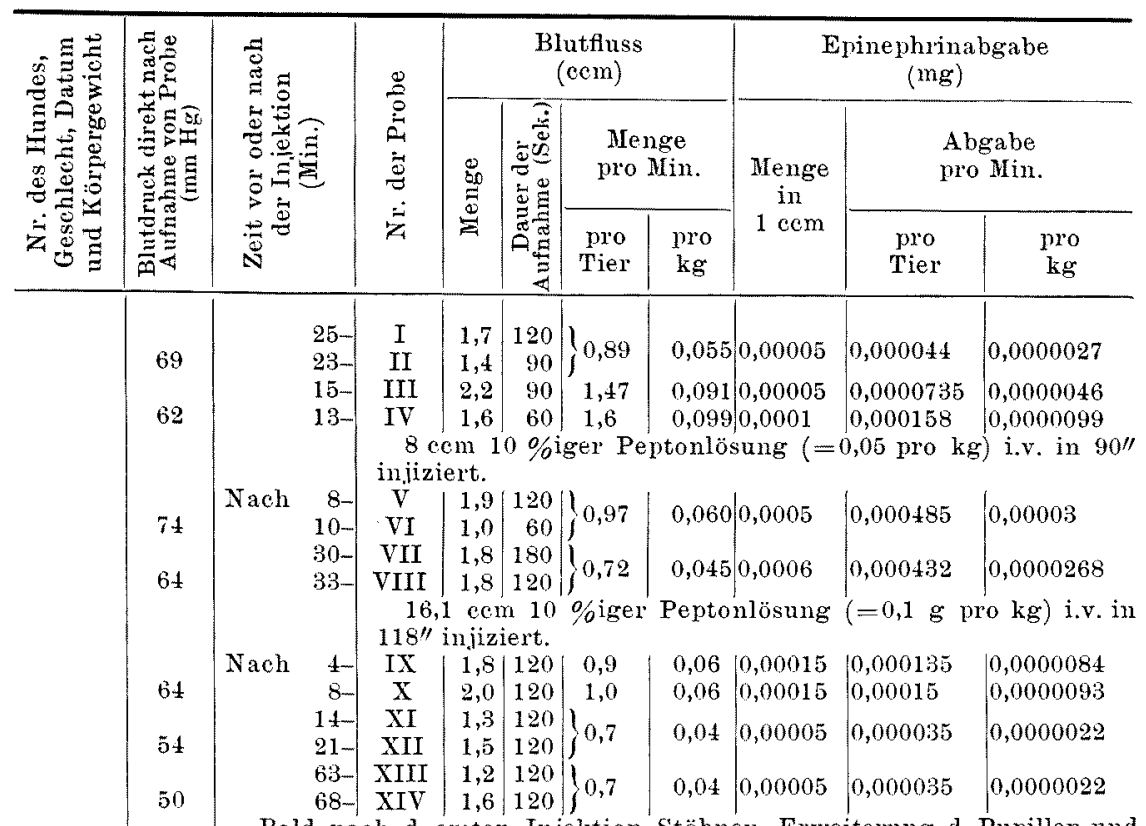

Bald nach d. ersten Injektion Stöhnen, Erweiterung d. Pupillen and herabgesetzter Blutdruck (bis $30 \mathrm{~mm} \mathrm{Hg}$ ). 33 Minuten nach d. ersten Injektion Blut etwas leicht gerinnbar. Bald nach d. Reinjektion Aufregung, Erweiterung d. Pupillen und Zittern, Blutdruck dabei bis $25 \mathrm{~mm}$ herab. Ca. $410 \mathrm{ccm}$ Blut wurden aus $A$. femoralis sin. entnommen, dann Tod.

Hund 11 . 6. VII 1928

5. VLI. Nachmittags unter Athernarkose Blosslegung d. VI. und VII. Halsmarke und einfache Hautnähte. $180 \mathrm{ccm} \ddot{A}$ ther mit geringem Chloroform verbraucht.

6. VII.

Vor 345- Unter Athernarkose (etwa $80 \mathrm{ccm}$ ) Transsektion d. vorher blossgelegten Halsmarkes. Linke Lumbaloperation, Dauer 85 Minuten.

4

48

44

42

36 \begin{tabular}{l|c|c|c|c|c|c|c|c|}
$110-$ & I & 3,5 & 120 & 1,75 & $0,058^{\prime} 0,00005$ & 0,0000875 & 0,0000029
\end{tabular}

\begin{tabular}{l|l|r|r|r|r|r|r|}
$108-$ & II & 2,2 & 90 & 1,47 & $0,0490,00005$ & 0,0000735 & 0,0000024
\end{tabular}

\begin{tabular}{l|l|l|l|l|l|l|l|l|}
$95-$ & III & 3,2 & 150 & 1,28 & 0,042 & 0,00005 & 0,000064 & 0,0000021
\end{tabular}

\begin{tabular}{l|l|l|l|l|l|l|l|l}
$92-$ & IV & 1,2 & 120 & 0,95 & 0,032 & 0,00005 & 0,0000475 & 0,00000158
\end{tabular}

80- Zweimal sensible Reizung anf N. saph. sin,; siehe Tabelle 43 IIII.

23- XI $|2,7| 120|1,35| 0,045,0,00015|0,000202 \quad| 0,0000067$

$15 \mathrm{cem} 10 \%$ iger Peptonlösung (etwa $0,05 \mathrm{~g}$ pro $\mathrm{kg}$ ) i.v. in $60^{\prime \prime}$ in iiziert.

\begin{tabular}{ll|l|l|l|l|l|l|l} 
Nach 4- XII & 2,3 & 180 & 0,77 & $0,0260,0024$ & 0,00185 & 0,000061
\end{tabular}

\begin{tabular}{l|l|l|l|l|l|l|l}
$7-$ & XIII & 2,3 & 120 & 1,15 & $0,038,0,00015$ & 0,000172 & 0,0000057
\end{tabular}

\begin{tabular}{l|l|l|l|l|l|l|l|}
$34-\mathrm{XIV}$ & 1,5 & 180 & 0,5 & $0,017 \mid 0,0001$ & 0,00005 & 0,0000017
\end{tabular}

$30 \mathrm{ccm} 10 \%$ iger Peptonlösung (etwa $0,1 \mathrm{~g}$ pro $\mathrm{kg}$ ) i.v. in 136 " injiziert.

\begin{tabular}{l|l|l|l|l|l|l|l|l}
$5-\mathrm{XV}$ & 2,3 & 180 & 0,77 & 0,02 & 0,0001 & 0,000077 & 0,0000026
\end{tabular}

\begin{tabular}{r|r|r|r|l|l|l|l|l}
$9-$ & XVI & 1,2 & 120 & 0,6 & 0,020 & & & \\
$30-$ & XVII & 1,8 & 180 & 0,6 & 0,020 & 0,0001 & 0,00006 & 0,000002
\end{tabular}

\begin{tabular}{l|l|l|l|l|l|l|l}
$30-$ XVIII & 1,8 & 150 & 0,72 & 0,024 & 0,0001 & 0,000072 & 0,0000024
\end{tabular}

Bald nach d. ersten Injektion traten Unruhe, Aufregung, Erweiterung der Pupillen u. unregelmässiger Puls auf ; Blutdruck dabei bis $10 \mathrm{~mm} \mathrm{Hg}$ 


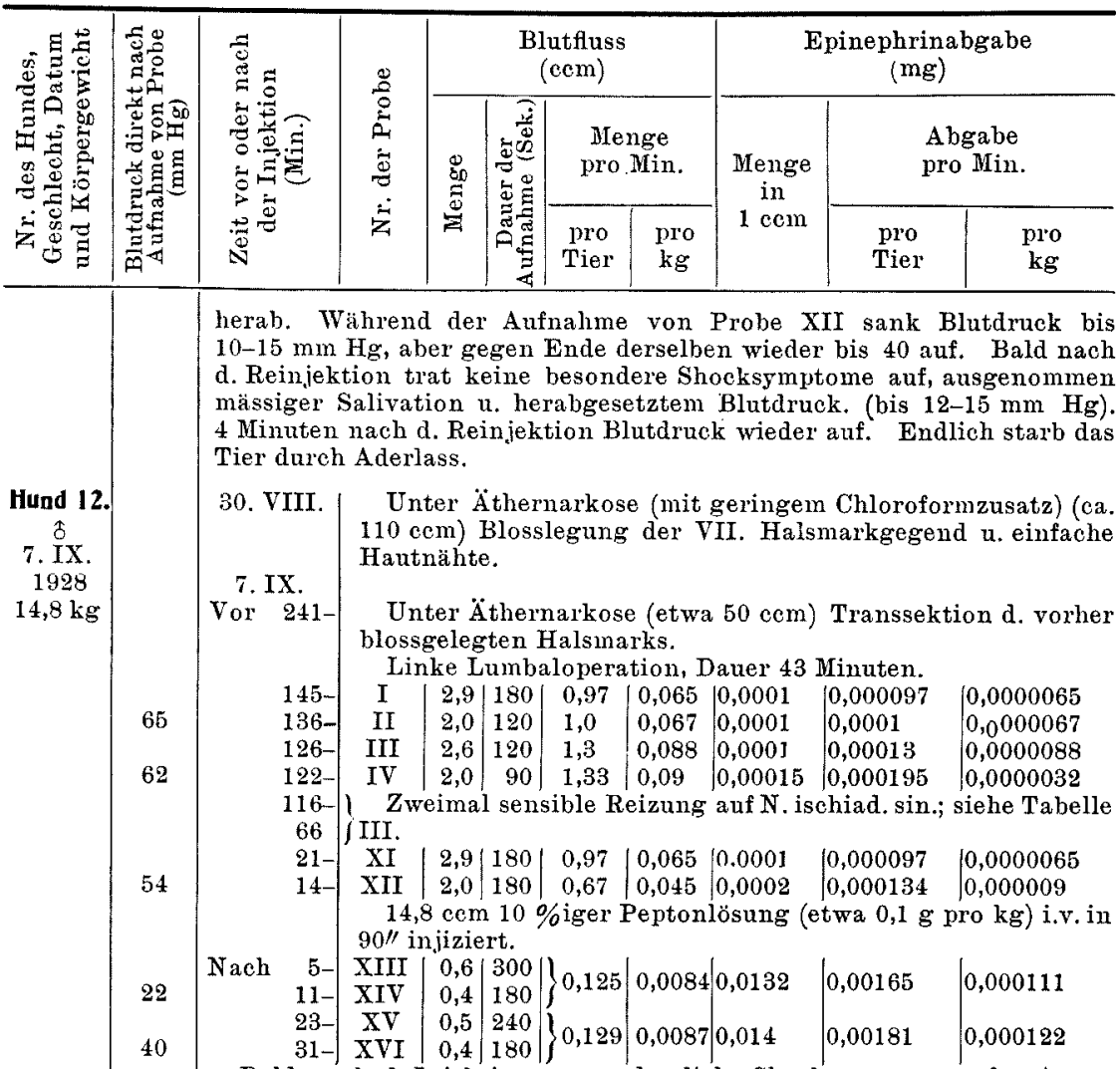

Bald nach d. Injektion traten deutliche Shocksymptome auf: Atembeschwerde, verkleinerter, unregelmässiger Puls, und Spasmns, zumal Tetanus. Blutdruck einmal bis 0 herab, durch künstliche Atmung gerettet. 44 Minuten nach der Injektion wieder Atembeschwerde. 64 Minuten nach der Injektion Blutansammlung schwer. 79 Minuten nach der Injektion Tod durch Aderlass.

Hund 13. $\hat{\delta}$ 14. IX. 1928 $26,3 \mathrm{~kg}$

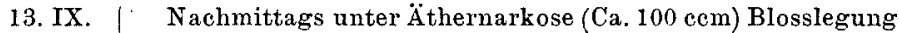
d. VII. Halsmarkgegend u. einfache Hautnähte.

14. IX.

Vor 310- Unter Äthernarkose (mit geringem Chloroform; ca. $50 \mathrm{ccm}$ ) Transsektion d, vorher blossgelegten Halsmarks.

Linke Lumbaloperation, Dauer 50 Minuten.

\begin{tabular}{l|l|l|l|l|l|l|l|l|}
$165-$ & I & 2,2 & 60 & 2,2 & 0,084 & 0,00005 & 0,00011
\end{tabular}

$0,084 \quad 0,00005-0,00011-\quad 0,0000042-$

\begin{tabular}{ll|l|l|l|l|l|l|l}
$152-$ & III & 2,2 & 60 & 2,2 & 0,084 & 0,00005 & 0,00011 & 0,0000042
\end{tabular}

\begin{tabular}{l|l|l|l|l|l|l|l|l|}
$151-$ & IV & 2,3 & 60 & 2,3 & 0,087 & 0,00005 & 0,000115 & 0,0000044
\end{tabular}

143- Zweimal sensible Reizung auf $\mathrm{N}$. ischiad. sin.; siehe

60 f Tabelle III.

\begin{tabular}{l|l|l|l|l|l|l|l|l|}
$18-\mathrm{XI}$ & 2,3 & 90 & 1,6 & 0,061 & $0,00005-$ & $0,00008-$ & $0,00000304-$
\end{tabular}

60

$13,2 \mathrm{ccm} 10 \%$ iger Peptonlösung (etwa $0,05 \mathrm{~g}$ pro $\mathrm{kg}$ ) i.v. in $105 /$ injiziert.

\begin{tabular}{ll|l|l|l|l|l|l|l|l|} 
Nach 2- XIII $|2,8| 180 \mid$ & $0,93|0,035| 0,0001$ & 0,000093 & 0,00000354
\end{tabular} 


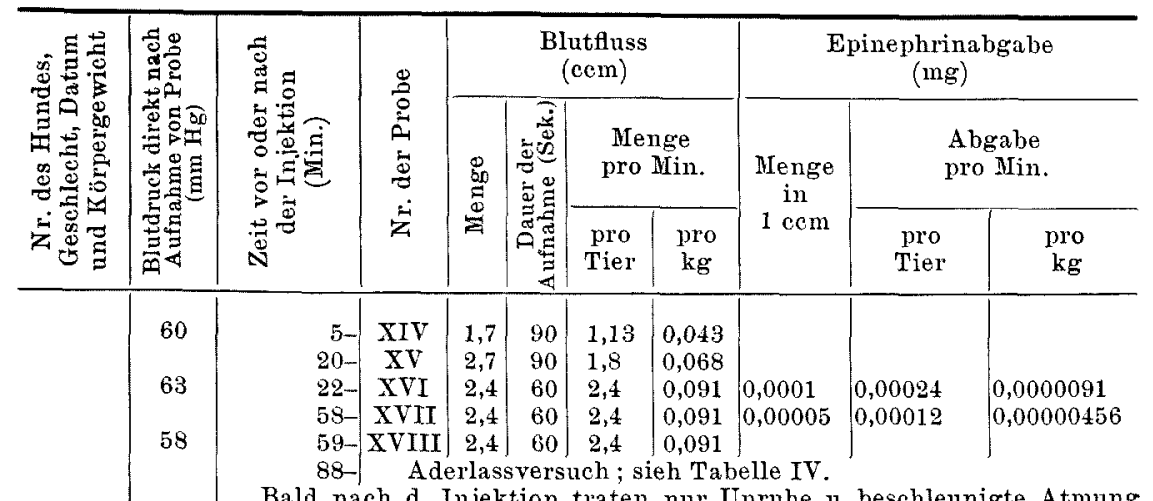

Bald nach d. Injektion traten nur Unruhe $u$. beschleunigte Atmung auf; Blutdruck ging während d. Aufnahme der Probe XIII bis etwa 38 $\mathrm{mm} \mathrm{Hg}$ herab, aber kurz danach wieder bis $60 \mathrm{~mm}$ auf. Vergiftungssymptome eher mangelhaft.

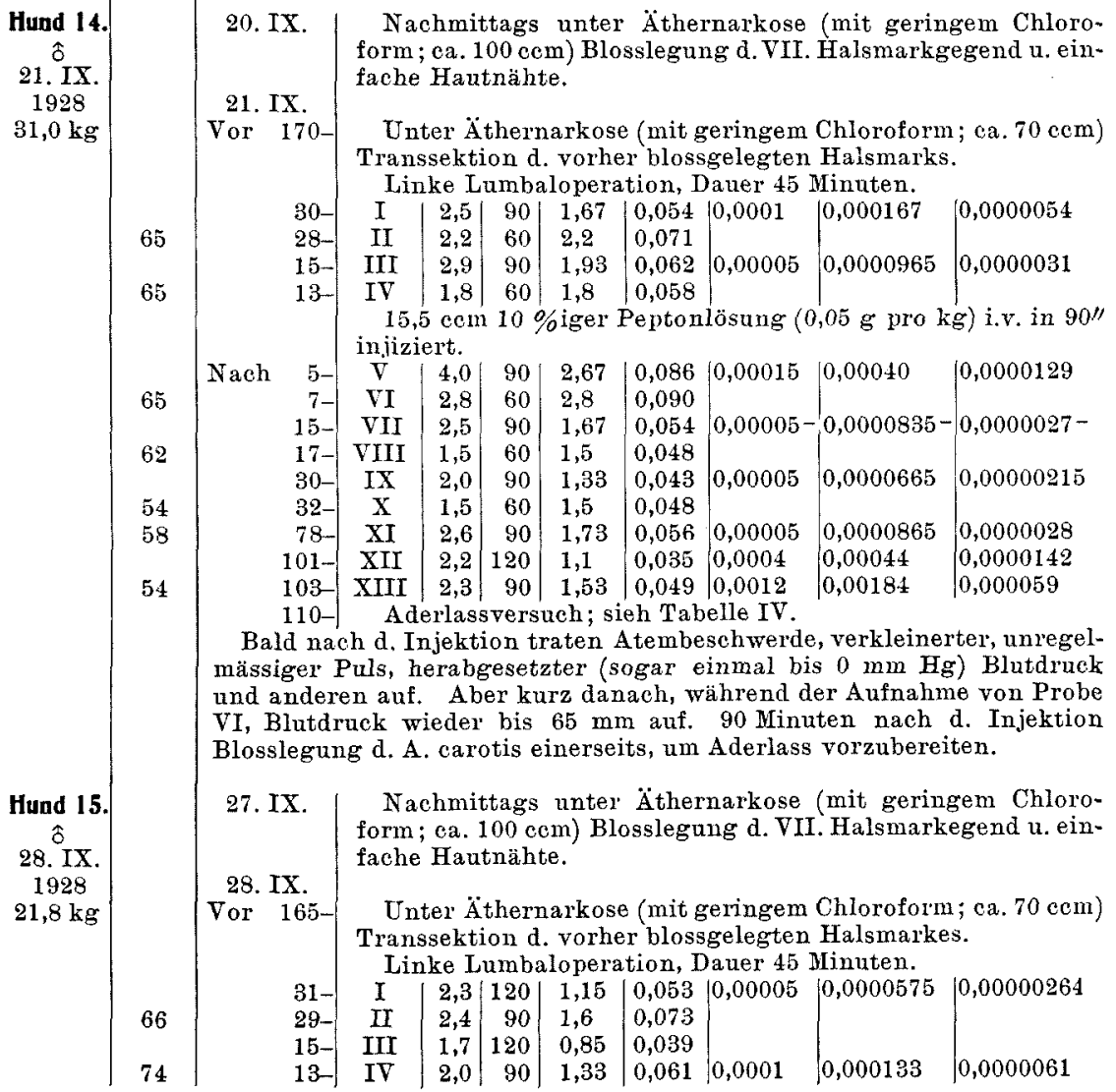




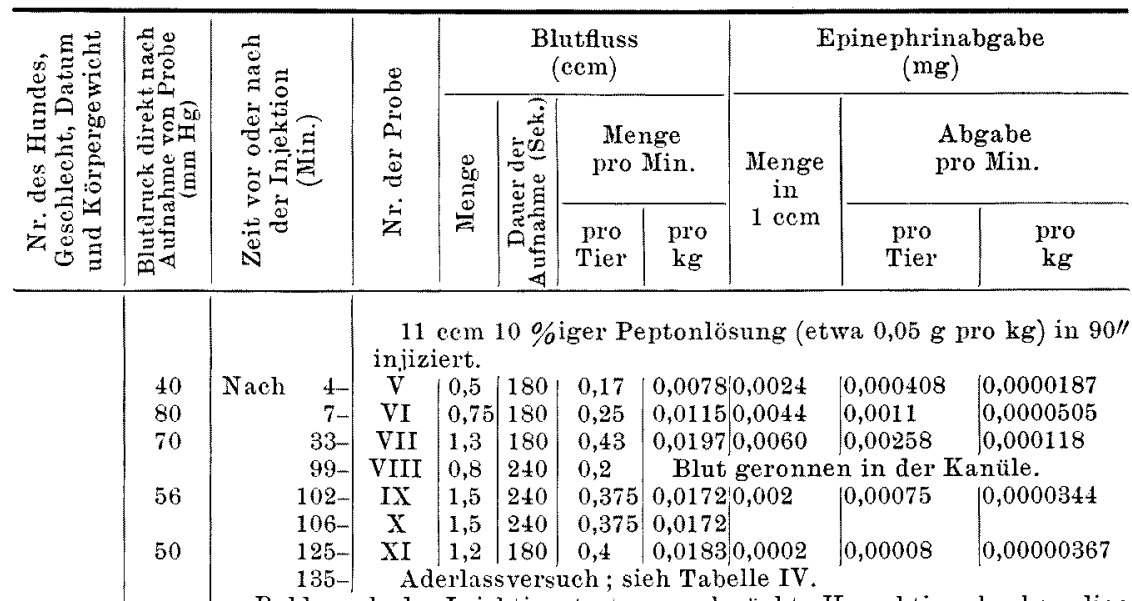

Bald nach der Injektion traten geschwachte Herzaktion, hochgradige Erweiterung der Pupillen, herabgesetzter Blutdruck (jis $10 \mathrm{~mm} \mathrm{Hg}$ ), Fehlen des Kornealreflexes, Tränenausfluss u. Atembeschwerde, zumal Stillstand; künstlicher Atmung kurze zeit ausgeführt. 7 Ninuten nach d. Injektion blieb Tränenausfluss aus; Blutdruck ging einmal bis $80 \mathrm{~mm}$ auf, aber nach etwa 5 Minuten wieder herab und schwankte zwischen 40 und 50. 33 Minuten nach d. Injektion wieder Tränenaustluss.

Hund 1

$5 . \mathrm{X}$ 1928 $21,3 \mathrm{~kg}$

Hund 17. 今 $\mathrm{x}$ 12. X. 1928 $21,8 \mathrm{~kg}$
4. X.

5. X. Vol' $160-$
$\mathrm{Nach}$
11. $\mathrm{X}$.

12. $\mathrm{X}$.

Vor 180

Nachmittags unter $\ddot{A}$ thernarkose (mit geringem Chloroform; etwa $100 \mathrm{ccm}$ ) Blosslegung d. VIII. Halsmarkgegend u. einfache Hautnähte.

Unter Äthernarkose (etwa $60 \mathrm{ccm}$ ) Transsektion d. vorherblossgelegten Halsmarks.

Linke Lumbaloperation, Dauer 45 Minuten.

\section{\begin{tabular}{l|l|l|l|l|}
$\mathrm{I}$ & 2,1 & 180 & 0,7 & 0,033 \\
$\mathrm{IIT}$ & 2,0 & 120 & 1,0 & 0,047
\end{tabular}}

\begin{tabular}{c|c|c|c|c|c|c|c|c}
$36-$ & I & 2,1 & 180 & 0,7 & 0,033 & & & \\
$33-$ & II & 2,0 & 120 & 1,0 & 0,047 & 0,00005 & 0,000050 & 0,0000023 \\
$20-$ & III & 2,0 & 120 & 1,0 & 0,047 & & &
\end{tabular}

\begin{tabular}{l|l|l|l|l|l|l|l|l}
$18-$ & IV & 2,2 & 120 & 1,1 & 0,052 & 0,00005 & 0,000055 & 0,0000026
\end{tabular}

$11 \mathrm{ccm} 10 \%$ iger Peptonlösung (etwa $0,05 \mathrm{~g}$ pro $\mathrm{kg}$ ) in $152 "$ i.v. injiziert.

\begin{tabular}{r|c|l|l|l|l|l|l|l|l}
$3-$ & V & 0,8 & 240 & 0,2 & 0,0094 & 0,00025 & 0,00005 & 0,0000023 \\
$10-$ & VI & 1,2 & 180 & 0,4 & 0,019 & 0,00015 & 0,00006 & 0,0000028 \\
$30-$ & VII & 0,9 & 180 & 0,3 & 0,014 & 0,0004 & 0,00012 & 0,0000056 \\
$33-$ & VIII & 0,6 & 180 & 0,2 & 0,0094 & & & \\
$90-$ & IX & 1,0 & 240 & 0,25 & 0,012 & 0,00015 & 0,0000375 & 0,0000017 \\
$120-$ & X & 1,0 & 180 & 0,33 & 0,016 & 0,00045 & 0,00015 & 0,000007
\end{tabular}

Bald nach d. Injektion trat nur herabgesetzter Blutdruck (bis $15 \mathrm{~mm}$ $\mathrm{Hg}$ ) auf, sonst keine nennenswertige Symptome nachweisbar. $30 \mathrm{Hinu-}$ ten nach d. Injektion Vorderbeine bewegt. 134 Minuten nach d. Injektion Aderlasstod.

Nachmittag unter Äthernarkose (mit geringem Chloroform; $100 \mathrm{~cm}$ ) Blosslegung d. VIII. Halsmarkgegend und einfache Hautnähte.

Unter Äthernarkose (etwa $50 \mathrm{ccm}$ ) Transsektion d. vorher blossgelegten Halsmarkes.

Linke Lumbaloperation, Dauer 35 Minuten.

$\left.\begin{array}{l|c|c|c|}37- & \text { I } & 1,6 & 120 \\ 35- & \text { II } & 1,7 & 120\end{array}\right\} 0,82|0,038| 0,00015|0,000123| 0,0000051$ 


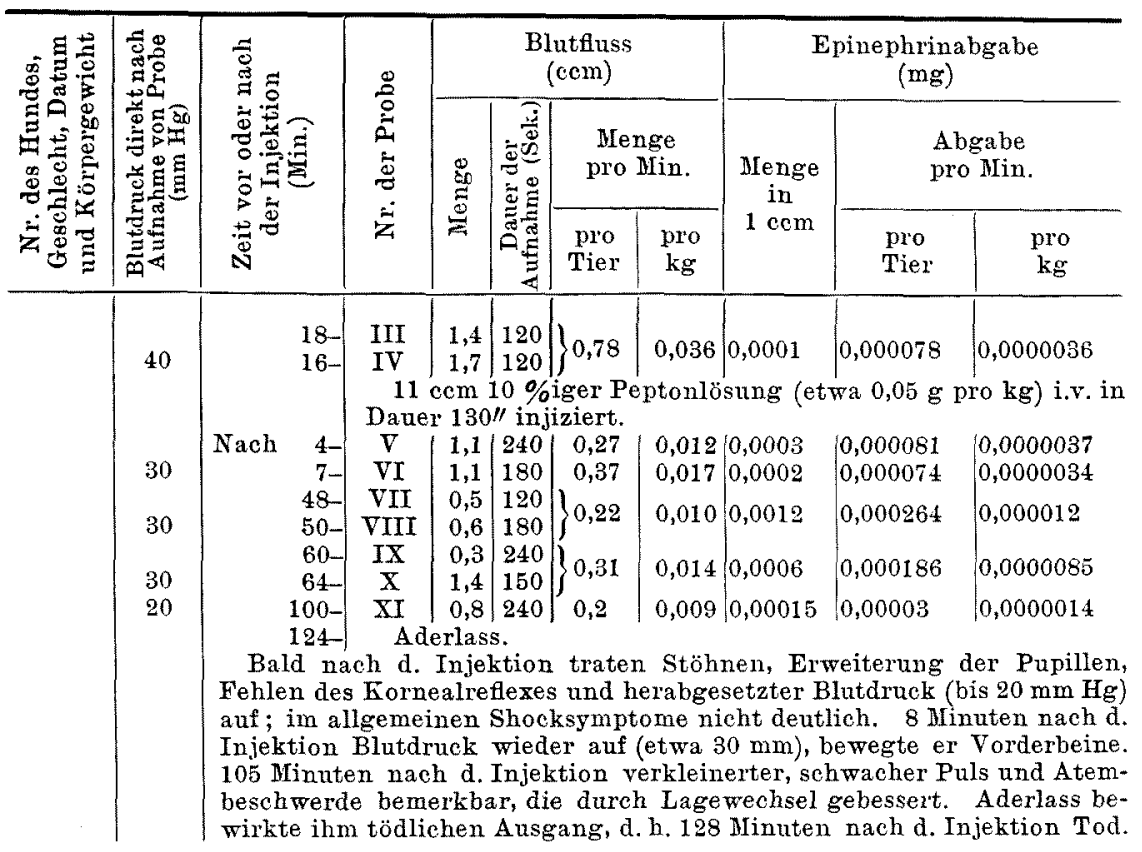

Ausströmungsgeschwindigkeit, mit der Ausnahme vom Hunde Nr. 14, dabei mehr oder minder nachliess.

Bei den übrigen Fällen (Hunde Nr. 13, 16 u. 17) trat nur eine geringe Vermehrung der Epinephrinabgabe durch die Peptongabe auf, und zwar mit einer etws langen Latenzzeit. Etwa 2-3 fach grössere Abgabe (von $0,00004 \mathrm{mg}$ pro $\mathrm{kg}$ pro Ninute auf $0,000009 \mathrm{mg}$, von $0,000003 \mathrm{mg}$ auf $0,000006 \mathrm{mg}$ und $0,000004 \mathrm{mg}$ auf $0,00001 \mathrm{mg}$ ) wurde etwa dreissig Ninuten nach der Infusion gefunden.

Abgesehen von den Fällen wo sich nur eine geringfügige Vergiftung nachweisen liess, darf man wohl mit Recht annehmen, dass das Pepton in der intravenös verabreichten Dose von $0,05 \mathrm{~g}$ pro kg eine mässige Hypersekretion des Epinephrins beim Hunde ohne Halsmark und oberem Zentralnervensystem, eine 3-12 fache Vergrösserung. der Sekretionsgeschwindigkeit veranlassen. In der Tat ibertraf die grösste Sekretion des Epinephrins, welche beim Hunde Nr. 15 als Folge der Vergiftung beobachtet worden war, diejenige der ursprünglichen um ungefähr $0,00006 \mathrm{mg}$ pro kg pro Minute. Bei einem normalen Hunde Nr. 29, der einzige Fall in welchem 0,05 g. Pepton pro $\mathrm{kg}$ bei den Versuchen von Watan abe intravenös verabreicht wurde, gab diese Dose den Anlass zu einer Beschleunigung der Epinephrinsekretion von $0,000025 \mathrm{mg}$ pro $\mathrm{kg}$ pro Minute auf $0,00019 \mathrm{mg}$. 
Der direkte Vergleich der Daten in den beiden Reihen von Experimenten, von Watanabe und von uns, dürfte wohl nicht zu Recht bestehen, wenn die Verschiedenheit der Versuchsbedingungen berücksichtigt wird, zumal die Zahl der Watanabe'schen Versuche mit dieser Dose zu klein war, d. h. der oben zitierte Versuch war der einzige. Der allgemeine Zustand des Tieres war durch die Transsektion bekannter Weise vielfach und ernstlich verändert, der Widerstand des Tieres gegen die Vergiftung, gemessen an der tödlichen Dose des Giftes, und die ursprüngliche Geschwindigkeit der Epinephrinabgabe waren stark vermindert.

Wenn sich der im verlängerten Marke oder an einer noch höheren Stelle befindliche Zentralmechanismus für die Epinephrins ekretion existiere, welcher lediglich durch die Operation ausgeschaltet wird und dabei die oben dargelegten Ergebnisse geliefert würden, so könnte man annehmen, dass das Pepton auf den höheren Zentralmechanismus, sowie auf den im Brustmark in gleicher Stärke wirke. In der Tat ist jedoch das Verhältnis gar nicht einfach; und solche Spekulationen würden zweifellos zu weit führen. In Hinsicht auf die Lokalizationsfrage, zum Beispiel, liegen keinerlei Anhaltpunkte dafür vor, ob man das Verhältnis der vermehrten Sekretion zu der ursprünglichen oder den Überschuss der ersteren über die letztere heranziehen soll, wenn man von der Grösse der Vermehrung der Epinephrinsekretion spricht.

Mit Sicherheit dürfte sich aber aus diesen Beobachtungen ergeben, dass das Pepton, intravenös gegeben, beim Hunde, dessen Rückenmark im untersten Halsmark durchgetrennt ist, die Geschwindigkeit der Epinephrinsekretion in mässigem Masse hinauftreibt.

\section{(B) Sensible Reizung.}

Sensible Reizung ruft beim normalen Tiere immer eine Vermehrung der Epinephrinabgabe hervor, ${ }^{12)}$ und zwar beinahe immer bei dem mit der Cava-Tasche versehenen Hunde, falls kein Narkotikum Anwendung findet. ${ }^{14)}$ Der Gebrauch desselben beeinträchtigt mehr oder minder den Effekt der sensiblen Reizung, ${ }^{15}$ und unter tiefer Narkose mag die Vermehrung der Sekretion ausbleiben.

Hinsichtlich der epinephrinaustreibenden Kraft steht die sensible Reizung in der Regel den andern Mitteln wie Peptonvergiftung, Aderlass und dergleichen nach. Die Untersuchung wurde jedoch auf die sensible Reizung ausgedehnt, weil es der Lösung der jetzigen Frage im höchsten Grade erforderlich zu sein scheint, dass dasselben Mittel das von früheren Beobachtern angewendet wurde auch hier zur Anwendung kommt, da dasselbe das Vorhandensein irgend eines Zentralmechanismus für die Epinephrinsekretion im Brustmarke in Abrede stellten. Der Ausgng der Experimente entsprach jedoch eher unserer Vermutung.

14) K od a ma, Tohoku J. of Exp. Med., 1923, 4, 166.

15) Derselbe, ebenda, 1924, 4, 465. 


\section{Tabelle III.}

Einfluss der sensiblen Reizung auf die Epinephrinabgabe bei den Hunden, deren Halsmark vorher unter Äthernarkose durch Transsektion getrennt wurde.

\begin{tabular}{|c|c|c|c|c|c|c|c|c|c|c|}
\hline \multirow{3}{*}{ 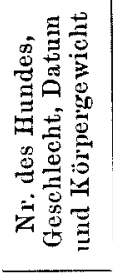 } & \multirow{3}{*}{ 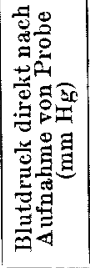 } & \multirow{3}{*}{ 苟 } & \multirow{3}{*}{ 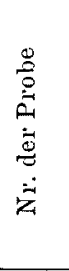 } & \multicolumn{4}{|c|}{$\begin{array}{l}\text { Blutfluss } \\
\text { (ccm) }\end{array}$} & \multicolumn{3}{|c|}{$\begin{array}{l}\text { Epinephrinabgabe } \\
\text { (mg) }\end{array}$} \\
\hline & & & & \multirow{2}{*}{$\begin{array}{l}8 \\
80 \\
9 \\
0\end{array}$} & \multirow{2}{*}{ 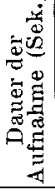 } & \multicolumn{2}{|c|}{$\begin{array}{l}\text { Menge } \\
\text { pro Min. }\end{array}$} & \multirow{2}{*}{$\begin{array}{l}\text { Menge } \\
\quad \text { in } \\
1 \text { com }\end{array}$} & \multicolumn{2}{|c|}{$\begin{array}{l}\text { Abgabe } \\
\text { pro Min. }\end{array}$} \\
\hline & & & & & & $\begin{array}{l}\text { pro } \\
\text { Tier }\end{array}$ & $\begin{array}{l}\text { pro } \\
\text { kg }\end{array}$ & & $\begin{array}{l}\text { pro } \\
\text { Tier }\end{array}$ & $\begin{array}{l}\text { pro } \\
\mathrm{kg}\end{array}$ \\
\hline $\begin{array}{c}\text { Hund 11. } \\
\text { (Exp. 19.) } \\
\hat{\mathrm{s}} \\
6 . \text { VII. } \\
1928 \\
30,08 \mathrm{~kg}\end{array}$ & $\begin{array}{l}42 \\
44\end{array}$ & $\begin{array}{rr}\text { 5. VII. } \\
\text { 6. VII. } \\
\text { a.m. } 9: 00- \\
\text { p.m. } 0: 55- \\
: 58- \\
1: 10- \\
: 13- \\
: 25- \\
: 27- \\
: 47- \\
: 49 \\
: 58- \\
2: 00- \\
: 23-\end{array}$ & $\begin{array}{c}\text { Tra } \\
\text { Lin } \\
\text { I } \\
\text { II } \\
\text { III } \\
\text { IV } \\
\text { V } \\
\text { VI } \\
\text { VII } \\
\text { VIII } \\
\text { IX } \\
\mathbf{X} \\
\text { XI }\end{array}$ & $\begin{array}{l}3,5 \\
2,2 \\
3,2 \\
1,9 \\
2,5 \\
1,2 \\
2,2 \\
2,5 \\
3,2 \\
2,1 \\
2,7\end{array}$ & $\begin{array}{r}120 \\
90 \\
150 \\
120 \\
120 \\
120 \\
120 \\
120 \\
120 \\
90 \\
120\end{array}$ & $\begin{array}{l}\text { d. VII } \\
\text { opera } \\
1,75 \\
1,47 \\
1,28 \\
0,95 \\
1,25 \\
0,6 \\
1,1 \\
1,25 \\
1,6 \\
1,4 \\
1,35\end{array}$ & $\begin{array}{l}\text { Hals } \\
\text { on, D } \\
0,058 \\
0,049 \\
0,042 \\
0,032 \\
\mathbf{0 , 0 4 2} \\
\mathbf{0 , 0 2} \\
0,037 \\
0,042 \\
\mathbf{0 , 0 5 3} \\
\mathbf{0 , 0 4 7} \\
\mathbf{0 , 0 4 5}\end{array}$ & $\begin{array}{l}\text { lle II. } \\
\text { Halsmarl } \\
\text { markes. } \\
\text { auer } 85 \text { I } \\
{\left[\begin{array}{l}0,00005 \\
0,00005 \\
0,00005 \\
0,00005 \\
\mathbf{0 , 0 0 0 1 5} \\
\mathbf{0 , 0 0 0 1} \\
0,0001 \\
0,0001 \\
\mathbf{0 , 0 0 0 1} \\
\mathbf{0 , 0 0 0 1} \\
0,00015\end{array}\right.}\end{array}$ & $\begin{array}{l}\text { gegend. } \\
\text { Iinuten. } \\
0,0000875 \\
0,0000735 \\
0,000064 \\
0,0000475 \\
\mathbf{0 , 0 0 0 1 8 7} \\
\mathbf{0 , 0 0 0 0 6} \\
0,00011 \\
0,000125 \\
\mathbf{0 , 0 0 0 1 6} \\
\mathbf{0 , 0 0 0 1 4} \\
0,000203\end{array}$ & {$\left[\begin{array}{l}0,0000029 \\
0,0000024 \\
0,0000021 \\
0,00000158 \\
\mathbf{0 , 0 0 0 0 0 6 2} \\
\mathbf{0 , 0 0 0 0 0 2} \\
0,0000037 \\
0,0000042 \\
\mathbf{0 , 0 0 0 0 0 5 3} \\
\mathbf{0 , 0 0 0 0 0 4 7} \\
0,0000067\end{array}\right.$} \\
\hline
\end{tabular}

V und VI: Reizung d. N. Saphenus sin. Dauer $4^{\prime} 30^{\prime \prime}$. Rollenabstand $3 \mathrm{~cm}$. Reiz selbst $30^{\prime \prime}$ vor der Probeaufnahme angefangen und $5 /$ frither als sie aufgehört; keine besondere Reaktion bemerkbar, ausgenommen der frequenten Atmung. IX und X: Reizung desselben Nerves, Dauer $4^{\prime}$. Rollenabstand $3 \mathrm{~cm}$, Reiz selbst $30^{\prime \prime}$ früher als Probeaufnahme angefangen und bis zum Ende der Aufnahme fortgesetzt, dabei nur frequente Atmung und Erweiterung der Pupillen bemerkbar. Nachher Peptonversuch.

7. IX. a.m. $9: 00$ \begin{tabular}{l|l} 
30. VIIT. & Sieh Hund 12 auf der Tabelle II. \\
Blosslegung d. VIII. Halsmarkge
\end{tabular}

Blosslegung d. VIrr. Halsmarkgegend.

Transsektion d. VIII. Halsmarkes.

Linke Lumbaloperation, Daner 43 Minuten.

\begin{tabular}{l|l|l|l|l|l|l|l|l|l|l|l|l|l|}
$10: 56-$ & I & 2,9 & 180 & 0,97 & 0,065 & 0,0001 & 0,000097 & 0,0000065
\end{tabular}

\begin{tabular}{ll|l|l|l|l|l|l|l}
$11: 05-$ & II & 2,0 & 120 & 1,0 & 0,067 & 0,0001 & 0,00010
\end{tabular}

\begin{tabular}{l|l|l|l|l|l|l|l|l|l|l|l|l|}
$: 15-$ & III & 2,6 & 120 & 1,3 & 0,088 & 0,0001 & 0,00013 & 0,0000088
\end{tabular}

\begin{tabular}{ll|r|r|r|r|r|r|r|r|}
$119-$ & IV & 2,0 & 90 & 1,33 & 0,090 & 0,00015 & 0,00020 & 0,0000135
\end{tabular}

\begin{tabular}{ll|l|l|l|l|l|l|l|l|l}
$: 26-$ & $\mathrm{V}$ & $\mathbf{2 , 6}$ & $\mathbf{1 2 0}$ & $\mathbf{1 , 3}$ & $\mathbf{0 , 0 8 8}$ & $\mathbf{0 , 0 0 0 1 5}$ & $\mathbf{0 , 0 0 0 1 9 5}$ & $\mathbf{0 , 0 0 0 0 1 3 2}$
\end{tabular}

\begin{tabular}{l|l|l|l|l|l|l|l|l|l|}
$: 29-$ & VI & 2,0 & 120 & 1,0 & 0,067 & 0,0002 & 0,0002 & 0,0000135
\end{tabular}

\begin{tabular}{ll|l|l|l|l|l|l|l|l}
$12: 00-$ VII & 2,1 & 120 & 1,05 & 0,071 & 0,0001 & 0,000105 & 0,000071
\end{tabular}

\begin{tabular}{ll|l|l|l|l|l|l|l|l}
$: 04-$ VIII & 2,6 & 120 & 1,3 & 0,088 & 0,0002 & 0,00026 & 0,0000176
\end{tabular}

\begin{tabular}{ll|l|l|l|l|l|l|l|}
$: 15-$ & IX & 2,0 & 120 & 1,0 & $\mathbf{0 , 0 6 7}$ & $\mathbf{0 , 0 0 0 1 5}$ & $\mathbf{0 , 0 0 0 1 5}$ & $\mathbf{0 , 0 0 0 0 1 0}$
\end{tabular}

\begin{tabular}{lll|l|l|l|l|l|l|l|l|l}
$: 17-$ & $\mathrm{X}$ & 2,6 & 120 & 1,3 & 0,088 & 0,00015 & 0,000195 & 0,0000132
\end{tabular}

\begin{tabular}{lll|l|l|l|l|l|l|l|l}
$1: 00-$ & IX & 2,9 & 180 & 0,97 & 0,065 & 0,0001 & 0,000097 & 0,0000065
\end{tabular}

\begin{tabular}{r|l|l|l|l|l|l|l|l|l}
$1: 00-$ & $1 \mathrm{X}$ & 2,9 & 180 & 0,97 & 0,065 & 0,0001 & 0,000097 & 0,0000090
\end{tabular}

V: Reizung des N. ischiadicus sin. Dauer $2 / 12^{\prime \prime}$. Rollenabstand $3 \mathrm{~cm}$. Reiz selbst $12 /$ früher als Probeaufnahme angefangen, während der Reizung starke Bewegungen. IX : Reizung, Dauer 2/11". Rollenabstand 3 $\mathrm{cm}$. Reiz selbst 11" früher als Probeaufnahme angefangen, Reaktion 


\begin{tabular}{|c|c|c|c|c|c|c|c|c|c|c|}
\hline \multirow{3}{*}{ 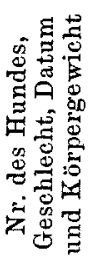 } & \multirow{3}{*}{ 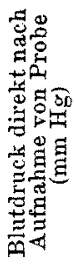 } & \multirow{3}{*}{ 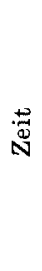 } & \multirow{3}{*}{ 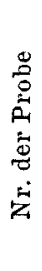 } & \multicolumn{4}{|c|}{$\underset{(\mathrm{ccm})}{\text { Blutfluss }}$} & \multicolumn{3}{|c|}{$\begin{array}{l}\text { Epinephrinabgabe } \\
\text { (mg) }\end{array}$} \\
\hline & & & & \multirow{2}{*}{ 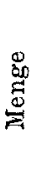 } & \multirow{2}{*}{ 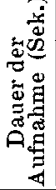 } & \multicolumn{2}{|c|}{$\begin{array}{l}\text { Menge } \\
\text { pro Min. }\end{array}$} & \multirow{2}{*}{$\begin{array}{l}\text { Menge } \\
\text { in } \\
1 \text { cem }\end{array}$} & \multicolumn{2}{|c|}{$\begin{array}{l}\text { Abgabe } \\
\text { pro Min. }\end{array}$} \\
\hline & & & & & & $\begin{array}{l}\text { pro } \\
\text { Tier }\end{array}$ & $\begin{array}{l}\text { pro } \\
\mathrm{kg}\end{array}$ & & $\begin{array}{c}\text { pro } \\
\text { Tier }\end{array}$ & $\begin{array}{c}\text { pro } \\
\mathrm{kg}\end{array}$ \\
\hline
\end{tabular}

Hund 13 (Exp. 21 8 14. IX 1928 $26,3 \mathrm{~kg}$

Hund 19. (Exp.22.) 19. $\mathrm{X}$. 1928 $21,8 \mathrm{~kg}$

auf Reiz deutlich: Aufregung, Zittern des ganzen Körpers, frequente Atmung, heftig Bewegung der vorderen Beine und die von der Fesselung zu befreiende Bestrebung. Nachher Peptoninjektion.

13. IX. $\mid$ Sieh auch Hund 13 anf der Tabelle II.

14. IX. a.m. 9:00Blosslegung d. VIII. Halsmarkgegend.

Transsektion d. VIII. Halsmarkes.

Linke Lumbaloperation, Dauer 50 Minuten.

11:25- $\quad$ I $\mid$\begin{tabular}{l|l|l|l|l|l|l|l} 
& 2,2 & 60 & 2,2 & 0,084 & 0,00005 & 0,00011
\end{tabular}

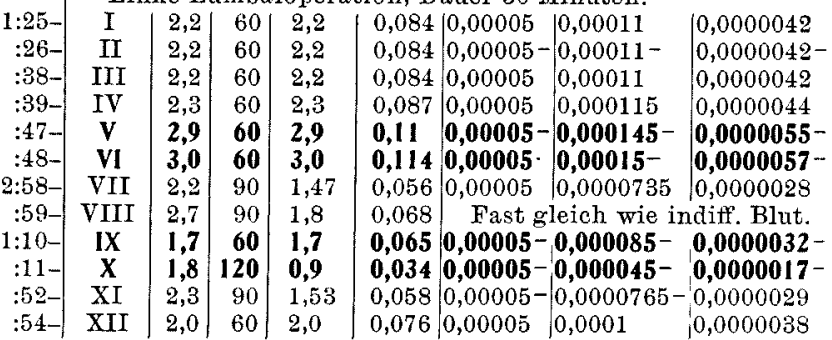

V und VI: Reizung des N. ischiadicus, Dauer $2^{\prime}$, Rollenabstand $3 \mathrm{~cm}$. Reiz selbst $7 /$ früher als die Probeaufnahme angefangen und 12 " vor ilur Ende aufghoben; während der Reizung strebte das Tier von der Fesselung zu befreien, Kopf, Hals und Beine bewegt. IX und X: Reizung, Dauer 2', Rollenabstand $3 \mathrm{~cm}$. Reiz selbst 11 " vor der Probeaufnahme angefangen und wegen der heftigen Bewegung Probeaufnahme bis $74^{\prime \prime}$ nach dem Ende der Reizung aufgestreckt. Reaktion auf Reizung heftig; während der Aufnahme der Proben XI und XII heftige Bewegungen und öfters Schreien. Nachher Peton- und Aderlassversuche ausgeführt.

18. X. Nachmittags unter Äthernarkose (mit geringem Chloroform, ca. $200 \mathrm{ccm}$ ) Blosslegung d. VIII. Halsmarkgegend und einfache Hautnähte.

19. X.

a.m. 9:55- Unter Äthernarkose Transsektion d. VIIr. Halsmarkes. Linke Lumbaloperation, Dauer 30 Minuten.

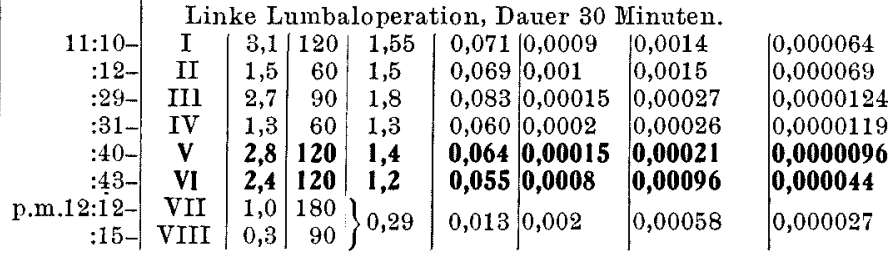

Mässige, alte Blutung an der vorher operierten Stelle. Nach der Transsektiou trat zumal Atemstillstand auf, der durch künstliche Atmung sich verschwund. 20 Minuten vor der sensiblen Reizung kamen verkleinerter, unregelmässiger Puls, Erweiterung der Puille, Fehlen des Kornealreflexes und verschlimmerter Znstand zur Erscheinung, was durch Lage- 


\begin{tabular}{|c|c|c|c|c|c|c|c|c|c|c|}
\hline \multirow{3}{*}{ 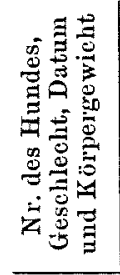 } & \multirow{3}{*}{ 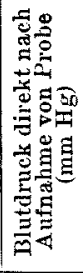 } & \multirow{3}{*}{ 荀 } & \multirow{3}{*}{ 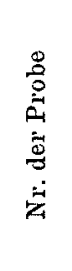 } & \multicolumn{4}{|c|}{$\begin{array}{l}\text { Blutfluss } \\
\text { (ccm) }\end{array}$} & \multicolumn{3}{|c|}{$\begin{array}{c}\text { Epinephximabgabe } \\
\text { (mg) }\end{array}$} \\
\hline & & & & \multirow{2}{*}{ 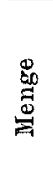 } & \multirow{2}{*}{ 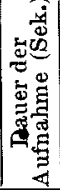 } & \multicolumn{2}{|c|}{$\begin{array}{l}\text { Menge } \\
\text { pro Min. }\end{array}$} & \multirow{2}{*}{$\begin{array}{c}\text { Menge } \\
\text { in } \\
1 \mathrm{ccm}\end{array}$} & \multicolumn{2}{|c|}{$\begin{array}{l}\text { Abgabe } \\
\text { pro Mlin. }\end{array}$} \\
\hline & & & & & & $\begin{array}{l}\text { pro } \\
\text { Tier }\end{array}$ & $\begin{array}{l}\mathrm{pro} \\
\mathrm{kg}\end{array}$ & & $\begin{array}{l}\text { pro } \\
\text { Tier }\end{array}$ & $\begin{array}{r}\text { pro } \\
\mathbf{k g}\end{array}$ \\
\hline $\begin{array}{c}\text { Hund 20. } \\
\text { (Exp. } 23 .) \\
s \\
30 . \mathrm{XI} . \\
1928 \\
18,3 \mathrm{~kg}\end{array}$ & $\begin{array}{l}46 \\
64\end{array}$ & $\begin{array}{r}11: 35- \\
: 37- \\
: 45- \\
: 47- \\
\text { p.m.12:00- } \\
: 02- \\
: 18- \\
: 20- \\
1: 18- \\
: 20- \\
: 30- \\
: 32- \\
: 45- \\
: 47- \\
2: 40- \\
: 42-\end{array}$ & $\begin{array}{c}\text { Un } \\
\text { Hals } \\
\text { mark } \\
\text { LiI } \\
\text { I } \\
\text { II } \\
\text { III } \\
\text { IV } \\
\text { V } \\
\text { VI } \\
\text { VII } \\
\text { VIII } \\
\text { IX } \\
\text { X } \\
\text { XI } \\
\text { XII } \\
\text { XIII } \\
\text { XIV } \\
\text { XV } \\
\text { XVI }\end{array}$ & $\begin{array}{l}\text { er } \\
\text { arks. } \\
\text { s. } \\
\text { se L } \\
2,4 \\
1,4 \\
2,2 \\
1,6 \\
2,5 \\
1,0 \\
2,6 \\
1,4 \\
2,5 \\
1,3 \\
2,5 \\
1,3 \\
2,8 \\
1,7 \\
2,4 \\
1,5\end{array}$ & $\begin{array}{c}\mathrm{mba} \\
90 \\
60 \\
90 \\
60 \\
\mathbf{9 0} \\
\mathbf{6 0} \\
90 \\
60 \\
90 \\
60 \\
90 \\
\mathbf{6 0} \\
90 \\
60 \\
90 \\
60\end{array}$ & $\begin{array}{c}\text { arko } \\
\text { d und } \\
\text { lopern } \\
1,6 \\
1,4 \\
1,47 \\
1,6 \\
1,67 \\
1,0 \\
1,73 \\
1,4 \\
1,67 \\
1,3 \\
1,67 \\
1,3 \\
1,87 \\
1,7 \\
1,6 \\
1,5\end{array}$ & $\begin{array}{c}\text { der } \\
\text { Reiz s } \\
\text { de dur } \\
\text { ngen } \\
\text { der H } \\
\text { (ca. } \\
\text { Tran } \\
\\
\text { ion, D } \\
0,087 \\
0,076 \\
0,080 \\
0,087 \\
\mathbf{0 , 0 9 !} \\
\mathbf{0 , 0 5 5} \\
0,094 \\
0,076 \\
0,091 \\
0,071 \\
\mathbf{0 , 0 9 1} \\
\mathbf{0 , 0 7 1} \\
0,102 \\
0,093 \\
0,087 \\
0,082\end{array}$ & $\begin{array}{l}200 \mathrm{ccm} \\
\text { ssektion } \\
0,00005- \\
0,00005- \\
\mathbf{0 , 0 0 0 0 5}\end{array}$ & $\begin{array}{l}\text { Blossleg } \\
\text { des betref } \\
\text { Iinuten. } \\
0,00008^{-} \\
0,000073^{-} \\
0,000083 \\
0,000086^{-}\end{array}$ & $\left\{\begin{array}{l}0,0000044- \\
0,0000040 \\
\mathbf{0 , 0 0 0 0 0 4 5} \\
0,0000047\end{array}\right.$ \\
\hline
\end{tabular}

Im allgemeinen umruhiges Tier. Vund VI unter der Reizung des N. ischiadicns sin. Dauer $2^{\prime} 30^{\prime \prime}$, Rollenabstand $3 \mathrm{~cm}$. Reiz selbst $35^{\prime \prime}$ vor der Probeaufuahme angefangen, Reaktion auf Reiz heftig; währen der Aufnahme von Probe V. zweimal spastische Muskelkontraktionen, während der VI.Aufnahme ebenso Aufregung und spastische Muskelkontraktion. XI und XII unter der Reizung, Dauer 9/30", Rollenabstand $3 \mathrm{~cm}$. Reiz selbst 94 vor der Probeaufnahne angefangen und 15" vor ihrem Ende aufgehoben. Reaktion auf Reizung, heftig. Nachher Aderlassversuch.

Huad 21 . (Exp. 24.) o

14. XII. 1928

$31,3 \mathrm{~kg}$
13. XII. Nachmittags unter Äthernarkose (mit geringem Chlorofor'm, etwa $130 \mathrm{ccm}$ ) Blosslegung d. VIII. Halsmarkgend und einfache Hautnäte.

14. XII.

a.m.10:00- Unter Äthernarkose (ca. $50 \mathrm{ccm}$ ) Transsektion d. VIII. Halsmarkes.

p.m. 1:20- I $|2,6| 90|1,73| 0,055 \mid$

\begin{tabular}{|c|c|c|c|c|c|c|c|c|c|}
\hline \multirow{3}{*}{50} & p.m. 1:20- & I & 2,6 & 90 & 1,73 & 0,055 & & & \\
\hline & $: 22$ & II & 1,8 & 60 & 1,8 & 0,057 & 0,00005 & 0,00009 & 0,0000029 \\
\hline & :32- & III & 2,3 & 90 & 1,53 & 0,049 & 0,00005 & 0,000076 & 0,0000024 \\
\hline \multirow[t]{2}{*}{48} & $: 34$ & IV & 1,5 & 60 & 1,5 & 0,048 & & & \\
\hline & $: 47-$ & V & 2,0 & 90 & 1,33 & 0,042 & 0,00005 & 0,000066 & 0,0000021 \\
\hline \multirow[t]{2}{*}{50} & $: 49$ & VI & 1,2 & 60 & 1,2 & 0,038 & & & \\
\hline & $2: 07$ & VII & 2,0 & 90 & 1,33 & 0,042 & 0,00005 & 0,000066 & 0,0000021 \\
\hline \multirow[t]{2}{*}{50} & $: 09$ & VIII & 1,3 & 60 & 1,3 & 0,041 & & & \\
\hline & $: 46$ & IX & 1,5 & 90 & 1,0 & 0,032 & & & \\
\hline
\end{tabular}




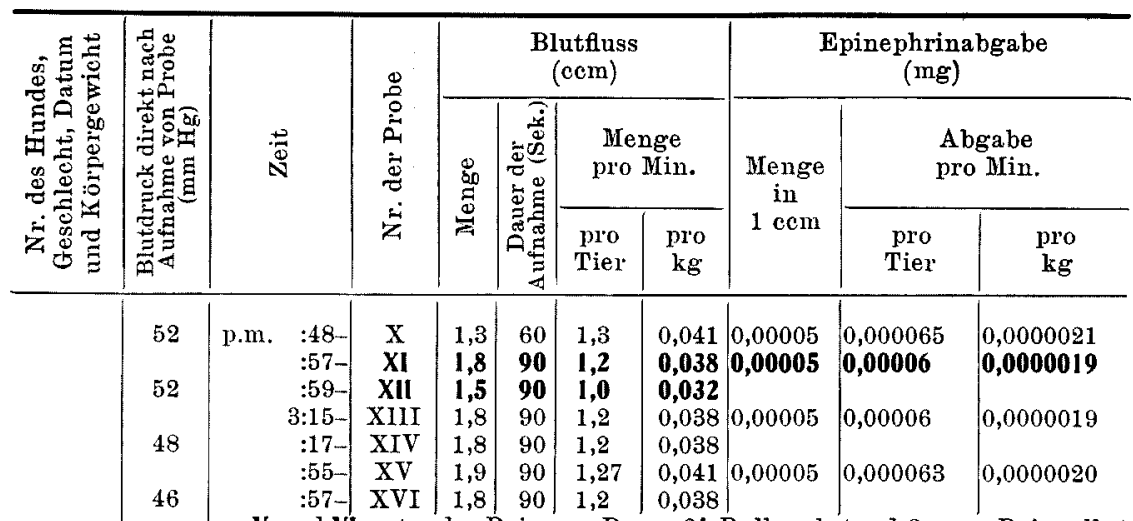

$V$ und VI unter der Reizung, Dauer 2 , Rollenabstand $3 \mathrm{~cm}$. Reiz selbst 12 " vor der Probeaufnahme angefangen und 16" vor ihrem Ende gestillt. Reaktion anf Reizung bedeutend heftig: Schmerzhaftigkeit, frequente Atmung, Zuckungen und Spasmen. XI und XII unter der Reizung, Dauer $3^{\prime}$, Rollenabstand $3 \mathrm{~cm}$. Reiz selbst $9^{\prime \prime}$ vor der Probeaufnahme angefangen und 15" vor ihrem Ende gestillt. Reaktion auf Reizung deutlich.

Nachher Aderlassversuch.

Im Ganzen wurde bei 6 Hunden der N. ischiadicus oder selten der Nr. saphenus mittels rhythmischen Induktionsstromes gereizt; die Reaktionen darauf waren meistens bedeutend: Aufregung, heftige Bewegungen und Zittern am ganzen Körper, frequente Atmung, oft Erweiterung der Pupillen. Der Blutdruck blieb meistens unverändert, zuweilen sank er ein wenig (Hunde Nr. 13 u. 19). Die Körpertemperatur und die Zahl der Herzschläge blieb ebenfalls meistens unverändert. Die Blutaufnahme wurde der Reizung des Nervenstammes gegenüber um einige Sekunden verspätet ausgeführt.

Unter 11 Reizversuchen bei 6 Hunden erwies sich die sensible Reizung nur zweimal sicher wirksam zur Förderung der Epinephrinabgabe; die Vermehrung blieb aber geringfügig. Beim Hunde Nr. 11 vermehrte sich die Sekretionsgeschwindigkeit von $0,000002 \mathrm{mg}$ pro $\mathrm{kg}$ Körpergewicht pro Minute auf $0,000006 \mathrm{mg}$ (Blutprobe V) nach der Reizung des N. saphenus. Es lies sich also eine etwa dreifache Vergrösserung der Epinephrinabgabe durch sensible Reizung erzielen; dabei vermehrten sich sowohl die Epinephrinkonzentration im Blute wie die Ausströmungsgeschwindigkeit. Eine darauffolgende Wiederholung der Reizung war völlig wirkungslos. Die Geschwindigkeit der Epinephrinabgabe, wie sie in Blutprobe IX beim Hunde 11 und in Proben V u. VI beim Hunde 13 zum Ausdruck kam, war etwas grösser als die vorangehende sowie die folgende, aber der Unterschied war nicht gross genug um mit Sicherheit von einem positiven Ausfall der Experimente zu sprechen. Beim Hunde Nr. 19 haben wir noch einmal einen positiven Effekt der sensiblen Reizung auf die Epinephrinabgabe (Blutprobe VI) gefunden. Bei den übrigen Fällen veranlasste die sensible 
Reizung keine Variation in der Sekretionsgeschwindigkeit des Epinephrins. Dies dürfte keineswegs wunderlich sein, da es schon lange bekannt ist, dass ein subnormaler Zustand des Zentralnervensystems infolge von Narkose, etc. den Effekt der sensiblen Reizung auf die Epinephrinabgabe vielfach beeinträchtigt. Kodama vermisste bisweilen eine Beschleunigung der Epinephrinabgabe durch sensible Reizung bei narkotisierten Tieren, und überdies hatten die ClevelandPhysiologen wegen ihrer ungünstigen Versuchsbedingungen kein Glück eine solche zu finden. ${ }^{16)}$ Hätten wir unsere Versuche ebenfalls auf eine nur kleine Zahl beschränkt, so würden wir die Frage sicherlich im Sinne Elliott's und Canno n's für erledigt gehalten haben. Ob Cann on und Rapport eine genügende Zahl Experimente auf den Effekt der sensible Reizung bei dem Tiere mit dem einige Millimeter hinter der Corpora quadrigemina posteriores durchgetrennten verlängerten Mark vorgenommen hatten, lässt sich aus ihres Beschreibung auf S. 340 nicht entnehmen.

Zieht die oben angeführten Arbeiten von Kodama und andern sowie die Wirksamkeit der Strychninvergiftung bei den Tieren denen das unterste Halsmark durchtrennt war zur Erzielung einer Mehrabgabe des Epinephrins, worauf Stewart und Rogoff bereits erschöpfend hinwiesen, ${ }^{11}$ in Betracht, so dürfte wohl einem positiven Ausfall der Experimente eine wesentliche Bedeutung für die Beurteilung der Beziehung der sensiblen Reizung zu der Epinephrinabgabe zukommen, wenngleich der Ausfall der Experimente nicht regelmässig, und sogar der positive Ausgang viel seltener eintrat.

\section{(C) Aderlass.}

Da das Vorhandensein des Zentralmechanismus für die Epinephrinsekretion im Brustmark, welches durch die Peptonvergiftung in Erregung gesetzt wird, einerseits einwandfrei bewiesen ist,-Es sei jedoch vorsichtshalber bemerkt, dass dieser Befund nicht so gedeutet werden soll, dass er die Ko-existenz eines noch höheren Zentrums ausschliesst-und da es anderseits sehr wahrscheinlich ist, dass die epinephrinaustreibende Wirkung des Peptons auf die durch dieses verursachte rasche und riesige Blutdrucksenkung in kausaler Beziehung steht, so liegt es nahe zu vermuten, dass der Zentralmechanismus im Brustmark wieder durch den Aderlass in Tätigkeit gerufen wird.

Dass der Aderlass die Epinephrinsekretion befördern kann steht heute ausser allem Zweifel. ${ }^{17}$ Die epinephrinaustreibende Wir-

16) Sieh: Kodama $(14,15)$, und Sugawara, Wat a nabe u. Saito( 8 ).

17) Saito, Tohoku J. of Exp. Med, 1928, 11, 79; Saito, Kamei u. Tachi, Ebenda, 205; S u zuki, Ebenda, 1929, 12, 406. Ausfïhrliche Literatur dort. 
kung des Aderlasses ist sehr stark, wenn er beim normalen, nichtnarkotisierten Tiere vorgenommen wird, während der Gebrauch eines Narkotikums seine Wirkung bedeutend beeinträchtigt. Der Verlust von einem Zehntel des Blutvolumens ist schon ausreichend um jenes Mal eine Hypersekretion des Epinephrins im normalen Hunde zu beobachten und zwar je grösser der Blutverlust ist, desto stärker ist die Abgabe des Epinephrins. Eine etwa zehn- bis dreissigfache Vergrösserung der Abgabe wird durch den Verlust von einem Drittel bis zwei Fünftel des Blutvolumens hervorgerufen. Das Narkotikum vergrössert den Schwellenreiz und verkleinert die Beschleunigung der Sekretionsgeschwindigkeit, ein Fünftel des Blutvolumens bzw. eine zwei-bis dreifache Vermehrung waren die bei Gebrauch von Äthers gewonnenen Werte nach Saito.

Bei 5 Hunden wurde der Aderlass im Anschluss an sensible Reizung oder Peptoninjektion nach dem Abklingen der dadurch entstandenen klinischen Symptome vorgenommen, und bei 13 andern der Aderlass allein.

Die Entnahme verschiedener Mengen Blut erzeugte im allgemeinen dementsprechende, verschiedenartige klinische Symptome. Durch eine grosse Blutung kam eine rasche und auffallende Blutdrucksenkung zu Tage, und die Tiere waren sehr aufgeregt: Schreien, Beinstrecken, Brüllen, Bellen, etc. traten auf, aber bald nachher wurden sie wieder völlig ruhig, und die Blutdrucksenkung liess allmählich nach falls der Blutverlust nicht zu gross war. Die Atmung beschleunigte sich in der Regel, zuweilen stand sie still; Pupillenerweiterung und das Fehlen des Kornealreflexes traten auch in Erscheinung; der Puls war oft kaum fühlbar. Die Körpertemperatur blieb im Laufe einiger Stunden nach dem Aderlass meistens unverändert, zu weilen stieg oder sank sie.

Das Blutvolumen wurde nach Meek und Gasser ${ }^{18)}$ zu 9,72 Prozent des Körpergewichtes berechnet.

Zunächst sollen die Ergebnisse an 13 Hunden an denen der Aderlass allein vorgenommen wurde, hier dargestellt werden.

In Bezug auf die Sekretionsgeschwindigkeit des Epinephrins nach der Durchtrennung der untersten Halsmarke bietet diese Reihe der Experimente nichts Abweichendes von den übrigen.

Der Aderlass von einem Zehntel des Blutvolumens wurde bei zwei Hunden (Nr. 22 u. 23) durchgeführt, mit einem völlig negativen Ausgang in Bezug auf die Epinephrinabgabe. Beim Hunde 22 sank der Blutdruck sofort bis $45 \mathrm{~mm} \mathrm{Hg}$ herab und beschleunigte die Atmung; sonst waren keine nennenswerten Erscheinungen da. Bei dem anderen Hunde war jedoch der Einfluss der Blutung viel intensiver, trotzdem war bei demselben kein Zeichen einer Hypersekretion des Epinephrins nachweisbar. Die Epinephrinkonzentration liess sich dabei

18) Meek und Gasser, Am. J. of Physiol., 1918, 47, 317. 


\section{Tabelle IV.}

Einfluss vom Aderlass auf die Epinephrinabgabe bei den Hunden, deren Halsmark vorher unter $\ddot{A}$ thernarkose durch

Transsektion getrennt wurde.

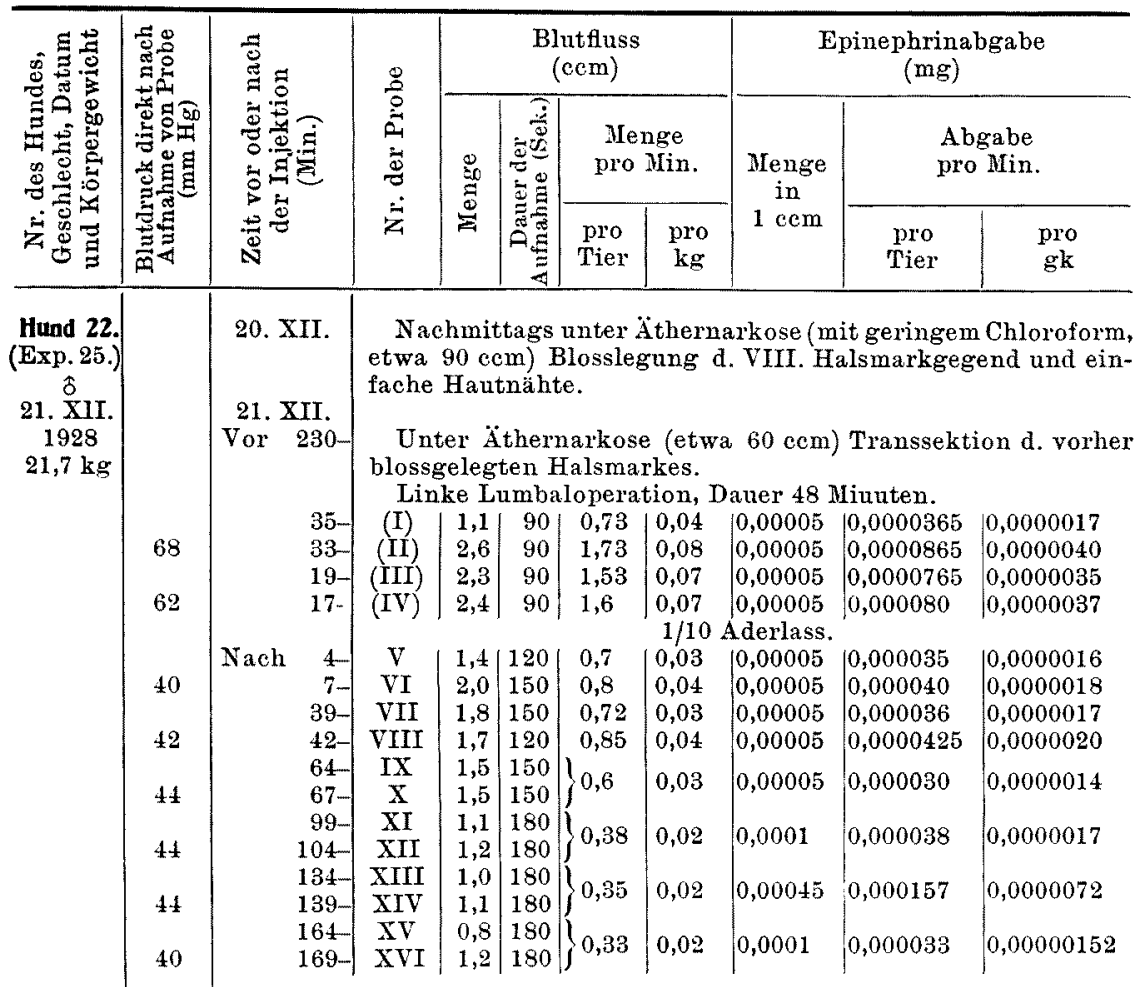

$210 \mathrm{ccm}$ Blutentnahme aus A. femoral. dext. in 137". Nach dem Aderlass sank der Blutdruck bis $45 \mathrm{~mm} \mathrm{Hg}$, beschleunigte die Atmung und bisweilein schrie das Tier, sonst o.B. Endlich Tod durch Luftembolie.

Hund 23. (Exp. 26.) $\hat{\delta}$

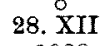
1928 $29,1 \mathrm{~kg}$
Vol 240- Unter Ätheruarkose (mit geringem Chloroform; etwa 140 ccm) Blosslegung d. VIII. Halsmarkgegend und Transsektion.

Linke Lumbaloperation, Daner 70 Minuten.

\begin{tabular}{l|l|l|l|l|l|l|l|l|l|l|l|l|} 
(I) & $\mathbf{3 , 0}$ & $\mathbf{1 8 0}$ & $\mathbf{1}, 0$ & 0,034 & 0,0014 & 0,0014 & 0,000048
\end{tabular}

\begin{tabular}{l|l|l|l|l|l|l|l|l}
$16-$ (II) & 2,4 & 120 & 1,2 & 0,041 & 0,00036 & 0,00043 & 0,000015
\end{tabular}

\begin{tabular}{l|l|l|l|l|l|l|l}
$9-$ (III) & 2,0 & 120 & 1,0 & 0,034 & 0,0016 & 0,0014 & 0,000048
\end{tabular}

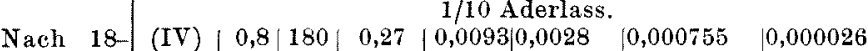

\begin{tabular}{l|c|l|l|l|l|l|l|l}
18 & $(\mathrm{IV})$ & 0,8 & 180 & 0,27 & 0,0093 & 0,0028 & 0,000755 & 0,000026 \\
$\mathbf{3 4}$ & $\mathrm{V}$ & 0,5 & 240 & 0,125 & 0,0043 & 0,0112 & 0,0014 & 0,000048
\end{tabular}

\begin{tabular}{l|l|l|l|l|l|l|l|l}
$74-$ & VI & 1,8 & 180 & 0,6 & 0,0206 & 0,0015 & 0,0009 & 0,000031
\end{tabular}

\begin{tabular}{c|c|c|c|c|c|c|c|c}
$102-$ & VII & 1,1 & 180 & 0,32 & 0,011 & 0,0024 & 0,00077 & 0,000026
\end{tabular}

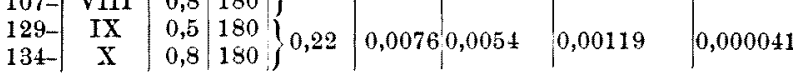




\begin{tabular}{|c|c|c|c|c|c|c|c|c|c|c|}
\hline \multirow{3}{*}{ 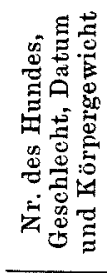 } & \multirow{3}{*}{ 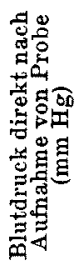 } & \multirow{3}{*}{ 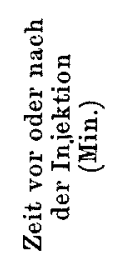 } & \multirow{3}{*}{ 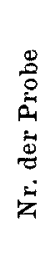 } & \multicolumn{4}{|c|}{$\underset{\text { (ccm) }}{\text { Blutfluss }}$} & \multicolumn{3}{|c|}{$\begin{array}{c}\text { Epinephrinabgabe } \\
(\mathrm{mg})\end{array}$} \\
\hline & & & & \multirow{2}{*}{$\begin{array}{l}0 \\
\stackrel{8}{0} \\
\stackrel{0}{\Xi}\end{array}$} & \multirow{2}{*}{ 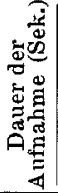 } & \multicolumn{2}{|c|}{$\begin{array}{l}\text { Menge } \\
\text { pro Min. }\end{array}$} & \multirow{2}{*}{$\begin{array}{c}\text { Menge } \\
\text { in } \\
1 \mathrm{cem}\end{array}$} & \multicolumn{2}{|c|}{$\begin{array}{l}\text { Abgabe } \\
\text { pro Min. }\end{array}$} \\
\hline & & & & & & $\begin{array}{c}\text { pro } \\
\text { Tier }\end{array}$ & $\begin{array}{c}\text { pro } \\
\mathrm{kg}\end{array}$ & & $\begin{array}{l}\text { pro } \\
\text { Tier }\end{array}$ & $\begin{array}{c}\text { pro } \\
\mathrm{kg}\end{array}$ \\
\hline & 22 & Nach 159 & $\underset{\text { XII }}{\text { XI }}$ & $\begin{array}{l}0,5 \\
0,7\end{array}$ & $\begin{array}{l}180 \\
180\end{array}$ & 0,2 & 0,006 & 0,006 & 0,0012 & 0,000041 \\
\hline
\end{tabular}

26 Minuten vor d. Aderlass trat Atembeschwerde auf, die durch künstliche Atmung sich versehwund. $280 \mathrm{ccm}$ Blutaufnahme aus A. femoral. dext. in $5^{\prime} 30^{\prime \prime}$, kurz darauf Atemstillstand, der nach vorübergehender künstlicher Atmung sich versehwund, 18 Minuten nach dem Aderlass wieder Atembeschwerde, Farbe der Blutprobe dunkel; kein Kornealreflex, sofort künstliche Atmung. 50 Minuten nach dem Aderlass wieder Atembeschwerde; 74 Minuten nach dem Aderlass wie sterbend; künstliche Atmung fortdauert. Hornhaut getrübt. 120 Minuten nach d. Aderlass blutiger und schleimiger Analausfluss mässiger Menge. 180 Minuten nach

dem Aderlass Tod durch Luftembolie.

Hund 24

(Exp. 27.) 今

18. I.

1929

$18,0 \mathbf{k g}$

Hund 25 .

(Exp. 28.)

3

25. I.

1929

$19,1 \mathrm{~kg}$

Vor 167- Unter Äthernarkose (mit geringem Chloroform; etwa 100 ccm) Blosslegung d. VIII. Halsmarkgegend und Transsektion.

Linke Lumbaloperation, Dauer 40 Minuten.

\begin{tabular}{l|l|l|l|l|l|l|l|}
$47-$ & (I) & 2,5 & 120 & 1,25 & 0,07
\end{tabular}

\begin{tabular}{ll|l|l|l|l|l|l|l}
$43-$ & (II) & 2,3 & 90 & 1,53 & 0,08 & 0,00005 & 0,0000765 & 0,0000042
\end{tabular}

11 \begin{tabular}{l|l|l|l|l} 
(III) & 2,0 & 90 & 1,33 & 0,08
\end{tabular} \begin{tabular}{l|l|l|l|l} 
(IV) & 2,7 & 90 & 1,8 & 0,1
\end{tabular}

\section{0}

34

22

30

30

22

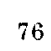

82
V $1,2|120| r_{1 / 6}$ Aderlass.

Nach 7-

\begin{tabular}{l|l|l|l|l|l|l}
1,2 & 120 & 0,55 & 0,03 & 0,00005 & 0,0000275 & 0,0000015 \\
1,0 & 120 & 0,55 & & & & \\
1,1 & 120 & & & & \\
0,9 & 120 & 0,5 & 0,03 & 0,00005 & 0,000025 & 0,0000014 \\
1,2 & 120 & 0,6 & 0,03 & 0,0001 & 0,00006 & 0,0000033 \\
1,4 & 180 & 0,62 & 0,04 & 0,0001 & 0,000062 & 0,0000034 \\
1,7 & 120 & 0,62 & & & & \\
1,6 & 240 & & & & \\
1,8 & 180 & 0,49 & 0,03 & 0,00005 & 0,0000245 & 0,0000014 \\
1,4 & 180 & & & & & \\
0,5 & 150 & 0,35 & 0,02 & 0,00005 & 0,0000175 & 0,0000010
\end{tabular}

$280 \mathrm{com}$ Blutentnahme aus A. femoral. dextra in $4^{\prime 34} /$. Bald danach traten Aufregung, frequente Atmung, herabgesetater Blutdruck (bis 14 $\mathrm{mm} \mathrm{Hg}$ ) und Stöhnen auf. Blutdruck aber rasch wieder auf (bis etwa 30 ). 43 Minuten nach d. Aderlass bedeutend aufregend und stöhnend. 248 Minuten nach d. Aderlass Luftembolietod.

Unter Äthernarkose (etwa $150 \mathrm{ccm}$ ) Blosslegung d. VIII. Halsmarkgegend, und Transsektion.

Linke Lumbaloperation, Dauer 60 Minuten.

\begin{tabular}{ll|l|l|l|l|l|l|l|l} 
Vor & $53-$ & (I) & 2,6 & 60 & 2,6 & 0,1 & 0,00005 & 0,00013 & 0,0000068
\end{tabular}

\begin{tabular}{l|c|c|c|c|c|c|c|c}
$53-$ & (I) & 2,6 & 60 & 2,6 & 0,1 & 0,00005 & 0,00013 & 0,0000068 \\
$50-$ & (II) & 3,4 & 60 & 3,4 & 0,2 & 0,00005 & 0,00017 & 0,0000089
\end{tabular}

\begin{tabular}{l|l|l|l|l|l}
$15-$ (III) & 2,5 & 60 & 2,5 & 0,1 & Fast wie ind. Blut
\end{tabular}

\begin{tabular}{l|l|l|l|l|l} 
12- (IV) & 3,1 & 60 & 3,1 & 0,2 & Fast wie ind. Blut
\end{tabular}

$1 / 3$ Aderlass.

$640 \mathrm{ccm}$ Blut aus A. femoral. dextra in $5^{\prime} 10^{\prime \prime}$. Danach wegen d. Herzschwäche Probeaufnahme unmöglich. 35 Minuten nach d. Aderlass letal. 


\begin{tabular}{|c|c|c|c|c|c|c|c|c|c|c|c|}
\hline \multirow{3}{*}{ 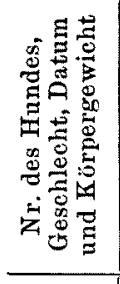 } & \multirow{3}{*}{ 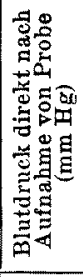 } & \multirow{3}{*}{\multicolumn{2}{|c|}{ 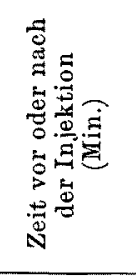 }} & \multirow{3}{*}{ 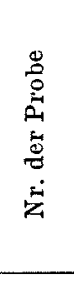 } & \multicolumn{4}{|c|}{$\begin{array}{l}\text { Blutfluss } \\
\text { (ccm) }\end{array}$} & \multicolumn{3}{|c|}{$\begin{array}{c}\text { Epinephrinabgabe } \\
(\mathrm{mg})\end{array}$} \\
\hline & & & & & \multirow{2}{*}{ 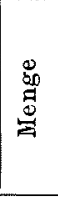 } & \multirow{2}{*}{ 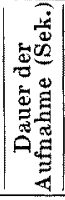 } & \multicolumn{2}{|c|}{$\begin{array}{l}\text { Menge } \\
\text { pro IIin. }\end{array}$} & \multirow{2}{*}{$\begin{array}{c}\text { Menge } \\
\text { in } \\
1 \mathrm{cem}\end{array}$} & \multicolumn{2}{|c|}{$\begin{array}{l}\text { Abgabe } \\
\text { pro Mlin. }\end{array}$} \\
\hline & & & & & & & $\begin{array}{l}\text { pro } \\
\text { Tier }\end{array}$ & $\begin{array}{l}\text { pro } \\
\text { kg }\end{array}$ & & $\begin{array}{c}\text { pro } \\
\text { Tier }\end{array}$ & $\begin{array}{l}\text { pro } \\
\mathrm{kg}\end{array}$ \\
\hline $\begin{array}{c}\text { Hund } 26 . \\
(\text { Exp. 29.) } \\
\delta \\
1 . \text { II. } \\
1929 \\
\mathbf{2 3 , 0} \mathbf{~ k g}\end{array}$ & $\begin{array}{l}48 \\
28\end{array}$ & Nach & $\begin{array}{r}5- \\
9- \\
30- \\
32- \\
60- \\
65- \\
90- \\
122-\end{array}$ & $\begin{array}{c}\text { Un } \\
\text { Halsı } \\
\text { Lin } \\
\text { (I) } \\
\text { (II) } \\
\text { (III) } \\
\text { (IV) } \\
\text { (V) }\end{array}$ & $\begin{array}{l}2,2 \\
1,5 \\
1,8 \\
1,4 \\
1,3 \\
1,4 \\
1,5 \\
1,8\end{array}$ & $\left|\begin{array}{l}180 \\
120 \\
180 \\
120 \\
180 \\
180 \\
180 \\
180\end{array}\right|$ & $\begin{array}{l}0,73 \\
0,75 \\
0,6 \\
0,7 \\
0,45 \\
0,5 \\
0,6\end{array}$ & $\begin{array}{c}\text { (etwi } \\
\text { ansse) } \\
\text { ion, D } \\
0,046 \\
0,087 \\
0,079 \\
0,070 \\
0,090 \\
1 / 5 A \\
0,032 \\
0,033 \\
0,026 \\
0,030\end{array}$ & $\begin{array}{l}100 \text { cen } \\
\text { tion. } \\
\text { auer } 50 \\
0,00005 \\
0,00005 \\
0,00005 \\
0,00005 \\
0,00002 \\
\text { derlass. } \\
0,0002 \\
0,00005 \\
0,0001 \\
0,0001\end{array}$ & $\begin{array}{l}\text { Minuten. } \\
\qquad \begin{array}{l}0,0000525 \\
0,0001 \\
0,00009 \\
0,00008 \\
0,000103\end{array}\end{array}$ & $\mid \begin{array}{l}0,0000063 \\
0,0000016 \\
0,0000026 \\
0,0000030 \\
0,0000029 \\
0,0000065 \\
0,0000078\end{array}$ \\
\hline
\end{tabular}

35 Minuten vor d. Aderlass mässig aufgeregt. 10 Minuten vor d. Aderlass Muskelrigidität, besonders am Lumbalmuskel, bemerkbar. $450 \mathrm{ccm}$ Blutentnahme aus A. femoral. dextra in 5'35"; dabei Aufregung, frequente Atmung und Schnarchen; Blutdruck bis $30 \mathrm{~mm} \mathrm{Hg}$ herab. Direkt nach d. Aderlass Blutprobe dunkel. 30 Minuten nach d. Aderlass mässig aufgeregt, Muskel rigid. 110 Minuten nach d. Aderlass Atmung erschwert, Herzaktion erschöpfend, wie etwa sterbend; also $150 \mathrm{ccm}$ eigenen, defibrinierten Blut transfusiert, mit Verbesserung des allegemeinen Zustandes; aber kein Blut mehr anfnehmbar. 145 Minuten nach d. Aderlass Tod dureh Luftembolie.

Hund 27. (Exp. 30.) $8 . \stackrel{1}{I I}$.
1929
$20,3 \mathrm{k}$
Vor 230- Unter Äther-Chloroformnarkose (ca. $30 \mathrm{ccm}: 10 \mathrm{ccm}$ ) Blosslegung d. VIII. Halsmarkgegend und Transsektion. Linke Lumbaloperation, Dauer 70 Minuten.

\begin{tabular}{|c|c|c|c|c|c|c|c|c|c|c|}
\hline & & $27-$ & (I) & 2,9 & 90 & 1,93 & 0,095 & 0,00006 & {$[0,0000965$} & 0,0000048 \\
\hline 68 & & $25-$ & (IÍ) & 2,7 & 60 & 2,7 & 0,133 & 0,00005 & 0,000135 & 0,0000067 \\
\hline & & $9-$ & (III) & 3,1 & 60 & 3,1 & 0,153 & 0,00005 & 0,000155 & 0,0000076 \\
\hline 68 & & $8-$ & (IV) & 2,5 & 60 & 2,5 & $\begin{array}{r}0,123 \\
1 / 5 \mathrm{~A}\end{array}$ & $0,0000 \tilde{}$ & $\{0,000125$ & 0,0000062 \\
\hline & Nach & $15-$ & V & 1,8 & 120 & $\begin{array}{l}0,9 \\
0.85\end{array}$ & $\begin{array}{l}0,044 \\
0,048\end{array}$ & 0,00005 & 0,000045 & {$[0,0000022$} \\
\hline & & $30-$ & VII & $\begin{array}{l}1,7 \\
1,4\end{array}$ & $\begin{array}{l}120 \\
180\end{array}$ & 0,89 & 0,042 & & & \\
\hline 25 & & $35-$ & VIII & 1,0 & 180 & 0,4 & 0,020 & 0,00005 & 0,00002 & 0,0000010 \\
\hline & & $60-$ & IX & 1,2 & 180 & 0,37 & 0,018 & 0,0001 & 0,000037 & 0,0000018 \\
\hline & & $65-$ & $\mathbf{X}$ & 1,0 & 180 & & & & & \\
\hline & & & $\begin{array}{l}X 1 \\
\text { XIT }\end{array}$ & $\begin{array}{l}1,7 \\
1,7\end{array}$ & $\begin{array}{l}180 \\
180\end{array}$ & 0,57 & 0,028 & $0,00005^{-}$ & $0,0000285^{-}$ & 0,0000014 \\
\hline & & 120 & XIII & 1,6 & 180 & 0,53 & 0,026 & 0,00005 & 0,0000265 & 0,0000013 \\
\hline & & & XIV & 2,1 & 240 & 0,52 & 0,026 & 0,00005 & 0,000026 & 0,0000013 \\
\hline & & & & 1,9 & 240 & 0,48 & 0,024 & 0,00005 & 0,000024 & 0,0000012 \\
\hline
\end{tabular}

$400 \mathrm{cem}$ Blnt ans A. femoral. dextra in $4^{\prime \prime}$; Blutdrack dabei bis $24 \mathrm{~mm}$ Hg herab, Atmung etwas frequent; sonst keine nennenswertige Veränderungen. Blutprobe nach dem Aderlass dunkel n. leicht coagulierbar. Tiel selbst während d. Versuches ganz ruhig. 250 Minuten nach dem Aderlass Tod durch Luftembolie. 


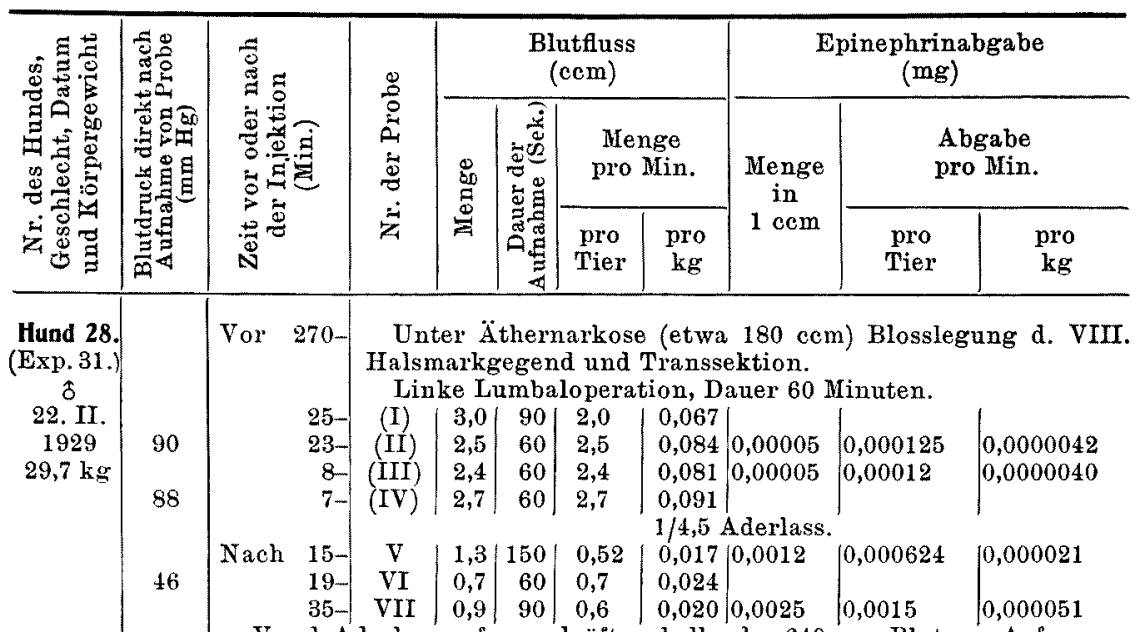

Vor d. Aderlass aufregend, öfters bellend. $640 \mathrm{ccm}$ Blut aus A. femoralis dextra in $9^{\prime} 33^{\prime \prime}$. Symptome am deutlichsten : Stöhnend, aufregend und Beine streckend, Blutdruck rasch bis $5 \mathrm{~mm} \mathrm{Hg}$ herab. Plötzlich Atemstillstand, aber sofort begann wieder spontan zu atmen. A temzahl vermehrt, Puls öfter's aussetzend, Kornealreflex fehlend, Pupillen mittelmässig erweitert. 15 Minuten nach dem Aderlass ruhig, Blutprobe dunkel. 30 Minuten nach dem Aderlass Zittern des Oberkörpers, Pupillenerweiterung, unregelmässiger Puls u. flache Atmung. 45 Minuten nach d. Aderlass letal.

Hund 29.

(Exp. 32.)

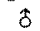

1. III. 1929 $31,0 \mathrm{~kg}$

Hund 30. (Exp. 33.) 古 9. III. 1929 $40,0 \mathrm{~kg}$
Vor 275- Unter Äthernarkose (etwa $150 \mathrm{ccm}$ ) Blosslegung d. VIII. Halsmarkgegend u. Transsektion.

Linke Lumbaloperation, Dauer 55 Minuten.

\begin{tabular}{l|c|l|l|l|l|l|}
$28-$ & (I) & 1,7 & 60 & 1,7 & 0,055 & \\
$26-$ & (II) & 3,7 & 90 & 2,47 & 0,080 & 0,00005 \\
$12-$ & (III) & 1,9 & 60 & 1,9 & 0,061 &
\end{tabular}

\begin{tabular}{ll|l|l|l|l|l|l}
$11-($ IV) & 1,8 & 60 & 1,8 & 0,058 & 0,00005 & 0,00009
\end{tabular}
$1 / 4,5$ Aderlass.

\begin{tabular}{r|c|l|l|l|l|l|l|l}
$16-$ & V & 1,6 & 180 & 0,53 & 0,017 & 0,0001 & 0,000053 & 0,0000017 \\
$24-$ & VI & 0,7 & 120 & 0,35 & 0,011 & 0,0001 & 0,000035 & 0,0000011 \\
$36-$ & VII & 1,1 & 180 & 0,37 & 0,012 & 0,0002 & 0,000074 & 0,0000024 \\
$51-$ & VIII & 1,2 & 180 & 0,4 & 0,013 & 0,00015 & 0,00006 & 0,0000019 \\
$66-$ & IX & 0,5 & 240 & 0,125 & 0,004 & 0,0015 & 0,000187 & 0,0000060 \\
$106-$ & X & 1,0 & 120 & 0,5 & 0,016 & 0,0012 & 0,0006 & 0,000019 \\
$121-$ & XI & 0,3 & 180 & 0,1 & 0,003 & 0,0018 & 0,00018 & 0,0000058
\end{tabular}

Unruhiges Tier. $670 \mathrm{cem}$ Blut von A. femoralis dextra in $13 / 10^{\prime \prime}$. Symptome direkt nach dem Aderlass nicht dentlich; nur starke Aufregung, etwa frequente Atmung $u$. allmählich absteigender Blutdruck. Blutprobe dunkel, leicht gerinnbar. 43 Minuten nach d. Aderlass Blutdruck einmal bis 0 herab, aber durch künstliche Atmung stieg er wieder auf. 64 Minuten nach $d$. Aderlass Blutdruck wieder bis 0 herab, Fehlen d. Kornealreflexe und Atemstillstand, was alles durch künstliche Atmung besserte. 90 Miuuten nach d. Aderlass Herzstillstand, daraus wieder durch künstliche Atmung gerettet, aber Kornealreflexe erschloschen, Pupillen erweitert, Hornhaut getrübt. 130 Minuten nach d. Aderlass letal.

Vor 250- Unter Äthernarkose (etwa $300 \mathrm{ccm}$ ) Blosslegung d. VIII. Halsmarkgegend und Transsektion.

Linke Lumbaloperation, Dauer 85 Minuten.

\begin{tabular}{lc|l|l|l|l|l|l|l|}
$18-$ & (I) & 2,6 & 40 & 3,9 & 0,1 & 0,0003 & 0,00117 & 0,000029 \\
$17-$ & (II) & 2,2 & 35 & 3,8 & 0,09 & 0,00025 & 0,00095 & 0,000024
\end{tabular}

\begin{tabular}{c|c|c|c|c|c|c|c|c}
$7-$ (III) & 2,9 & 60 & 2,9 & 0,07 & 0,00005 & 0,000145 & 0,0000036
\end{tabular} 


\begin{tabular}{|c|c|c|c|c|c|c|c|c|c|c|c|}
\hline \multirow{3}{*}{ 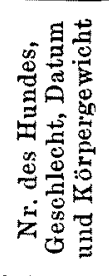 } & \multirow{3}{*}{ 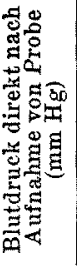 } & \multirow{3}{*}{\multicolumn{2}{|c|}{ 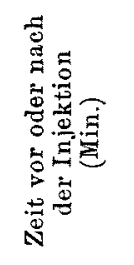 }} & \multirow{3}{*}{$\begin{array}{l}\stackrel{0}{0} \\
0 \\
0 \\
0 \\
\dot{0} \\
\dot{8} \\
\dot{z} \\
\dot{z}\end{array}$} & \multicolumn{4}{|c|}{$\begin{array}{l}\text { Blutfluss } \\
(\mathrm{ccm})\end{array}$} & \multicolumn{3}{|c|}{$\begin{array}{l}\text { Epinephrinabgabe } \\
\text { (mg) }\end{array}$} \\
\hline & & & & & \multirow{2}{*}{ 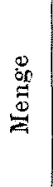 } & \multirow{2}{*}{ 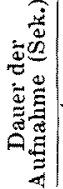 } & \multicolumn{2}{|c|}{$\begin{array}{l}\text { Menge } \\
\text { pro Min. }\end{array}$} & \multirow{2}{*}{$\begin{array}{l}\text { Menge } \\
\text { in } \\
1 \mathrm{cem}\end{array}$} & \multicolumn{2}{|c|}{$\begin{array}{l}\text { Abgabe } \\
\text { pro Min. }\end{array}$} \\
\hline & & & & & & & $\begin{array}{l}\text { pro } \\
\text { Tier }\end{array}$ & $\begin{array}{c}\text { pro } \\
\mathrm{kg}\end{array}$ & & $\begin{array}{l}\text { pro } \\
\text { Tier }\end{array}$ & $\begin{array}{l}\text { pro } \\
\mathrm{kg}\end{array}$ \\
\hline & 68 & Vor & & (IV) & 1,4 & 30 & 2,8 & $\begin{array}{l}0,07 \\
1 / 4,5\end{array}$ & $\begin{array}{l}0,00005 \\
\text { Aderlass. }\end{array}$ & 0,00014 & 0,0000035 \\
\hline & 34 & Nach & $20-$ & $\mathrm{V}$ & 1,4 & 150 & 0,56 & 0,01 & {$[0,0002$} & 0,000112 & 10,0000028 \\
\hline & 32 & & 28 & VI & 1,1 & 210 & 0,31 & 0,008 & 0,0004 & 0,000124 & 0,0000031 \\
\hline & 24 & & 48 & VII & 1,0 & 210 & 0,29 & 0,007 & 0,0006 & 0,000174 & 0,0000045 \\
\hline & 16 & & $63-$ & VIII & 0,6 & 90 & 0,4 & 0,01 & 0,0018 & 0,00072 & 0,000018 \\
\hline
\end{tabular}

Unruhiges Tier. $860 \mathrm{ccm}$ Blut aus A, femoral. dextra in 14.40". Symptome nicht deutlich; nur frequente Atmung, herabgesetzter Blutdruck (bis etwa $30 \mathrm{~mm} \mathrm{Hg}$ ), aber Kornealreflexe u. Pupillenreaktion erhalten. $20 \mathrm{Mi}$ nuten nach d. Aderlass Blut leicht gerinnbar, dunkel und Muskeln stark gespannt. 63 Minuten nach d. Aderlass Herzaktion sehwach, zumal Stillstand, was durch künstliche Atmung sich verschwund. Ab und $z u$ bedeutend starke Muskelkontraktionen. 78 Minuten nach dem Aderlass letal.

Hund $\mathbf{3 1}$. (Exp. 34.) $\hat{\delta}$

22. III 1929

$21,2 \mathrm{~kg}$

Hund 32 . (Exp. 35.) fo
5. IV.
1929
$24,8 \mathrm{~kg}$
Vor 280- Unter Äthernarkose (etwa $150 \mathrm{~cm}$ ) Blosslegung d. VII. Halsmarkgegend und Transsektion.

Linke Lumbaloperation, Dauer 35 Minuten.

\begin{tabular}{l|l|l|l|l|l|l|l|}
$31-(I)$ & 1,7 & 90 & $\mathbf{1}, 13$ & 0,05 & $0,00005-0,0000565-0,0000027-$
\end{tabular}

28- (II) $1,8 \quad 90 \quad 1,2$

15- (III) 2,2 120 $\quad 1,1$

\begin{tabular}{l|l|l|l|l}
$12-$ & (IV) & 2,8 & 120 & 1,4
\end{tabular}

\section{0,06}

$0,0520,00005-0,000055-0,0000026-$ 0,066

1/4,5 Aderlass.

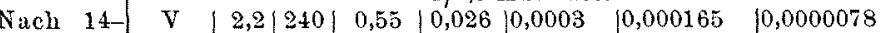

\begin{tabular}{l|l|l|l|l|l|l|l|l|l|l}
$28-$ & VI & 1,1 & 240 & 0,275 & 0,013 & 0,0008 & 0,00022 & 0,0000104
\end{tabular}

\begin{tabular}{l|l|l|l|l|l|l|l|l|l}
$50-$ & VII & 0,9 & 300 & 0,18 & 0,008 & 0,0018 & 0,000324 & 0,0000153
\end{tabular}

$73-$ VIII

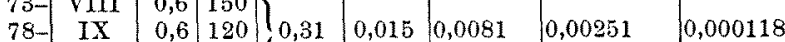

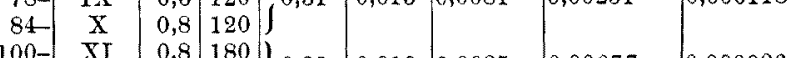

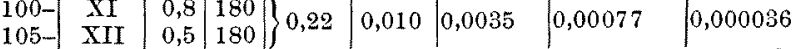

Ruhiges Tier. $460 \mathrm{ccm}$ Blut aus A. femoral. dextra in 11'35", dabei keine besondere Symptome, ausgenommen der Pupillenerweiterung und der Blutdrucksenkung. 27 Minuten nach d. Aderlass Blut dunkel. 42 Minuten nach d. Aderlass Herzaktion schwach und zumal Atemstillstand, daraus das Tier aber durch künstliche Atmung und Befreien von $d$. Gesichtsfesselung sich erholte. 59 Minuten nach d. Aderlass wieder Atemstillstand, also wieder künstliche Atmung. 63 Minuten nach d. Aderlass Atemstillstand u. Erweiterung d. Pupillen. 127 Minuten nach d. Aderlass letal.

Vor 270- Unter Äthernarkose $(150 \mathrm{ccm})$ Blosslegung d. VIII. Halsmarkgegend und Transsektion.

Linke Lumbaloperation, Daner 60 Minuten.

\begin{tabular}{l|l|l|l|l|l|l|l|l|l|}
$23-$ & 0,064 & 0,00005 & 0,00008
\end{tabular}

$\begin{array}{lll}0,00005 & 0,00008 & 0,0000032\end{array}$

\begin{tabular}{l|l|l|l|l|l|l|l|l}
$16-$ (III) & 2,2 & 90 & 1,47 & 0,059 & 0,00005 & 0,0000735 & 0,0000030
\end{tabular}

\begin{tabular}{l|l|l|l|l|l|}
14 & $(\mathrm{IV})$ & 1,7 & 60 & 1,7 & 0,069
\end{tabular}

25

$1 / 4$ Aderlass

20

20
$20-$
$30-$
$42-$ 42- VII \begin{tabular}{l|l|l|l|l|l}
1,2 & 150 & 0,48 & 0,019 & 0,0001
\end{tabular}

\begin{tabular}{l|l|l|l|l|l|}
1,3 & 120 & 0,65 & 0,026 & 0,0003 \\
1,1 & 120 & 0,55 & 0,022 & 0,0004
\end{tabular}

0,000048

.0,0000019

$0,000195 \quad 0,0000079$

0,00022
0,0000079
0,0000089 


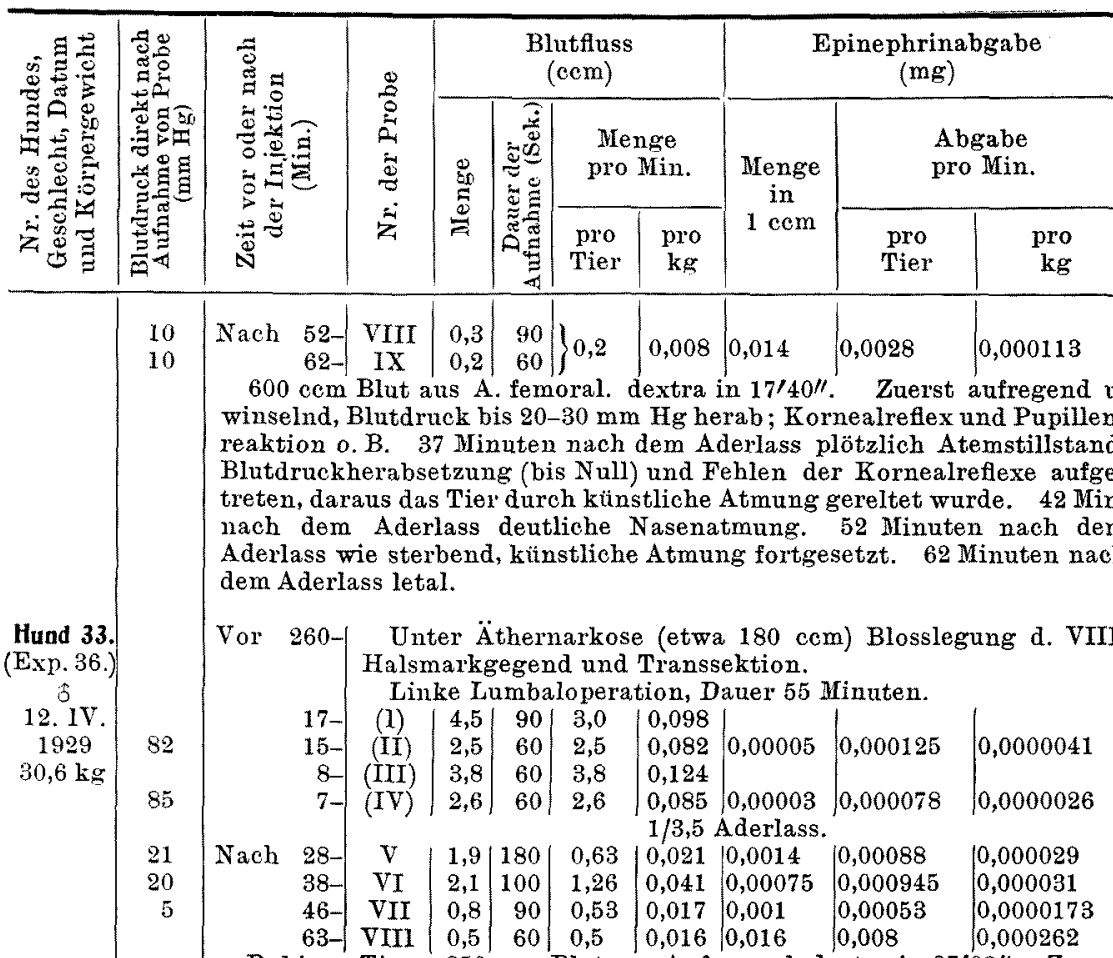

Ruhiges Tier. $850 \mathrm{ccm}$ Blut aus A. femoral. dextra in 27/03". Zuerst Aufregung und allmählich herabsetzender Blutdruck aufgetreten, dann wieder ruhig aber Atmung frequent. 38 Minuten nach dem Aderlass unregelmässiger Puls and Atemstillstand, was durch künstliche Atmung sich versuchwund. $46 \mathrm{Min}$. nach dem Aderlass wieder künstliche Atmung. 64 Min. nach dem Aderlass wie sterbend. 69 Min. nach dem Aderlass wirklich letal.

Hund 34 (Exp. 37.) 3<smiles>[As]=[W]</smiles>
1929 $25,1 \mathrm{~kg}$
Vor 265- Unter Äthernarkose (etwa $180 \mathrm{ccm}$ ) Blosslegung d. VIII. Halsmarkgegend und Transsektion.

Linke Lumbaloperation, Dauer 35 Minuten.

$22-$ (I) $|3,7| 120|1,85| 0,074$

\begin{tabular}{c|c|c|c|c|c|}
$20-$ & (II) & 2,0 & 60 & 2,0 & 0,080
\end{tabular}

\begin{tabular}{l|l|l|l|l|l|}
$6-$ & (III) & 2,7 & 90 & 1,8 & 0,072
\end{tabular}

\begin{tabular}{l|l|l|l|l}
0,072 & 0,0001
\end{tabular}

\begin{tabular}{r|r|r|r|r|r} 
IV) & 1,8 & 60 & 1,8 & 0,072 & 0,00005 \\
& & \\
$1 / 3$ Aderlass.
\end{tabular}

wahrend d. Aderlasses

$\mathrm{Nach}$ 19-

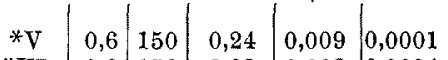

\begin{tabular}{l|l|l|l|l|l|l|l|l|l}
$* \mathrm{VI}$ & 0,2 & 150 & 0,08 & 0,003 & 0,0024 & 0,000024 & 0,0000096
\end{tabular}

\begin{tabular}{l|l|l|l|l|l|l|l} 
VII & 0,2 & 60 & 0,2 & 0,008 & 0,0064 & 0,00128 & 0,000051
\end{tabular}

* Probe V wurde während d. Aderlasses, 27 Minuten von Anfang desselben, aufgenommen, als er etwa dém 1/5 Aderlass entsprach. Probe VI wurde also während des Aderlasses, 39 Minuten vom Anfang desselben, anfgenommen, als er etwa dem 1/3,5 Aderlass entsprach.

Unruhiges Tier. $810 \mathrm{ccm}$ Blut aus A. femoralis dextra in 45', Anfangs Aufregung, 6 Minuten darnach unregelmässiger Puls, allmähliche Blutdrucksenkung (bis etwa $20 \mathrm{~mm} \mathrm{Hg}$ ), aber im ganzen ruhig. $40 \mathrm{Min}$, nach 


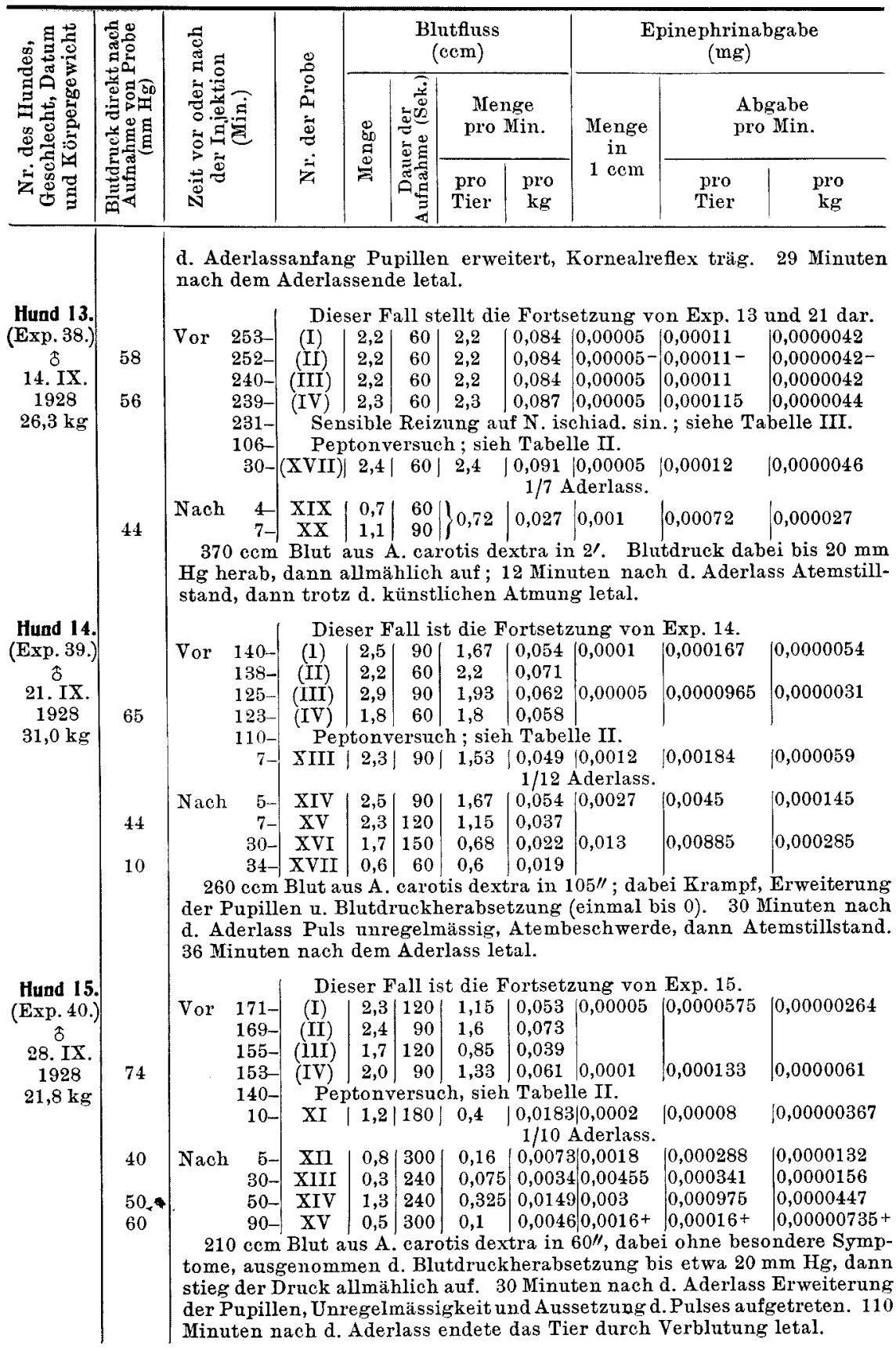




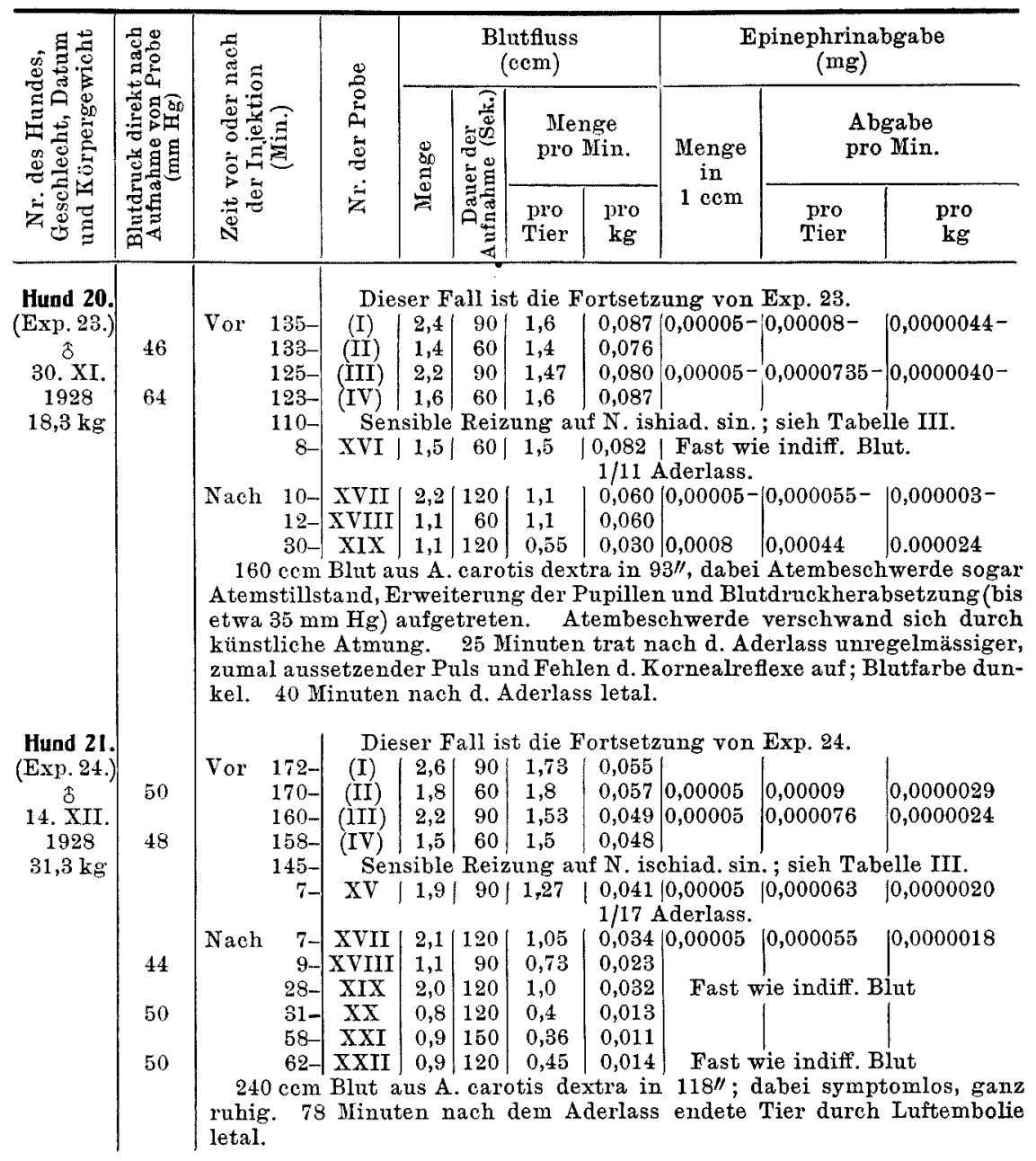

nach dem Aderlass als vermehrt nachweisen, aber die Ausströmungsgeschwindigkeit auch liess nach, sodass die Vermehrung der Konzentration völlig verdeckt wurde. Nur 130-140 Minuten nach dem Aderlass wurde eine kleine Vermehrung der Sekretionsgeschwindigkeit beim Hunde 22 bestimmt.

Der Verlust von einem Sechstel des ganzen Blutes rief etwas intensivere Symptome hervor, jedoch unterlag die Sekretionsgeschwindigkeit des Epinephrins keiner definitiven Veränderung (Hund Nr. 24).

Bei Hunden Nr. 26 u. 27 wurde der Blutverlust auf ein Fünftel des totalen Volumens gesteigert. Bei dem einen waren klinische 
Symptome etwas bedeutender und etwa eine hundert Minuten nach dem Aderlass war das Tier hochgradig mitgenommen, während das andere Tier die Verblutung mit nur geringfügigen Symptomen gut ertrug. Bei beiden Hunden lies sich keinerlei Steigerung der Sekretionsgeschwindigkeit nachweisen, bei dem zweiten trat sogar eine mässige Verminderung auf, was in der Verminderung der Ausströmungsgeschwindigkeit trotz des Konstantbleibens des Epinephrinkonzentration im Blut seinen Grund hat. Eine ähnliche Erscheinung, d.h. eine unverkennbare Verminderung der Sekretionsgeschwindigkeit zeigte sich auch bei Hunden Nr. 22 und 24 nach der Entblutung von einem Zehntel, bzw. einem Sechstel des gesamten Blutvolumens.

Die Entnahme von zwei Neuntel des gesamten Blutes wurde nunmehr an vier Hunden ausprobiert und zwar wurde eine mässige Hypersekretion des Epinephrins bei zwei von ihnen mit Sicherheit wahrgenommen. Beim Hunde Nr. 28 stieg die Sekretionsgeschwindigkeit von $0,000004 \mathrm{mg}$ pro $\mathrm{kg}$ pro Minute bis auf $0,00002 \mathrm{mg} 15$ Minuten und auf $0,00005 \mathrm{mg} 35$ Minuten nach dem Aderlass, also eine etwa zwölffache Vergrösserung derselben trat auf, was durch die Vermehrung der Epinephrinkonzentration im Blut verursacht wurde. Die Durchströmungsgeschwindigkeit verminderte sich im allgemeinen etwas. Die klinische Symptome waren bedeutend, und 45 Minuten nach dem Aderlass trat eventuell der Tod des Tieres ein. Beim Hunde Nr. 29 waren die klinischen Symptome direkt nach dem Aderlass nichtso stark, jedoch mit der Zeit sank der Blutdruck allmählich herab, um schliesslich den Wert 0 zu erreichen wobei Atemstillstand eintrat, aus dem das Tier durch künstliche Atmung gerettet wurde. Etwa eine Stunde nach dem Aderlass war der Blutdruck wieder stark erniedrigt; dabei wurde die Sekretionsgeschwindigkeit des Epinephrins als vermehrt gefunden ; sie stieg noch weiter, und eine Stunde später war die $\mathrm{Hy}$ persekretion fortdauernd vorhanden. Die Akme betrug etwa das sechsfache des ursprünglichen Wertes. Eine ausgiebige Hypersekretion des Epinephrins kam beim Hunde Nr. 31 nach dem Aderlass zur Geltung, deren Akme etwa eine Stunde danach erreicht wurde, und $0,0001 \mathrm{mg}$ pro $\mathrm{kg}$ pro Minute, d. h. über 30 Fache des ursprünglichen Wertes betrug. Aufregung war bei diesem Hunde in keiner Weise ausgeprägt, aber die Zirkulations- und Atmungsstörungen schritten mehr und mehr fort, und waren sehr erheblich als die Epinephrinsekretion ihren Gipfel erreichte. Die Ergebnisse mit dem Hunde Nr. 30 gingen mit denen der übrigen parallel, wenn eine nicht unerhebliche Sekretionsgeschwindigkeit direkt nach der Halsmarkdurchtrennung und zwar 17-18 Minute vor dem Aderlass ausser Betracht gelassen wird. Der Aderlass von zwei Neuntel erwies sich jedes Mal letal für die operierten Hunde, die Halsmarkdurchtrennung niedrigt 
nämlich den Widerstand des Hundes gegen die Verblutung beträchtlich.

Hund Nr. 32 konnte nach der Halsmarkdurchtrennung die Blutung von einem Viertel der Gesamtblutmenge etwa eine Stunde überleben. Aufregung folgte unmittelbar auf den Aderlass, und etwa eine halbe Stunde später traten Atmungs- und Zirkulationsstörungen in markanter Weise hervor, dabei begann die Sekretionsgeschwindigkeit des Epinephrins höher zu gehen, und beide, die Störungen und die Geschwindigkeit, schritten weiter fort bis der Tod erfolgte. Die letztere betrug $0,00011 \mathrm{mg}$ pro $\mathrm{kg}$ Körpergewicht pro Minute, der Aderlass versursachte also eine etwa vierzigfache Vergrösserung der Epinephrinsekretion.

Eine noch grössere Blutung wurde beim Hunde Nr. 33 vorgenommen, welcher sie gut vertrug und welche eine noch ausgiebige Beschleunigung in der Sekretionsgeschwindigkeit des Epinephrins lieferte. Der Aderlass wurde unmittelbar von Aufregung begleitet, das Tier verhielt sich sonst völlig ruhig, nur standen hochgradige Zirkulations- und Atmungsstörungen als klinische Erscheinungen im Vordergrunde. Etwa eine halbe Stunde nach dem Aderlass betrug die Sekretionsgeschwindigkeit etwa das Zehnfache des ursprünglichen Wertes, und eine halbe Stunde später, als das Tier dem Tode nahe war, wurde eine etwa hundertfache Geschwindigkeit der Epinephrinsekretion beobachtet.

Ein Drittel des gesamten Blutes wurde bei zwei Hunden (Nr. 25 u. 34) entnommen; der eine (Nr. 25) starb 35 Minuten darnach, und es war in dieser Zeit wegen Zirkulationsmangel unmöglich Blutproben aufzunehmen. Beim andern Hunde wurden zwei Blutproben während der Verblutung aufgenommen, und zwar die zweite als etwa zwei Siebentel des gesamten Blutes abgegeben wurden. Anfangs war das Tier aufgeregt, und dann kam die Zirkulationsstörung zur Wirkung. Während des Aderlasses, welcher etwa 45 Minuten in Anspruch nahm, war das Tier wieder ruhig, es war kraftlos geworden und dabei wurde die Sekretionsgeschwindigkeit als einigermassen beschleunigt gefunden. Etwa 22 Minuten nach der Beendigung des Aderlasses war eine etwa fünfzehnfache Vergrösserung der Sekretionsgeschwindigkeit bemerkbar, dabei war das Tier dem Tode schon sehr nahe.

Einige Hunde, an denen Peptoninjektion, sensible Reizung oder beide bereits ausgeführt worden war, wurden schliesslich zum Aderlassversuche benutzt. Sie erwiesen sich der Manipulation gegenüber etwas empfindlicher als sonst, d. h. bei 4 Hunden war Verblutung von einem Siebentel (Nr. 13), einem Zwölftel (Nr. 14), einem Zehntel (Nr. 15) oder einem Elftel (Nr. 20) wirksam, um eine Hypersekretion des 
Epinephrins hervorzurufen, während eine noch kleinere Blutung wie die von einem Siebzehntel gar keine Veränderung in der Sekrektionsgeschwindigkeit sowie im Verhalten des Tieres bewirkte (Nr. 21). Der Schwellenreiz war also bei ihnen bedeutend ermiedrigt, auch die Latenzzeit war viel kürzer.

Dass die vier Hunde in Bezug auf die Reizschwelle, sowie die Latenzzeit der Aderlasshy perepinephrinämie die anderen, welche nur zum Aderlassversuche verwandet wurden, wesentlich übertrafen, dürfte dadurch eine Erklärung finden, dass der Aderlass bei den ersteren viel später nach dem Aufhören der Narkose ausgeführt wurde. Bei den ersten drei Hunden wurde sogar die untere Halsmarkgegend einen Tag vorher blossgelegt, und am betreffenden Tag wurde lediglich die Transsektion des Halsmarkes unter Narkose in einer kurzen Zeitspanne getan. Was für einen Einfluss die vorangehende Erregung des Zentralmechanismus der Epinephrinsekretion durch Pepton oder sensible Reizung auf die nachher durch Aderlass hervorgerufene hat spielt, soll vorderhand völlig dahingestellt bleiben.

Bei einer zusammenfassenden Betrachtung der beiden oben gegebenen Versuchsreihen ist $\mathrm{zu}$ sagen, dass kein merklicher Unterschied in Bezug auf die Reizschwelle besteht, d. h. den minimalen wirksamen Blutverlust zur Erziehung einer Förderung der Epinephrinsekretion zwischen den Brustmarkshunden, besonders den zuletzt zitierten, und den Hunden mit dem intakten Zentralnervensystems von Saito. ${ }^{17}$ Die Reizschwelle war etwas grösser bei den vorliegenden Experimenten, wo der Aderlass allein ausgeführt wurde. Wenn man das Verhältniss des höchsten Wertes der Sekretionsgeschwindigkeit nach dem Aderlass von zwei Neuntel bis zwei Siebentel der gesamten Blutmenge in den vorliegenden Experimenten und von einem Fünftel bis einem Drittel in denen von Saito zum präformierten Werte vergleicht, so übertreffen die obigen bei weitem die letzteren, woil der ursprüngliche Wert bei dem Hunde dessen unterstes Halsmark durchgetrennt war viel kleiner ist als beim normalen, wovon oben wiederholt die Rede war. Die grösste Sekretionsgeschwindigkeit nach dem Aderlass von zwei Neunteil bis zwei Siebentel der gesamten Blutmenge betrug bei den obigen Versuchen 0,0001-0,00026 mg pro kg Körpergewicht pro Minute (bei Hunden 31-33), während die nach einem solchen von einem Fünftel bis einem Drittel bei Saito 0,0002$0,0005 \mathrm{mg}$ betrug; es ist also kein grosser Unterschied vorhanden!

Der Zeitpunkt, wo das Maximum der Beschleunigung in der Sekretionsgeschwindigkeit in Erscheinung kam, stimmte bei beiden Gruppen der Experimente, der von Saito und der von uns, fast überein, d. h. es trat etwa nach einer Stunde oder etwas später auf. Während Sait o fast jedesmal das Nachlassen der Hyperepinephrinämie zu beobachten imstande war, starben unsere Tiere etwa ein bis zwei Stunden nach dem erfolgten Aderlass, falls zwei Neuntel des gesamten 
Blutes oder mehr entgenommen wurden, und eine bedeutende Hyperepinephrinämie gab sich meistens kurz vor dem Tode kund. Wenn man den allgemeinen Zustand des Tieres am Ende des Versuches berücksichtigt, so könnte man sofort mit Recht die Asphyxia als die Ursache der Hyperepinephrinämie ansehen. Es ist überflüssig zu erwähnen, dass die Aderlasshyperepinephrinämie nichts anders als eine Art Asphyxiahyperepinephrinämie ist.

\section{Zusammenfassung.}

Diese Arbeit hatte das Ziel eine etwaige Beziehung des Brustmarkes zur Epinephrinsekretion aus dem Nebennieren festzustellen. Das Nebennierenblut wurde vom Rücken aus aufgenommen, und derEpinephringehalt mit Hilfe des Kaninchendarmstückverfahrens bestimmt. Im folgenden sind die Ergebnisse der Versuche zusammengefasst.

(1) Als das unterste Halsmark unter đ̈thernarkose durchgetrennt wurde, sank die Sekretionsgeschwindigkeit des Epinephrins auf etwa ein Fünftel bis ein Vierzigstel des ursprünglichen Wertes herab. Die Ruhesekretion des Epinephrins bei dem Hunde, dem das unterste Halsmark durchgetrennt wurde, beträgt ungefähr ein Zehntel derjenigen des normalen, nicht-narkotisierten, nicht-gefesselten Tieres. Diese starke Reduktion darf man nicht sofort dem Fortfall des Zentralmechanismus für die Epinephrinsekretion im höher liegenden Zentralnervensystem alle in zuschreiben, man muss aber himreichende Rücksicht auf das Vorhandensein desselben nehmen.

(2) Pepton, in der Dose von 0,05 oder $0,1 \mathrm{mg}$ pro $\mathrm{kg}$ Körpergewicht bei intravenöser Darreichung, rief beim Hunde dem das unterste Halsmark durchgetrennt war 3-13 fache Vergrösserung der Sekretionsgeschwindigkeit des Epinephrins hervor, falls zumindest mëssige Vergiftungssymptome da waren.

(3) Sensible Reizung rief beim Hunde dem das unterste Halsmark durchgetrennt war ebenfalls eine Hypersekretion des Epinephrins hervor. Dieselbe war aber in nur selten zu nennenden Fällen positiv und dann auch nur gering.

(4) Der Aderlass von einem Zwölftel und mehr des gesamten Blutvolumens, gewöhnlich von zwei Neuntel bis zwei Siebentel desselben, rief eine ausgiebige Vergrösserung der Sekretionsgeschwindigkeit des Epinephrins hervor. Der absolute Wert der grössten Geschwindigkeit nach dem Aderlass stand dem beim nicht-narkotisierten, nicht-gefesselten Hunde mit dem intakten Zentralnervensystem nicht viel nach. 
Das Vorhandernsein eines Zentralmechanismus für die Epinephrinsekretion im Brustmark, welcher durch direkten Angriff wie durch Pepton und Aderlass sowie auf reflektrischem Wege in Erregung gesetzt werden kann um eine Hypersekretion des Epinephrins herbeizuführen, ist nun auf diese Weise ausser Zweifel gesetzt. Unter den drei, hier angewendeten Mitteln wirkt der Aderlass auf den Zentralmechanismus im Brustmark am stärksten ein, die sensible Reizung dagegen am schwächsten.

Ein unverkennbarer Unterschied in der Sekretionsgeschwindigkeit des Epinephrins vor und nach der Durchtrennung des Rückenmarkes im Halsmark, sowie der Unterschied in der Ruhesekretion beim nicht-narkotisierten, nicht-gefesselten Hunde mit dem intakten Zentralnervensystem gegenüber der Sekretion beim Hunde mit durchgeführter Halsmarkdurchtrennung legen die Annahme nahe, dass der noch höher liegenden Zentralmechanismus für die Epinephrinsekretion selbst beim beinahe normal physiologischen Verhalten des Tieres oder bei einem davon nicht stark abweichendenstes in Funktion ist.

Zum Schluss möchte der Verfasser noch eines Befundes Erwähnung tun, den die Herren Dr. Sato, Kanowoka und Ohmi nachträglich im Jahre 1930 erzielten: Insulin, welches beim Hunde mit dem intakten Zentralnervensystem eine beträchtliche Hypersekretion des Epinephrins ambahnen kann, vermag bei den wie in unserem Falle operierten Hunden nicht mehr Beförderung der Sekretionsgeschwindigkeit zu veranlassen. Es ist bedeutungsvoll und von sehr grossem Interesse, dass ein Blutdrucksenkendes Mittel beim Tiere mit der Halsmarkdurchtrennung noch in ausgiebiger Masse eine Hypersekretion des Epinephrins hervorruft und das ein den Blutzucker gehalt senkendes Mittel diese einbüsst, obgleich beide Mittel beim Hunde mit einem intakten Zentralnervensystem eine beträchtige Hypersekretion verursachen. 